\title{
A question of scale? The challenge of expanding the impact of non-governmental organisations' HIV/AIDS efforts in developing countries
}

Jocelyn DeJong

Follow this and additional works at: https://knowledgecommons.popcouncil.org/departments_sbsr-hiv

Part of the Diseases Commons, and the International Public Health Commons How does access to this work benefit you? Let us know!

\section{Recommended Citation}

DeJong, Jocelyn. 2001. "A question of scale? The challenge of expanding the impact of non-governmental organisations' HIV/AIDS eforts in developing countries." Washington, DC: Population Council. 


\section{A Question of Scale?}

The Challenge of Expanding the Impact of Non-Governmental

Organisations' HIV/AIDS Efforts in Developing Countries

\section{by Jocelyn DeJong}
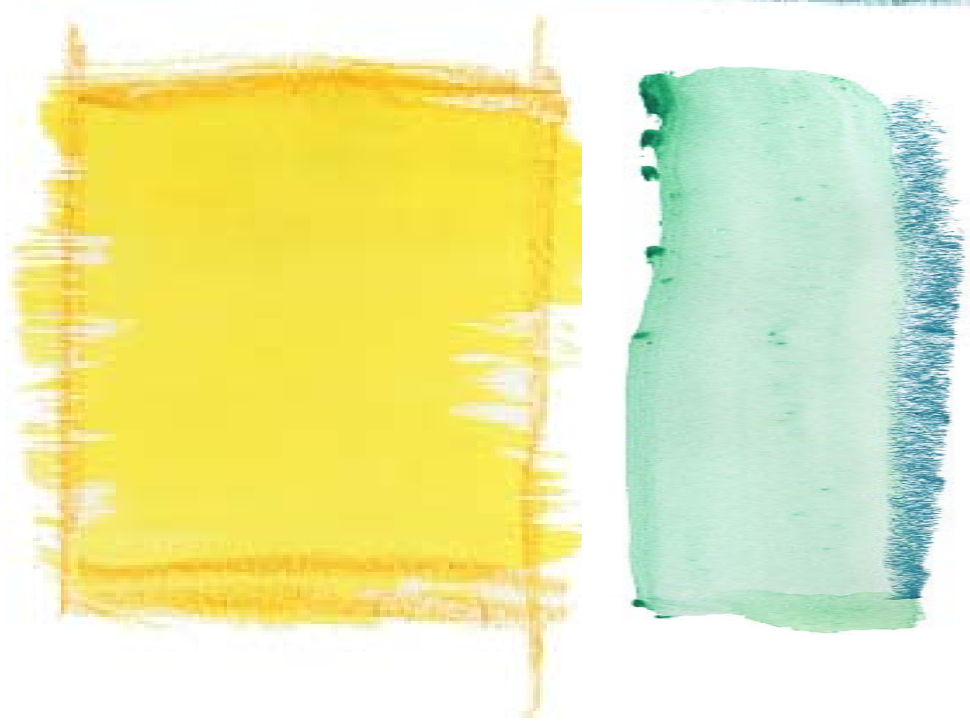

\section{Hgrizons}

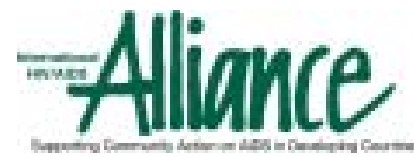


This activity was supported by the Horizons Programme and the International HIV/AIDS Alliance. Horizons is funded by the U.S. Agency for International Development, under the terms of HRN-A-00-97-00012-00. The opinions expressed herein are those of the authors and do not necessarily reflect the views of the U.S. Agency for International Development.

August 2001.

The Population Council is an international, nonprofit, nongovernmental

\section{(2) Population Council} institution that seeks to improve the wellbeing and reproductive health of current and future generations around the world and to help achieve a humane, equitable, and sustainable balance between people and resources. The Council conducts biomedical, social science, and public health research and helps build research capacities in developing countries. Established in 1952, the Council is governed by an international board of trustees. Its New York headquarters supports a global network of regional and country offices.

Copyright $@ 2001$ The Population Council Inc.

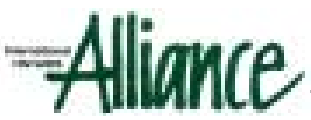

The International HIV/AIDS Alliance is an international non-governmental organisation that supports communities in developing countries to prevent the spread of HIV, to support and care for those infected and to ease the impact of HIV on families and communities. Since its establishment in 1993, the Alliance has provided both financial and technical support to over 1,500 HIV/AIDS projects and has worked with NGOs and CBOs from over 40 countries.
A book developed from the work of this report will be published by ITDG Publishing in 2002 entitled A Question of Scale: Expanding NGO Impact in HIV/AIDS by Jocelyn DeJong. ISBN 1853394963 . For further details, please contact the Marketing Department at ITDG Publishing, 103-105 Southampton Row, London WC1B 4HL, United Kingdom, tel +44 (0)20 74369761, fax +44(0)20 74362013 or visit

A report covering practical aspects of NGO experience of scaling up community work on HIV/AIDS, "Expanding community action on HIV/AIDS: NGO/CBO strategies for scaling up", is available from the International HIV/AIDS Alliance. This is the report of the third year of the "Community Lessons, Global Learning" collaboration between the Alliance and Positive Action, GlaxoSmithKline's Positive Action programme. 
Horizons

4301 Connecticut Ave NW

Suite 280

Washington DC 20008

USA
International HIV/AIDS Alliance

Queensberry House 104-106 Queens Road

Brighton BN1 3XF

UK 


\section{Table of Contents}

Acknowledgements $\quad x$

Abbreviations $\quad x i$

$\begin{array}{ll}\text { i. Background and Definitions } & 01\end{array}$

$\begin{array}{ll}\text { 1. Introduction } & 01\end{array}$

2. Why Scaling Up is Important 02

3. The Need and Urgency to Scale Up in HIV/AIDS 04

4. What is Meant by "Scaling Up" in Development? 05

5. Defining Scaling Up in the Context of AIDS: Different Perspectives 07

Impact 11

$\begin{array}{ll}\text { Sustainability } & 13\end{array}$

$\begin{array}{lr}\text { 6. Scaling Up as a Process } & 15\end{array}$

A Dynamic Relationship Between Prevention, Care and Mitigation 18

Scaling up from an Economist's Perspective $\quad 20$

7. Is there Necessarily a Trade-Off Between Expansion and Quality? 24

\begin{tabular}{ll} 
ii. Strategies & 29 \\
\hline
\end{tabular}

8. The Development Literature on Scaling Up:

$\begin{array}{ll}\text { Relevance to HIV/AIDS } & 29\end{array}$

9. A Proposed Typology of Scaling Up with Application to HIV/AIDS 31

9.1. Strategy 1: Organisational Expansion 32 
9.2. Strategy 2: Catalysing Other Organisations

a) Technically; b) Financially 33

9.3. Strategy 3: Diffusion $\quad 35$

9.4. Strategy 4: Influencing Policy/Legislation 36

9.5. Strategy 5: Mainstreaming in Development 37

9.6 TASO: An Example of the Evolution of

Scaling Up Strategies $\quad 39$

10. Partnerships/Alliances 41

Government-NGO Relations $\quad 42$

NGO-CBO Relations $\quad 45$

NGO-Research 46

11. The Importance of Context 47

12. Decisions as to Whether or Not to Scale Up 48

13. What is the Motivation for Scaling Up? 52

14. Risks Entailed in Scaling Up NGO Efforts 54

15. Special Challenges in Scaling Up HIV/AIDS Efforts 55

Donor Funding $\quad 55$

Cultural and Political Resistance $\quad 57$

Greater Visibility $\quad 58$

Promoting "Community Participation"/Facilitating

Incorporating Diversity $\quad 59$

The Pace of Scaling Up $\quad 59$

Risk of Failure $\quad 60$

iii. Institutional Implications of Scaling Up 61

16. Internal Dimensions of Scaling Up 61

$\begin{array}{ll}\text { Preparing for Scaling Up } & 61\end{array}$ 
Changes in Institutional Culture and Processes

17. Implications for Donors and NGO-Support Organisations 67

18. Conclusion 69

\section{Appendix Section}

\section{Appendix: A}

Case Studies from Scaling Up Seminar sponsored by HORIZONS and the International HIV/AIDS Alliance

South India AIDS Action Programme (SIAAP): Its Role, Growth and Development in Meeting the Challenge of HIV/AIDS

Naz Foundation (India) Trust: An Implementer's Perspective of the Highways Project 


\section{Appendix: B}

Potential Target Groups for HIV/AIDS Interventions and Prevention,

Care and Support Activities According to Need, Complexity and Cost

Table 1: Potential Target Groups (PTG) for HIV/AIDS

Interventions and Activities

02

Table 2: Care and Support Activities, by

Need, Complexity and Cost

03

\section{Appendix: C}

International HIV/AIDS Alliance, 1993-2000

01

Table 1: Main community level responses supported by

the Alliance in the start-up phase 1994-6

Table 2: Pilot projects 1994-97

Appendix: D

List of Participants

01

References

04 


\section{Table of Figures}

Figure 1 Various Definitions of Scaling Up Used in the

Development Literature

06

Figure 2 The Relationship Between Coverage and Impact

According to Level of HIV Prevalence

Figure 3 A Vision of the Shift from Linear to Integrated

Programming

20

Figure 4 Introduction to Economic Concepts of Cost and Scale

22

Figure 5 Programme Learning Curves (as defined by Korten)

27

Figure 6 A Proposed Typology of Scaling Up in HIV/AIDS

31

Figure $7 \quad$ Government - NGO Relations

42

Figure 8 Six Preconditions for Scaling Up

49

(Baba Gamboula, ANCS, Senegal) 


\section{Acknowledgements}

This publication is primarily based on a background paper written by Jocelyn DeJong of the Institute for Development Policy and Management at the University of Manchester, UK. The paper was commissioned by the Horizons Programme and the International HIV/AIDS Alliance to inform discussions at an international seminar on scaling up NGO HIV/AIDS programmes held in Windsor, UK, in September, 2000. We are grateful to the participants at that seminar for providing inspiring examples of scaling up NGO activities in HIV/AIDS and for their insightful comments at the seminar.

Other contributions to $A$ Question of Scale came from a literature review produced by Thom Eisele, Tulane University, and a set of NGO case studies on scaling up submitted by a dozen NGOs and discussed at the above seminar. We are grateful to Lilani Kumaranayake from the London School of Hygiene and Tropical Medicine who contributed a section and other suggestions on costing aspects of scaling up.

This activity was supported by the Horizons Programme. Horizons is funded by the U.S. Agency for International Development, under the terms of HRN-A-00-9700012-00. The opinions expressed herein are those of the authors and do not necessarily reflect the view of the U.S. Agency for International Development.

Horizons and the International HIV/AIDS Alliance would like to thank Paurvi Bhatt (formerly of USAID and now currently with Abbott's "Step Forward" Programme) and Margarita Quevedo of KIMIRINA in Ecuador for reviewing earlier drafts of this publication.

Jeff O'Malley, Sue Lucas and Helen Parry at the International HIV/AIDS Alliance all contributed substantial comments for the final publication and supported the organisation of the seminar. Christopher Castle, seconded to the Horizons Programme from the International HIV/AIDS Alliance, also provided guidance and contributed comments on all drafts of this publication. He was responsible for the overall technical and managerial support for this project.

We are grateful to Elaine Mercer in Manchester who carefully edited several drafts of the publication. We would also like to thank Emily Knox and Eva Roca at the Horizons Programme, and Elaine Ireland, James Togut and Garry Robson at the International HIV/AIDS Alliance for their logistical support for the seminar and for assistance in production of this publication. 


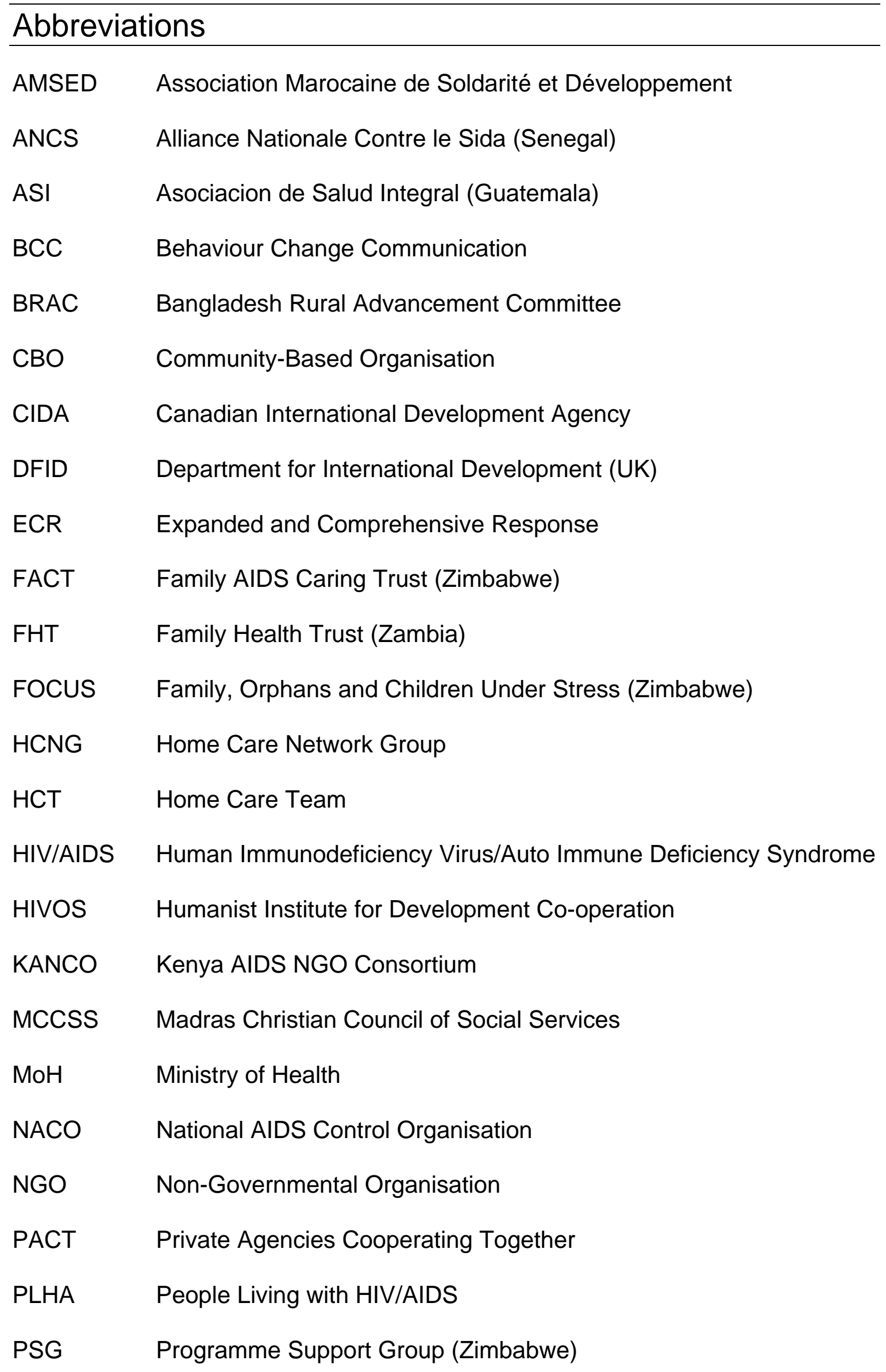


PTG Prevention Target Group

SIAAP South India AIDS Action Programme

STI/STD Sexually Transmitted Infection/Sexually Transmitted Disease

TASO The AIDS Support Organisation (Uganda)

UNAIDS United Nations Joint Programme on HIV/AIDS

UNICEF United Nations Children's Fund

USAID US Agency for International Development

VCT Voluntary Counselling and Testing

WHO World Health Organisation

YRG Care Y.R. Gaitonde Center for AIDS Research and Education (India) 


\section{i. Background and Definitions}

1. Introduction

It is estimated that there are currently over 36 million people living with HIV/AIDS globally and in 1999, 5.3 million individuals were newly infected with the virus. ${ }^{1}$ The organisations currently addressing this rapid and devastating spread of the pandemic clearly are not operating at sufficient scale or with enough impact to stem its progress. The areas of the globe where 95 per cent of those living with HIV reside, and which is experiencing the fastest and most relentless growth of the epidemic, are broadly defined as developing countries. These are the very countries that are least able to afford to ensure broad and equitable access to the new anti-retroviral therapies against HIV/AIDS and treatments for opportunistic infections, or to provide care and support for those with HIV. Thus there is an urgent moral dimension to the struggle to enlarge the scale of HIV/AIDS activities.

AIDS activities initiated by non-governmental organisations (NGOs) have been highly influential on thinking and strategies found within the HIV/AIDS sector. Yet despite their proliferation, NGOs often experience particular difficulties in increasing the scale of their activities to reach larger numbers of people, to have an impact at levels higher than the "community" and to address the broader social determinants of HIV/AIDS. Much of the pioneering contribution of NGOs active in HIV/AIDS to wider public debate and approaches in the sector has been spontaneous, as has often been the case in development, rather than a result of planned and deliberate strategy.

Perceiving the urgent need for NGOs to expand the scale of their activities in the face of an escalating epidemic, Horizons and the International HIV/AIDS Alliance launched an initiative to examine the nature of the challenge to scale up in the context of HIV/AIDS internationally. This publication was prepared as part of this initiative and addresses the specific challenge of deliberately increasing the scale of HIV/AIDS prevention, care and support programmes in developing countries. It asks whether there are lessons from the broader literature on development which are of relevance to HIV/AIDS. An initial draft of this publication was presented to an international seminar convened as part of this project at which $12 \mathrm{NGOs}$ from

${ }^{1}$ UNAIDS/WHO AIDS Epidemic Update, December 2000 
around the world presented their own experience of scaling up. ${ }^{2}$ Examples of increasing the scale of NGO activities in HIV/AIDS given here draw primarily on these case studies, presentations and comments at the seminar and relevant available published documentation. While the focus of the publication is on the activities of non-governmental organisations, it recognises that increasingly NGOs are engaging in partnerships with governments, academic institutions and other organisations in their quest to widen the impact of their activities.

The publication consists of three main sections. The first provides a background to and definitions of the term "scaling up" and describes contrasting perspectives to defining this term within the field of HIV/AIDS. In section two, drawing on the existing broader experience of scaling up development programmes, a typology of these processes relevant to HIV/AIDS is proposed. Substantial attention is paid to some of the risks inherent in the scaling up process, as cautionary tales for those interested in embarking on it. The publication also analyses the varied obstacles to scaling up programmes, both in general and how the sensitive nature of HIV/AIDS and diversity of contexts complicate the process. The third section examines the institutional implications of scaling up and the many internal dimensions that must be taken into consideration to prepare for scaling up. The publication concludes with some discussion of the relevance of the arguments made here for both donors and AIDS-support organisations.

\section{Why Scaling Up is Important}

The last quarter of the $20^{\text {th }}$ century witnessed a proliferation of nongovernmental organisations in social development (Edwards and Hulme 1992) and in health specifically (DeJong 1991; Gilson et al. 1994; Jareg and Kaseje 1998). Ironically, the role of NGOs was promoted both on the political left and right (Bratton 1989) and supported through donor assistance across the spectrum. On the one hand, NGOs were sought out by the political right as an avenue to circumvent the public sector, perceived to be slow in its response, bureaucratic and often corrupt. The advent of structural adjustment programmes calling for government cutbacks and a reduction in state-subsidised services paved the way for NGOs to fill the gaps left by reduction of state activity. At the same time, however, NGO expansion was also fuelled by voices on the left. They argued that their participatory nature, the fact that they represented the poor and marginalised, and their concern to address sensitive issues perpetuating

\footnotetext{
2 Horizons/Alliance Seminar on Scaling Up, Windsor, England, September 1-5, 2000. (Hereafter referred to as Horizons/Alliance Seminar) See Appendix A for a complete description of these case studies. Note that the authors of each case-study and his/her organisation have reviewed the edited text for content and accuracy. Appendix $D$ is a list of participants at the seminar.
} 
underdevelopment and social problems make them a liberating influence on political processes in developing countries.

A more pragmatic argument for the contribution of NGOs has arisen with the recognition that in resource-poor settings where state capacity is weak, achieving broad national coverage in all areas of social development is beyond the capacities - and indeed sometimes the interests - of governments acting alone. This is arguably particularly the case in HIV/AIDS.

In recent years, however, this unchecked optimism has been somewhat moderated by the more sober assessment that while laudable, the impact of NGOs has often been limited in scale, in many cases fails to address the broader structural determinants of the problems they are addressing and does not translate into sustainable national programmes (Drabek 1987; Edwards and Hulme 1992). Moreover, there has been belated recognition that to achieve wider effect, in many cases NGOs need to abandon their staunch independence and forge better and more strategic links with government, despite the political difficulties in so doing on both sides of that relationship. NGOs, in this view, "ignore government at their peril" (Edwards and Hulme 1992).

Thus in development circles at least, there has been a growing chorus of voices calling for NGOs to increase the scale and impact of their activities and to build strategic alliances such that the effects of any one organisation are multiplied and the pool of beneficiaries increases exponentially. Yet there has also been recognition that expansion may bring with it trade-offs - among them, between quality, quantity and costs, and between accountability to one's declared constituency and accountability to external funders financing the costs of expansion (eg. Edwards and Hulme 1997; Pearce 1993). Thus, while a tentative consensus is emerging over the importance of scaling up, there is much less shared understanding of the contexts most conducive to scaling up, the type of organisations or programmes appropriate to expand, the relative costs of different types of programmes, the internal implications of scaling up, how to define objectives, measure the impact of scaling up and how these processes depend on and interact with the political and social environment. 


\section{The Need and Urgency to Scale Up in HIV/AIDS}

The most convincing argument behind pressing calls to expand the scale of activities in HIV/AIDS in developing countries is the moral and humanitarian one. Every day there are approximately 16,000 new HIV infections globally (UNAIDS 2000). Epidemiologically, the rapid transmission of HIV/AIDS can only be countered when prevention efforts are organised at sufficient scale to affect the dynamics of the epidemic. The demographics of the HIV/AIDS epidemic reveal the extent to which it is the working-age and younger generations that are disproportionately affected. Internationally, the fact that more and more adolescents are having sexual relations before marriage (Smith and Colvin 2000) and that the age at which first sexual intercourse occurs is decreasing, means the pool of young women and men at risk of contracting sexually transmitted infections generally and HIV/AIDS specifically is ever-expanding.

There is increasing frustration in development with the failure of many small-scale research, pilot or demonstration projects to get "out of the hothouse" to have a larger influence on policies and programmes (Myers 1992: 370). This frustration is perhaps more pronounced in the area of HIV/AIDS as the epidemic escalates. The World Bank report on Sub-Saharan Africa notes, for example, that among the lessons that have been learned about successful HIV/AIDS prevention efforts is that small pilot programmes with no chance of duplication or replication are not helpful (World Bank 1999). In an article in Science (Binswanger 2000) the director for rural development and environment at the World Bank gives a stark example of limited coverage in the Kagera Region of Tanzania, where 200,000 of the region's 1.9 million people are children orphaned by AIDS. There, NGO directors stated that they operate mainly in two out of five districts, leaving three with almost no services, and in the two districts where they do work, they serve no more than an estimated 5 per cent of the population.

Elsewhere, as the UNAIDS recent report states: "...action remains sporadic and patchy rather than comprehensive. 'Boutique' projects may provide services for one or two communities, while large areas of the countryside have nothing. Many programmes have yet to become comprehensive in either geographical coverage or content." (UNAIDS 2000). Indeed such is the lack of information about access and coverage that it is not generally known who has access to, let alone uses, HIV/AIDS related services (Paurvi Bhatt, USAID/DC, Horizons/Alliance Seminar). Estimates of current levels of coverage in subSaharan Africa for HIV/AIDS prevention interventions suggest that overall coverage is less than $20 \%$ of the target populations in most countries 
(Kumaranayake and Watts 2000). Clearly the onus is now on the HIV/AIDS community - including funding organisations - to explore the question of increasing scale and to make efforts, fully cognisant of the risks involved, to identify what programmes or which aspects of their programmes can be scaled up. While there may be consensus on the need to scale up, there is less agreement over the objectives and the most appropriate approaches to scaling up, as will be addressed in the next section.

\section{What is Meant by "Scaling Up" in Development?}

Considerable confusion surrounds the various terms used to expand the scale of activities, whether "going to scale", "scaling up" or "widening impact." The word "scale" is both a relative and an absolute concept (Myers 1992) and thus may indicate on the one hand, reaching a greater number of people, or on the other hand, a notion of a particular size of population, activity or particular measure of interest. The actual unit of measurement is also a source of confusion. In the development literature, scale has been used to refer to what could be described as both the "input" and "output" aspects of scaling up - that is, on the one hand to organisational size or type of activity engaged in, and on the other to "outputs" such as scale of coverage of people or geographic area (Figure 1). Even within the concept of coverage there is a difference between coverage of absolute numbers of people, and coverage as expressing a percentage of a total population or particular groups (Myers 1992). 
Figure 1 - Various Definitions of Scaling Up Used in the Development Literature Source: - Jocelyn DeJong

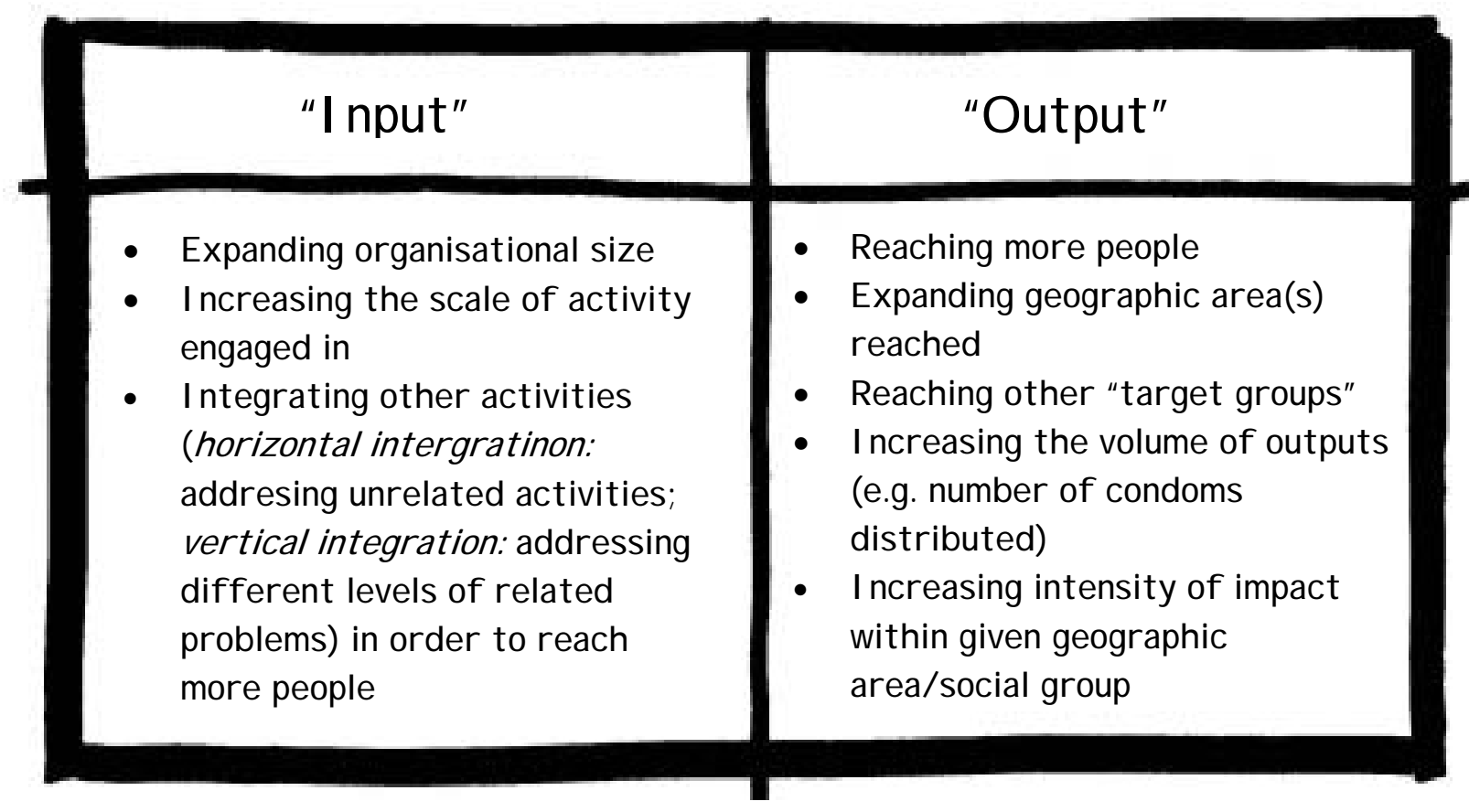

Looking at the range of processes that are relevant to HIV/AIDS, it is clear that scaling up may entail simply increasing the size or level of activity of a particular organisation. As used in the development literature (e.g. Edwards and Hulme 1992) the term has also been used to imply enlarging the scope of the activities of an organisation in order to reach more people. For example, an organisation focusing on HIV/AIDS prevention and awareness raising, may move into support and care for people with HIV/AIDS as the epidemic progresses and prevalence rises. A distinction has been made by Edwards and Hulme (1992) between integrating other horizontal activities - that is unrelated activities, as opposed to vertical activities that deal with the same problem. For example, an organisation providing micro-credit might diversify horizontally to provide health services, or vertically to develop programmes addressing high default rates on repayment. An example of horizontal integration of HIV/AIDS work into income-generation work can be found in Morocco, where the Association Marocaine de Soldarite et Devéloppement (AMSED) has scaled up its work on HIV/AIDS by reaching out to the micro-credit community which, in Morocco, is already considerably mobilised (Issam Moussaoui, PASA/IST-SIDA Horizons/Alliance Seminar).

On the "output" side, scaling up may entail increasing the absolute numbers of people reached, or it could include expansion to other geographic areas (regions or countries), whether through opening new branches or linking with other 
organisations. An organisation may diversify the range of social groups with which it interacts. Economists in particular may measure "scaling up" simply by the volume of outputs of activities, such as the number of condoms provided or distributed (Kumaranayake 2000). Less frequently, scaling up in the development literature has been used to mean intensifying effort within a particular social group, population or geographic area in order to increase impact.

Drawing on the above definitions of "scaling up" as applied within the development literature more broadly, this publication discusses a number of strategies used by NGOs to scale up their HIV/AIDS efforts. These encompass both the "input" and "output" aspects of scaling up, and denote the process of expanding the scale of activities with the ultimate objective of increasing the numbers of people reached and the impact (a term which will be discussed further below) on the problem at hand. As Myers (1992) reminds us, a preoccupation with increasing scale can distract us from the actual objective of scaling up, which in this case is to reduce the spread or to alleviate the effects of the epidemic. A programme that increases its scale may well lose in terms of its impact (Edwards and Hulme 1992) as the intensity of effort is necessarily reduced. In HIV/AIDS for instance, a larger organisation may no longer be able to provide the personalised education and care of a small organisation and thus be less effective. Thus the goal of increasing coverage is clearly insufficient in and of itself. The relationships between coverage, impact, cost and quality are dynamic, and change according to both the level of the epidemic and the objectives of the scaling up. These dimensions of scaling up will be addressed in the context of HIV/AIDS in the following section.

\section{5. $\quad$ Defining Scaling Up in the Context of HIV/AIDS: Different Perspectives}

As was evident at the seminar on scaling up convened by Horizons/Alliance however, reaching a consensus definition of "scaling up" is particularly difficult in HIV/AIDS given the sensitive nature of HIV/AIDS and the variety of perspectives engaged in HIV/AIDS efforts.

Perhaps more than most development matters, debates over the appropriate approach to the epidemic are heated. In most developing countries HIV/AIDS is fatal because of the non-availability or non-affordability of anti-retroviral therapies; prevention of HIV/AIDS requires behavioural change in the most intimate aspects of human experience and adequate care and support is premised on breaking down entrenched social prejudices. While in some quarters, the devastation 
brought by the rapidly spreading epidemic calls for strong, centralised measures, others argue that many HIV/AIDS interventions run a high risk of creating ethical and human rights violations, as programmes in both developed and developing countries have shown. ${ }^{3}$ Both sides of this debate agree that high level political commitment to addressing HIV/AIDS is critical, but differences emerge in approach in that the latter would attach more importance than the former to equipping individuals and communities with the information, tools and ultimately power to reduce vulnerability.

This somewhat exaggerated dichotomy also reflects differences in the broader health arena as to whether one adopts a medical or social model of health (Evans 1999). A medical model would assume that programmes should focus on particular interventions or technologies that are known to affect the limited range of specific behaviours that have an impact on the evolution of the epidemic. By contrast, the social model of health would focus more on the broader social determinants of the health problems concerned. In the case of HIV/AIDS, therefore, this would entail addressing the social processes and inequalities driving the epidemic and intensifying its effects. For example, structural changes in gender inequalities and in the differential power in sexual negotiation between men and women, and the elimination of sexual coercion are considered by many to be critical to reducing vulnerability to HIV transmission. This approach would argue that without greater control by people over the circumstances governing their health behaviour, long-term vulnerability to the epidemic would not be addressed. In practice, many non-governmental organisations active in HIV/AIDS may derive elements of their programmes from both perspectives, but in general the social model is likely to predominate. ${ }^{4}$

Following from these debates, definitions of objectives of scaling up and the question of impact depend on whether one adopts a national or community perspective, a public health/epidemiological or development approach, or whether one is referring to prevention or caring for, supporting and improving the quality of life of those infected by HIV. National governmental authorities generally want to reach a scale that represents a significant proportion of that country's population. They would share with those supporting a public health/epidemiological perspective a major concern in preventing the epidemic, and therefore reaching a sufficient scale to have an impact on the evolution of the

\footnotetext{
${ }^{3}$ For an argument that HIV/AIDS should not be granted special status and should be confronted with more of the "traditional tools of public health" in the context of the US, see Chandler Burr's "The AIDS Exception: Privacy vS. Public Health", Atlantic Monthly, June 1997.

4 This debate echoes that about child health in the 1980s when there were calls in some quarters for the implementation of selective technical interventions known to be effective in combating childhood diarrhoeal disease, for example. These were countered by others who argued that the social factors leading to disease such as poverty and poor sanitation must be addressed - see Rifkin and Walt 1988.
} 
epidemic. While care and support of those infected or those affected by it may also be a national priority, it is typically not given as much priority by governments as prevention until a relatively high level of prevalence is reached. Similarly, economists (whose perspective is presented more on pages 20-21) would analyse scale in terms of the coverage reached or impact attained in relation to a finite level of resources ${ }^{5}$ - a concern about resource allocation shared by governments and international donors. To those subscribing to the above perspectives, therefore, "scale" is likely to denote an absolute level of coverage (usually of services, or interventions) in order to have impact (usually defined in terms of spread of the epidemic).

By contrast, a community-based or non-governmental organisation, however, might share the above long-term goals but be more immediately concerned about changing the underlying social parameters in which HIV/AIDS activities are carried out, such as reducing stigma, passing legislation which makes discrimination in HIV/AIDS less likely or helping households and communities to cope when their members are hit by HIV/AIDS. Impact in these cases is clearly difficult - although not impossible -- to measure. Their notion of "scaling up" is likely to be a more relative one, evaluated in relation to the capacity of their own organisation, the need in the particular population group they aim to reach or the social trends they are confronting. While many may focus on services or interventions, their emphasis lies more on the process of engaging their respective constituents and eliciting a response, a component of which is likely to be greater demand for services.

According to a social model of health, the need to scale up may focus on inducing long-term social change that would enable societies or particular communities to come to terms with the HIV/AIDS epidemic. ${ }^{6}$ An individual is more likely to change behaviour if those around him or her - and particularly peers in similar social contexts - are also changing (Hughes 1993), and thus change on a collective level acts to reduce the risk factors conducive to the spread of HIV between individuals. The heart of behavioural change, however, lies deeper within the norms and values perpetuated by society across generations. Modifying expectations, beliefs and attitudes at a societal level is necessary in the long-term for sustained behavioural change to become the norm.

Such changes, however, are only likely to come about and be sustained when there is corresponding progress in the policy and legislative context underpinning

\footnotetext{
${ }_{5}$ As a recent World Bank paper on costing HIV/AIDS scaling up states this concern: "How can we reach the greatest number in the cheapest manner?" AIDS Campaign Team for Africa, World Bank, "The Costs of Scaling HIV Program Activities to a National Level in Sub-Saharan Africa" p. 2.

${ }^{6}$ Or, in the words of the local response team at UNAIDS, making "AIDS-competent societies".
} 
HIV/AIDS efforts. This, in turn, is most often induced when there is sufficient public debate and civic engagement concerning HIV/AIDS to demand it. Thus the issue of scale becomes a prerequisite to broader change. In many cases, such pressures have been brought about through community organising at a local level by groups disproportionately affected by the epidemic, who individually often lack political power but collectively are able to have an impact. The organisation of gay groups in the United States is of course a classic example. Yet at the same time, activism based on identity politics can also have its dangers in impeding efforts to expand interventions more broadly so that they permeate the whole society. As Richard Parker has expressed: "The very effectiveness of local-level politics has made it difficult to build a broader coalition to address HIV/AIDS as a global issue and the kinds of social movements that have emerged around other (similarly global) issues such as environment, or reproductive health and rights." (Parker 1998).

Disparities of definitions of scaling up, therefore, reflect more than semantics but rather underlying differences in philosophy, approach and objectives. To clarify from the outset, the focus of this publication, and the workshop on which it draws, is on increasing the scale of NGOs which, although they themselves vary enormously in initial scale, largely share the second perspective outlined above. That is, the process of scaling up at the micro or community level is given more attention than reaching a specific level of scale in terms of the epidemiological picture at the national level. ${ }^{7}$ Emphasis is placed on the social change needed to both prevent HIV/AIDS and improve the lives of those affected by it.

It should be noted, however, that not all NGOs start from a similar initial scale of activity or the same micro level frame of reference. Indeed, examples in this publication range from small community-based operations (such as that by Family AIDS Caring Trust/Family, Orphans and Children Under Stress (FACT/FOCUS)), to national (such as Kenya AIDS NGO Consortium (KANCO)), to regional (such as the Programme Support Group (PSG)) and even to international initiatives led by NGOs (such as Private Agencies Co-operating Together (PACT) or the International HIV/AIDS Alliance). Moreover, many NGOs, particularly those that assume a "catalysing role" in supporting other smaller organisations both technically and financially (see Strategy 2 in the section on Strategies) may begin with a national frame of reference. And NGOs acting together can clearly combine to create a national force, as is the case with the national coalition of HIV/AIDS organisations comprised by KANCO, which

\footnotetext{
For this reason, preference is shown here for "scaling up" rather than "going to scale" because of the implication in the latter expression that scale is a particular size and that the diverse perspectives on scaling-up could agree on the optimal absolute level of scale.
} 
does not operate local field-offices. Indeed, Myers' term association described below, which he argued might be particularly useful in the field of early childhood education, may similarly be an effective strategy in HIV/AIDS. As noted below, he uses the term to mean expanding programme size through common efforts and alliances among a group of organisations, each of whom develop similar programmes but tailor them to the needs of specific communities or populations.

Whatever the discrepancies in starting points and definitions of scaling up, however, there is a consensus and a shared concern that the ultimate objective of scaling up initiatives is to have greater impact on preventing the epidemic and mitigating its effects. Moreover, all perspectives recognise that scaling up needs to be sustainable, not only in financial terms but according to a number of other criteria (discussed below). Again, there may be differences in how both these dimensions of scaling up are expressed and measured, as is addressed in the following section.

\section{Impact}

To categorise the concerns of non-governmental organisations in scaling up as being more relevant to a relative notion of scaling up rather than an absolute level or scale, however, is not to release NGOs from the need to demonstrate impact. As is noted in the case study on the Programme Support Group, which began as a university research department and pays careful attention to monitoring the impact of their programmes on measurable outcomes such as condom use "Process cannot be a substitute for structure or results."

HIV/AIDS in this respect is more challenging than many other health problems in terms of measuring the impact of interventions. Perhaps most strikingly, for example, HIV/AIDS is distinctive in its mutually reinforcing relationship between prevention and care. As the UNAIDS (2000) report on the global AIDS epidemic states, not only do sick individuals benefit from care and support, but prevention efforts will only be credible and effective if they are matched by humane and high-quality care and support services. It is important, for example, that discrimination and stigma directed at those suffering from HIV/AIDS is reduced at a social level so that people with HIV/AIDS will not be fearful of disclosing their status, but will seek care and support and will be assured of full information and the means to prevent transmission of HIV/AIDS to others. Thus impact in this sense cannot solely be measured by a reduced incidence of HIV/AIDS. 
HIV/AIDS differs from many other health problems for which intervention efforts have been scaled up, such as disability or diarrhoeal disease. Efforts to increase the use of oral rehydration therapies for the treatment of diarrhoea, for example, have succeeded in reaching a large scale in many developing countries; yet the behavioural change implied, though affected by socio-economic context, is not as conditioned by social and gender power relations as is condom use, for example. And, unlike the area of early childhood care, where Myers recommends focusing the scaling up effort on those "at risk" - defining such a population in HIV/AIDS may be difficult given the lack of knowledge about sexual behaviour, and there is a danger that it may lead to stigmatising that group and in the worst case, abuse of ethical and human rights principles. Thus while targeted interventions are critical to limit the spread of the epidemic, sensitivity to stigma needs to be foremost among those engaged in planning the intervention concerned. As Jeff O'Malley of the International HIV/AIDS Alliance stated: "A key lesson from the Alliance's programming experience has been the importance of paying attention to key populations that affect epidemic dynamics, especially in low prevalence countries with concentrated epidemics. However, this does not mean ignoring other populations, since one community affects another's choices and options. Scaling up involves providing both intensive services and programmes for key populations, while working more cheaply with broader communities to raise awareness, challenge stigma and to ensure referrals when appropriate to more intensive efforts." (International HIV/AIDS Alliance 2001)

One example of a sensitive public health issue that has been scaled up in a number of contexts was presented at the Horizons/Alliance Seminar on scaling up - namely that of post-abortion care. ${ }^{8}$ It represents a similar challenge to scaling up HIV/AIDS in its sensitivity and the need to address cultural norms and attitudes in order to expand the scale of this service. In this presentation, scaling up was defined as reaching a greater number of people and increasing the impact of the intervention with a specific objective of regularising it into routine public sector health services. A comparative analysis of the successes and failures of such scaling up efforts was made across four countries (Kenya, Ghana, Mexico and Columbia) and it was found that where efforts over-focused on the technology rather than on changing attitudes, the scaling up was less successful. Scaling up was most successful where there was an understanding of the implications for essential systems and standards, such as supervision, and where there was both committed leadership and sufficient support for the intervention among the general public rather than with health personnel

\footnotetext{
${ }^{8}$ Presentation by Julie Solo of the Reproductive Health Alliance (London) on scaling up post-abortion care. "Postabortion care" was defined to include treatment or complications resulting from the abortion, provision of family planning services and linkages to other reproductive health services.
} 
exclusively. Thus many interesting and relevant lessons emerged from this case study for HIV/AIDS.

There are a number of specific challenges in finding measures of evaluating the impact of scaling up in HIV/AIDS. As elaborated above, the objective of organisations in scaling up their programmes may not only be an epidemiological one, as measured in incidence of new cases of HIV/AIDS. Rather, they may seek social change - such as affecting social norms or reducing prejudice and stigma associated with HIV/AIDS -- which is very difficult to measure and of which assessments of quality tend to be highly subjective. Quantitative indicators may not reflect the quality of effort the organisation undertakes, particularly at the level of person-to-person contact, nor be sufficient to assess how well objectives of reducing stigma and discrimination are met, or how humane the care and support services are.

Many NGOs addressing HIV/AIDS lack baseline data on which to evaluate the effectiveness of their scaling up. This may be at least partly due to a lack of research capacity or institutional culture favouring the collection and analysis of data (Shyamala Nataraj, SIAAP, Horizons/Alliance Seminar). Or, as Margarita Quevedo noted about Ecuador, for example, while epidemiological information on HIV/AIDS is available on the Internet, most of the small community-based organisations with which her organisation, KIMIRINA, works lack computers. Even where epidemiological information is available, for example, reliable and valid sexual behaviour data is often extremely difficult to obtain or collect for both cultural and political reasons. Where sexual behaviour studies have been conducted, such data - and particularly projections based on them -- have to be scrutinised carefully for potential bias in such a sensitive aspect of behaviour.

In reality, then, NGOs often make programmatic choices without being fully informed by empirical data about impact. Participants at the Horizons/Alliance Seminar agreed on the importance of evaluating interventions before scaling them up, but there was extensive discussion of the difficulty of doing so.

\section{Sustainability}

A central dimension of scaling up is sustainability, whether in terms of people, geographic area, social group or activity. A program must be built with sufficient financial, technical, social and political support so that it lasts over time. 
The most frequent use of the term sustainability refers to whether or not there are sufficiently strong economic bases to keep a given programme effective over a period of time. The issue of limited resources and the need to contain costs and improve efficiency through achieving economies of scale is perhaps the most widely heard justification - beyond the humanitarian rationale -- for expanding HIV/AIDS efforts. HIV/AIDS related organisations, as is the case in many other areas of development, are often deficient in not fully taking into consideration the cost implications of alternative strategies. There is an urgent need for more information on costing HIV/AIDS programmes (Kumaranayake and Watts 2000b). ${ }^{9}$

A broader understanding of sustainability embraces a much fuller range of dimensions. Avina, in an article on the evolutionary cycles of NGOs, defines sustainability as follows: "An expansion is successful if the organisation has evolved institutionally to the point where it can manage the augmented level of activities effectively, can finance itself into the foreseeable future, has retained the necessary level of programme autonomy from external actors and is providing desired and sustainable services to its target beneficiaries" (Avina 1993: 465-66). Both the programmatic and the organisational sustainability need to be considered. That is, has the organisation accumulated sufficient programme experience and momentum to operate at a larger scale? And does the organisation have in place the requisite trained staff, processes and structures to sustain a greater level of activity to meet the objectives of a scaled up programme? Indeed, the process of increasing the scale of activity may in itself reduce sustainability as the organisation becomes over-stretched ${ }^{10}$ and programme effectiveness is diluted. Thus it is critical that a thorough assessment of the capacity of the organisation to scale up is made prior to engaging in the exercise.

The above dimensions of sustainability focus more on the organisation itself and its supply, or delivery of services. But the objectives of scaling up may be more than sustaining any particular programme or intervention in delivery terms, and relate more to sustaining the response of communities and the relevant constituencies of the organisation to the epidemic, particularly in terms of sustained behavioural change. According to Geoff Foster, one of the key lessons emerging from FACT/FOCUS support to community-led orphan support programmes in Zimbabwe was the degree to which community ownership made

\footnotetext{
${ }^{9}$ Of the fourteen case-studies of scaling up NGO activities presented at the Horizons/Alliance Scaling Up Seminar, only 3 explicitly addressed costs - the Program Support Group in Zimbabwe, the NGO-Government collaboration for Home Care in Cambodia and the International HIV/AIDS Alliance (see appendices A and C).

${ }_{10}$ Sue Lucas, personal communication
} 
the project more sustainable. Foster argues convincingly that African countries affected by HIV/AIDS have responded on their own terms in a number of ways to the epidemic, yet initiatives of external agencies - whether NGOs, governments or donors, often fail to recognise these community initiatives or in the worst cases, disregard or undermine them. ${ }^{11}$

Thus sustainability in this sense focuses on strengthening local initiatives and sustaining community ownership of programmes. The social context in which the programme expands its scale of activities is therefore critical to sustainability in that it is a predictor of the demand for it. The challenge for external agencies seeking to act as a catalyst to these efforts - whether NGOs, governments or donors - is to build on these initiatives. At the same time, they may need to encourage communities to recognise issues that are hidden or controversial, or to address social groups at the margins of society. It is possible, however, that increasing supply of HIV/AIDS programmes generates its own demand by breaking down social barriers and reducing stigma. In this sense a "virtuous cycle" could be created where increased coverage generates more demand and thus the programme in question becomes more effective (Paurvi Bhatt, USAID/DC, Horizons/Alliance Seminar).

\section{Scaling Up as a Process}

As important as it is to be clear about the end objectives of scaling up, the process of reaching these aims is significant both programmatically and for the organisation involved. The great strengths of NGO activity to date in HIV/AIDS prevention have been the relationships of trust they have inspired among their constituencies and the processes of participatory decision-making they encourage, both of which have enabled them to address sensitive issues. As Fowler (1991) has written of development NGOs in general, their comparative advantage lies more in the quality of their relationships than in the size of resources they command.

Approaches to scaling up expounded by the private sector, such as franchising and developing particular pilot models of which exact replicas are planted in starkly different contexts, have been very influential in development circles (Wazir and van Odenhoven 1998). Yet they may not be appropriate strategies for the field of HIV/AIDS, where the importance of factoring in local specificities, and the need for attention to processes and values is pre-eminent. As Myers notes, the ${ }^{11}$ Foster and others note that these community initiatives are more likely to emerge in care and support, than
prevention, as will be discussed below. 
challenge is to think about scale in a way that "allows a qualitative, decentralised and participatory approach to that goal, as contrasted with the more quantitative, centralised and imposed approach that seems to predominate" (Myers 1992). Nonetheless, the opposite extreme of arguing that programmes are so contextspecific as to make lessons or replication to other areas impossible, an approach that Wazir and van Odenhoven (1998) refer to as "contextualist", is also unhelpful. There is much that can be learned from small-scale efforts that is of larger relevance and applicability.

Examples of successful scaling up efforts of NGOs with clear impact suggest that some degree of distinctiveness and integrity of process needs to be sacrificed in the interest of reaching a greater scale. Both the Programme Support Group in Zimbabwe and the AIDS Support Organisation (TASO) in Uganda, for instance, illustrate that the development of standardised approaches with enough flexibility to allow for diversity among different communities can be highly effective. The prevention and mitigation efforts of the Programme Support Group share a common approach by training community volunteers through the use of modules, manuals and structured participatory approaches. As they describe it: "[Both prevention and mitigation] work with community volunteers to deliver large-scale, economical, locally relevant services that increase community response capacity (Appendix A, p. 44 PSG case study)." The organisation is exceptional in its rigorous attention to results. In one area, for example, they were able to demonstrate that Bulawayo condom use in sex work rose from $18 \%$ at outset to $72 \%$ within 2 years (p. 49 case study). While, particularly at the beginning, early partnerships "resent the loss of attention and uniqueness as scaling up proceeds" this resistance seems to wane as clear indications of the success of this approach emerges. PSG has grown from a small-scale effort based on a research project to a regional organisation operating in three Southern African countries.

Similarly, TASO helps local community-based organisations to develop counselling and clinical services for those with HIV/AIDS, thus leading to a proliferation of "TASO-like" services each of which are tailored to specific communities. (see TASO report on page 39 , Section ii).

If scaling up, then, is conceived as a process occurring over time, objectives of the exercise may vary according to, for example, the different stages or level of the epidemic. At low levels of epidemic, when infection may be more restricted to certain social groups, different strategies may be called for than when the epidemic is more generalised within the population at large. For example, more "targeted" interventions can prevent the spread of HIV into the "general" 
population. Where HIV/AIDS is widespread, however, there needs to be a relatively high level of coverage within the general population in order to have the same degree of impact (although an incremental increase in coverage may have a significant relative impact). ${ }^{12}$ This is illustrated further in a diagram drawn by a small group at the Horizons/Alliance Seminar and replicated below in Figure 2. Thus, as discussed further in section ii below, the target groups of programmes are likely to change over time.

Figure 2 - The Relationship Between Coverage and Impact According to Level of HIV Prevalence

Source - From a group exercise at the Horizons/Alliance Seminar

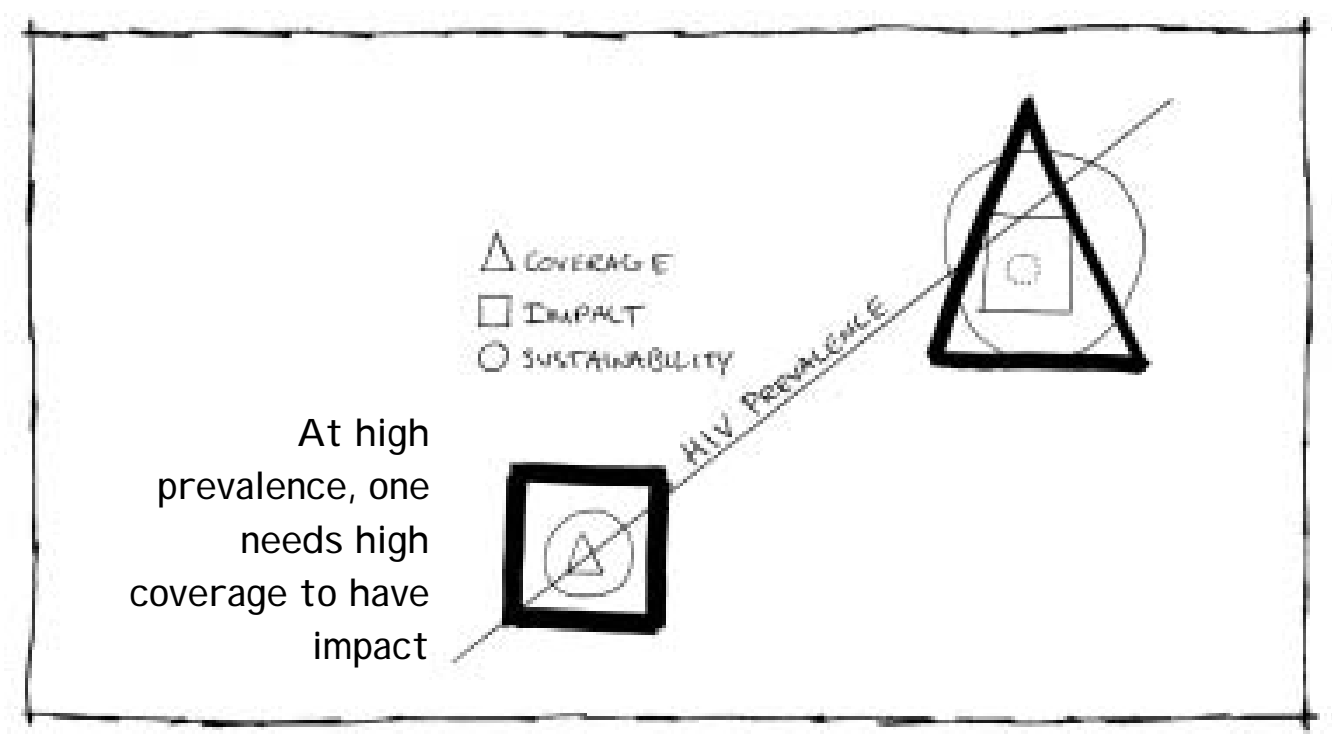

Modifying the objectives of programmes as scaling up proceeds may also be necessitated by changes in the political context. Two case studies presented at the Horizons/Alliance Seminar emphasised the importance of being able to respond to unanticipated changes in the policy environment during the scaling up process. For example, changes in the donor landscape in HIV/AIDS conditioned the strategy adopted by the International HIV/AIDS Alliance (Alliance case-study, appendix c). And in India, the course of scaling up the Healthy Highways project to reduce transmission among truck workers and their sexual partners was affected by both policy changes within the main funding organisation, the UK Department for International Development (DFID), as well as the desire of the Government of India to command greater direction over HIV/AIDS activities (Robert Grose, DFID, Horizons/Alliance Seminar).

\footnotetext{
${ }_{12}$ I am grateful to Helen Parry of the International HIV/AIDS Alliance for clarifying this point in her comments on this publication.
} 
Objectives of scaling up may also change over time due to the internal situation of the organisation. One participant at the Horizons/Alliance Seminar noted that at some stages in the scaling up process there was actually a cutting back in order to strengthen programmes and prepare for expansion - thus an organisation may initially need to scale down in order to scale up (Shyamala Nataraj, SIAAP). ${ }^{13}$ It is not clear, however, whether this example is representative of other NGO experiences of scaling up.

\section{A Dynamic Relationship Between Prevention, Care and Mitigation}

As noted above, HIV/AIDS is distinctive among health problems in its dynamic relationship between preventing its incidence, and supporting, caring for and treating those infected and affected by it. If the premise of scaling up initiatives is to build the capacity of individuals and communities to respond to the epidemic, many would argue that the starting point should be problems identified by the constituencies that NGOs work with. In many contexts, such community initiatives are more likely to emerge to care for and support those affected by HIV/AIDS such as in the area of orphan support. Children may often represent the most visible victims of the epidemic to whom humanitarian efforts are readily addressed. There is often more resistance to working with marginalised social groups who may be subject to prejudiced views that they are somehow "morally responsible" for the epidemic. Thus - although care may provide the catalyst for a broader approach to HIV/AIDS, scaling up prevention programmes may require more external motivation than that of care programmes. For example, churchbased programmes across Africa have emerged to care for orphans and support families affected by the epidemic (Foster n.d.), but many find prevention messages addressing condoms and sexual behaviour more sensitive.

In some cases, however, community initiatives have emerged in the area of prevention and have subsequently moved into care. For example, the Anti-AIDS Clubs that the Family Health Trust has supported in Zambia moved from awareness raising and prevention in schools to working with orphans. According to Dixter Kaluba, this has helped to familiarise youth with problems associated with the epidemic and thus "young people don't feel the epidemic is so distant". Elsewhere, in low prevalence settings, where HIV/AIDS is not visible to the majority of community members, it may be easier to stimulate community

\footnotetext{
${ }^{13}$ At this stage, SIAAP - which was operating with 40 employees, cut their staff down to only 6 , prior to a subsequent "re-scaling" (Shyamala Nataraj, SIAAP, Horizons/Alliance Seminar).
} 
participation in prevention rather than care. This is the case in Ecuador, for example, according to the director of KIMIRINA.

In Cambodia, a home-based care programme has provided a critical link between care, prevention and mitigation. Cambodia has one of the fastest growing epidemics in the world, yet faces a severe shortage of hospital beds, a poor population only a minority of whom can pay for prophylactic drug therapies and a high incidence of people living with HIV/AIDS (PLHA) having opportunistic infections (Wilkinson et al. 2000). Community leaders in Phnom Penh mentioned to an evaluation team, for example, that until the Home Care Team started visiting, people did not believe there was AIDS in their areas. The visits helped to increase knowledge about HIV/AIDS and understanding of preventive measures (Wilkinson et al. 2000).

Identifying and building on the appropriate strategy, however, may take a "trial and error" period of learning. As the founder of the South India AIDS Action Programme (SIAAP) aptly described: "It took SIAAP four years of sustained community-based interventions with women in prostitution, truckers, blind people and people with HIV/AIDS to understand the need to include community organisation, counselling and care as critical processes, perhaps even the first ones, in any community-based intervention that aimed at empowerment as a fundamental outcome." (SIAAP case study Appendix A, p. 10) She drew a broader lesson of the importance of not singling out individual interventions for scaling up, without seeing the synergies between them. She illustrated her vision of these synergies and the importance of community organisation in figure 3. 
Figure 3 - A Vision of the Shift from Linear to Integrated Programming Source - Presentation by Shyamala Nataraj at the Horizons/Alliance Seminar

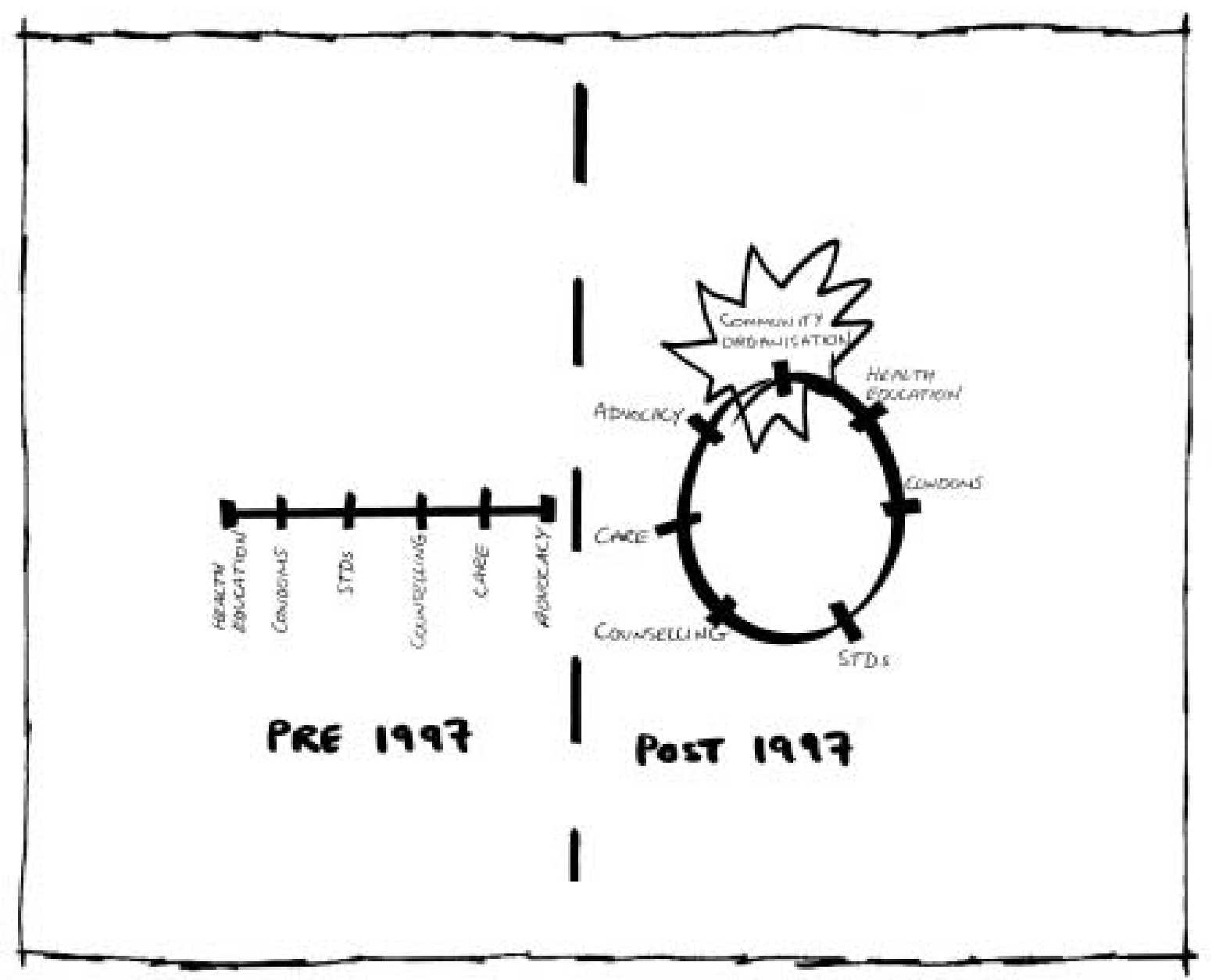

Despite the evident synergies in scaling up prevention, care and mitigation efforts, in many contexts interventions in these areas may compete for resources. A recent World Bank report on costing the expansion of HIV/AIDS programmes in Africa notes, for example, that as HIV prevalence rises there are increasing costs associated with the burden of care. Therefore there will be greater tensions in allocating scarce resources between prevention and care interventions (World Bank 2000).

\section{Scaling up From an Economist's Perspective}

Much of the economic analysis that has been applied to scaling up within the context of HIV/AIDS is premised on a public health perspective as outlined above and tends to focus on the large-scale delivery of services usually by governments or the private sector. As noted above, there is a dearth of costing analysis of NGO programmes and NGOs themselves often neglect to consider the cost 
implications of alternative strategies. Cost is defined as the value of resources used to provide a service, and the total cost of an intervention represents the cost of all inputs used, and varies with the number of people reached. The assumed impact on HIV/AIDS from an economist's perspective is the output of an intervention, usually in terms of the number of people reached with a specific intervention. This makes it difficult to apply costing in areas where impact is defined more broadly and in more qualitative terms, and where the definition of scaling up is not solely based on increasing coverage, as outlined above.

Nevertheless, the concepts economists apply to assessing costs of scaling up can be applied in a variety of ways and thus are essential for those engaged in scaling up to understand. The following therefore presents a description from an economist's point of view of the main questions relating to a determination of costs. $^{14}$

There are a number of issues that come to the forefront when thinking about scaling up and costs from an institutional perspective. The organisational approach to increasing the number of people being reached will affect the consideration of costs. Increased coverage might be the result of expanding existing interventions to reach more people or it might mean creating similar new interventions, and then is referred to as replication of an intervention (Kumaranayake 2000). While both could increase coverage, the implications for costs are quite different.

A basic diagram of these relationships is provided in Fig. 4. The underlying notion behind the expansion of activities is that an organisation which is expanding its scale of activities will likely initially have decreasing average costs (or the cost per person reached). Beyond a certain point, continued expansion due both to organisational characteristics (e.g. need for more coordination etc) and characteristics of the groups being reached (e.g. less accessible) will mean increasing cost per person reached. Thus expansion of activities has been encouraged as a means of achieving economies of scale (and so improving the efficiency of delivering services). However, beyond a certain level of activity, continued expansion will lead to diseconomies of scale, and an increase in the average cost per person.

\footnotetext{
${ }^{14}$ We are grateful to Lilani Kumaranayake of the London School of Hygiene and Tropical Medicine for providing the material for this section.
} 
The curve below illustrates a typical short-run relationship between average cost (AC, or the total cost per person reached) and marginal costs (MC, or the change in total cost of reaching an additional person), hypothesised by economic theory. The AC curve refers to average costs and MC refers to marginal costs. The average cost is often thought to have a U-shaped relationship with respect to the level of output. This reflects the fact that at relatively low levels of activity (or scale), as the number of people being reached increases, average costs or the

Figure 4 - Introduction to Economic Concepts of Cost and Scale adapted from Kumaranayake 2000).

\section{Relationship between average and marginal costs for a project}

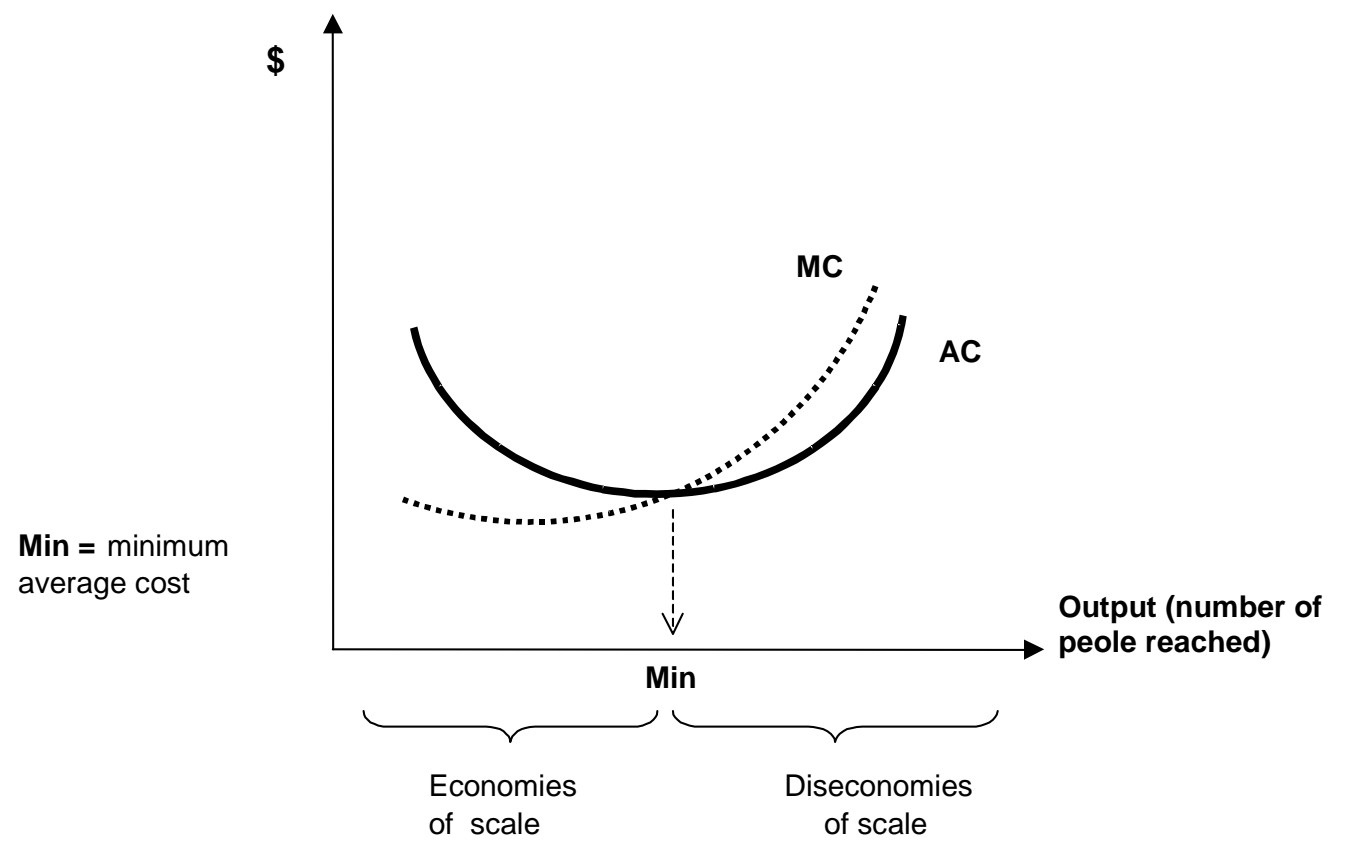

cost per person being reached decreases. However, at higher levels of activity (or scale) average costs are thought to increase reflecting the fact that one might need to add substantially more inputs in order to increase the number of people being reached. We see that marginal costs start to increase at lower levels of activity relative to average costs, reflecting that marginal costs will start to increase before average costs.

When diseconomies of scale occur, that is when the cost per person reached actually increases as the project is expanded, cost reductions can be made by both reducing the scale of activity or replicating the project (on the more efficient 
smaller scale) in another location. Thus, from a cost perspective, both expanding current activities or replicating projects may be desirable, and is dependent on the actual cost-structure of the project, the location where it is operating, and the nature of the target population that it is trying to reach.

There is a dearth of evidence about the nature of costs as projects are replicated or expanded. This is particularly unfortunate given the degree to which costs vary according to a wide range of criteria related to motivation, organisational characteristics and geography among others. For example, a study looking at the replication of peer education interventions for HIV prevention among sex workers in Cameroon found that, even within the same country, there was a two to three-fold difference in average costs across different cities, and that the costeffectiveness varied substantially. This reflected differences in project implementation, motivation of project staff, capacity of staff to reach target populations and differences in the sex worker populations across cities (Kumaranayake, Pepperall Goodman, et al 2000).

A second issue related to costs of scaling up activities lies in the nature of resources which are used in a project and which are directly paid for by an NGO. Financial costs represent actual expenditure on goods and services purchased. In a financial costing, costs are described in terms of how much money has been paid for the resources used. In order to ascertain the financial costs of a project we need to know the price and quantity of all the resources used, or alternatively the level of expenditure on these goods and services. In contrast, economic or opportunity costs recognise the cost of using resources that could have been productively used elsewhere. Thus, economic costs include the estimated value of goods or services for which there were no financial transactions (such as unpaid volunteer time), or when the price of the good did not reflect the cost of using it productively elsewhere (such as donated radio time) (Kumaranayake, Pepperall, Goodman et al 2000).

Financial costs are important when considering budgeting or cost-recovery within a project. However, they may not give a full picture of the overall resources used for an activity. Economic costs are particularly useful when considering the resources needed to replicate or to scale up existing activities, when it may not be possible to utilise similar donated or subsidised inputs. In this case, simply using financial costs as a guide to resource requirements for scaling up may seriously underestimate the resources required if a large proportion of inputs are provided for free, and if this proportion declines as activities are expanded or replicated. 
Where activities have been delivered on a pilot or small scale, which is of particular relevance to NGOs, expansion or replication of activities may require significantly more resources than previously. This is both because of the ways in which additional services are delivered and the nature of what now has to be paid for (for example employing paid staff rather than enlisting volunteers).

\section{Is there Necessarily a Trade-Off Between Expansion and Maintaining Quality?}

In analysing the impact of NGO activities in HIV/AIDS on approaches within the sector more generally, it becomes clear that the small-scale nature of many NGO activities has in many ways been their strength. A range of NGOs is active in HIV/AIDS, varying from very small organisations to those operating at the national level. Developing typologies of NGOs active in HIV/AIDS is problematic, but one useful categorisation made is: 1) indigenous NGOs established and managed by community "outsiders"; 2) indigenous community-based NGOs originated and managed by members of the community (also called communitybased organisations or CBOs); 3) organisations of people living with HIV/AIDS; 4) foreign NGOs (Sittitrai 1994). Perhaps the most effective, however, have been those which have emerged within particular communities. The larger, more professional AIDS organisations certainly have a critical role to play, such as in providing information, influencing government policy and providing support to other organisations. However, their ability to inspire behavioural change is often more limited. As O'Malley and co-authors say of these larger, more professional groups:

"Such groups tend to be technically stronger, have more effective access to decision-makers, and despite higher costs, can of ten be very cost-efficient because of the scale of their operations..but very few such large groups can actually convince a young man to use condoms if he has not tried the m before. "( $O$ Malley et $a(1996)$.

There are a number of positive features that represent a comparative advantage for NGOs in working on HIV/AIDS, as compared to other types of organisation, although these characteristics are by no means shared by all NGOs. The commitment of the truly constituency-based organisations to being rooted within their communities, which they often know intimately, for example, enables them to work in a personalised manner and ethically with the sensitive and stigmatising issues raised by HIV/AIDS. In turn, they are able to come to understand the specific local risk factors for HIV transmission. Without the impediments faced by 
larger and more visible organisations, they can work with marginalised groups such as sex workers, drug users and illegal immigrants. Their small size enables them to respond flexibly to the rapidly evolving nature of the epidemic, and they can change directions quickly as they adapt to lessons learned. Less weighed down by bureaucracy than their larger or governmental counterparts, they can more easily integrate work across functions, rather than being restricted to single types of activity. Finally, their commitment to their communities means that they provide often the only sustained response to the epidemic, and are more likely to offer care and support as well as engage in preventive activities.

Therefore the challenge of scaling up activities in HIV/AIDS must address the question of whether such values of characteristics should and can be preserved as the programme or institution expands. This means not only extending the technical aspects of HIV/AIDS work, but also maintaining the integrity of the processes and values that have been the hallmark of NGO approaches to the epidemic.

At the Horizons/Alliance Seminar, it was not the consensus among organisations present that such aspects of quality are necessarily jeopardised with expansion. Indeed, several cited cases where the aspects of the original model were not lost or diluted in the process of scaling up (e.g. Foster re FACT/FOCUS; ASI). Some argued that a slight drop off in quality may be an inevitable stage of the process of scaling up (Geoff Foster, Family AIDS Caring Trust, Horizons/Alliance Seminar) - that is, that in the interest of reaching a greater number of people, some sacrifice of quality is acceptable. This may be particularly the case if many elements or programmes are scaled up simultaneously (International HIV/AIDS Alliance 2000b), although ensuring proper planning of the scaling up may limit this risk. The question then becomes whether the quality drops below an "acceptable" level and indeed whether such a level can be specified (International HIV/AIDS Alliance 2000b). Yet, as noted above, many NGOs lack sufficient monitoring capacity or data to assess changes in quality as the scaling up proceeds.

One example of an organisation that did pay careful attention to monitoring quality during the process of expansion is that of the Asociation de Salud Integral (ASI) in Guatemala. By enlisting volunteer medical students to collect data, they were able to track changes in quality as a rapid expansion of the counselling and clinical service coverage took place. Analysis of that data indicated that while an increasing number of people were coming to their services for voluntary testing, they were often not returning for their results. Further investigation into the reasons for this revealed that the time between test and results had increased 
due to the increase in numbers. Thus data was helpful in guiding a redirection of strategy.

There have, however, been documented cases in which a rapid increase of coverage has led to a decline in quality. Anti-AIDS Clubs in Zambia began in the 1980 s as a result of a presentation by a doctor on sex education in high schools. Students sold the idea to their friends during the holidays, and the clubs continued to multiply across the nation. Over time, the activities of the Anti-AIDS Clubs in Zambia, for example, had proliferated rapidly and for a number of reasons they were no longer particularly effective and the clubs starting dying out. Thus the scaling up efforts of the Family Health Trust aimed initially to rethink and boost the quality of an initiative that was already operating at national level. The experience reinforces the view that during a scaling up process, one may need to concentrate on one dimension - such as quality or coverage possibly at the expense of the other (Horizons/Alliance Seminar).

The struggle to maintain quality while the organisation expands may pose a strain on staff. As Naomi Gonahasa of TASO stated at the Horizons/Alliance Seminar: "It began so well but things got tough when it turned to scaling up." In some cases, NGOs have realised that a key challenge in scaling up is knowing when to stop. As Dr. Suniti Solomon of YRG Care in India has stated "One of the most important things for YRG Care is the quality of services we provide. As a result, we chose to stop expanding our in-patient care when we reached 24 beds so that the quality we provided remains at a high level." (International HIV/AIDS Alliance 2001)

This understanding of dynamic relationships between quality and coverage has also been examined within the broader development arena by David Korten, who attempted to draw commonalities among five community-based projects in Asia which successfully expanded the scale of their operations. ${ }^{15}$ He concludes that there is no single blueprint for scaling up, but organisations go through a number of stages during expansion (figure 5) each of which entails a learning process. The first is 'learning to be effective', when the organisation learns what strategies are effective among particular populations. At this stage, errors are made, but effectiveness steadily increases; efficiency has not yet been achieved and coverage is likely to be relatively low. At the next stage, the organisation is 'learning to be efficient', and unit costs tend to fall. Only in the third and final stage does the organisation move into expansion, and there is likely to be some loss of effectiveness and efficiency as the expansion occurs. As the process of expansion continues, it is likely that average costs will tend to rise, and so raising

\footnotetext{
${ }^{15}$ This discussion draws on Korten 1980 and Myers 1992
} 
the issue of when it is optimal to continue to expand rather than replicating the project at a smaller scale. The extent to which this "trial and error" process is permitted and learning is encouraged depends on both the external environment - in terms of finance and political commitment - and the internal characteristics of the organisation. This is addressed in the final section of this publication.

Figure 5 - Programme Learning Curves (as defined by Korten)

Source - Korten, 1980.

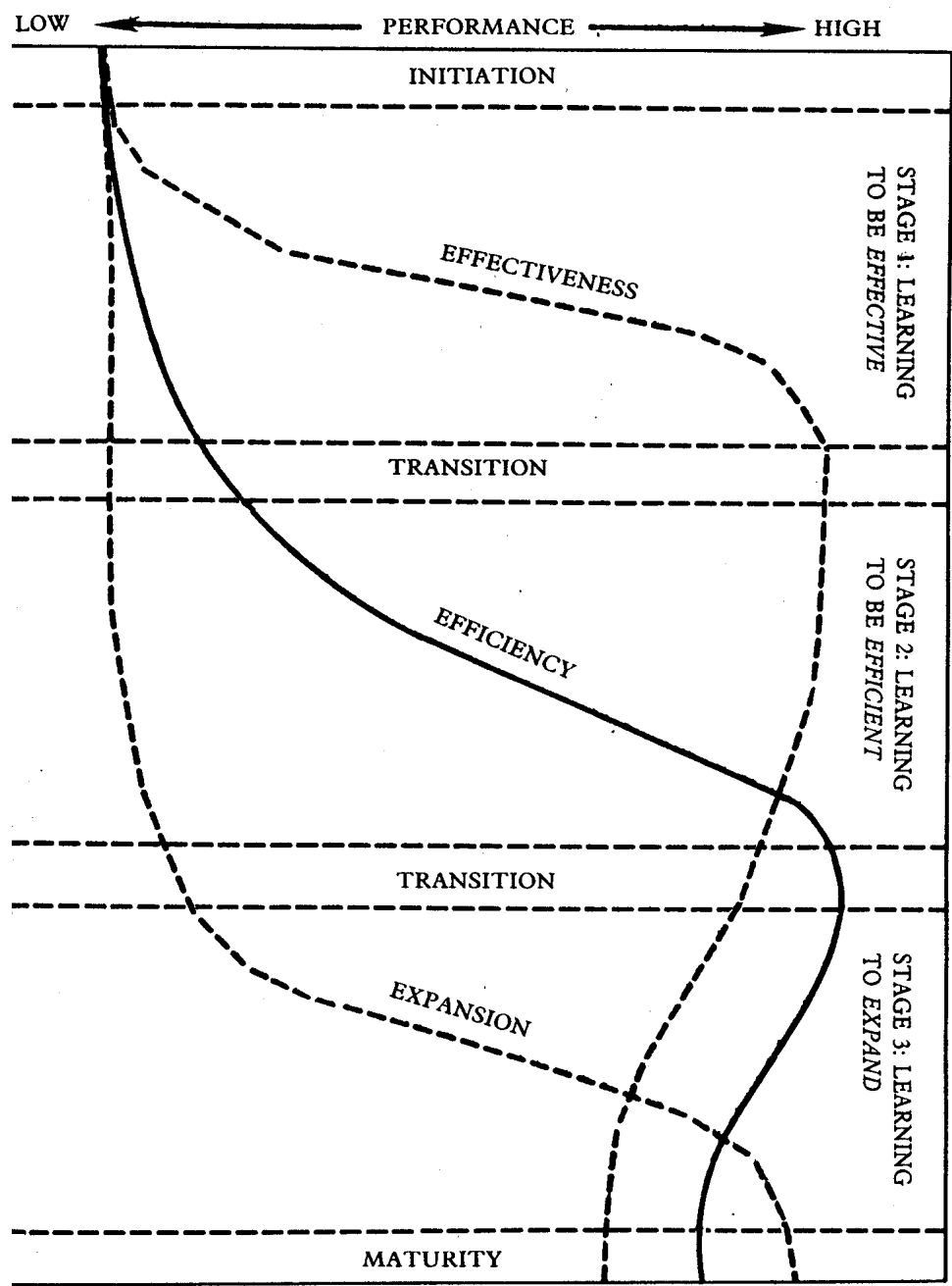

Note: There are likely to be trade-offs between effectiveness, efficiency, and expansion which will lead to some loss of effectiveness as efficiency increases, and to losses in both effectiveness and efficiency during expansion. 
Section: i 


\section{ii. Strategies}

\section{The Development Literature on Scaling Up:} Relevance to HIV/AIDS

In describing the mechanisms or pathways through which development NGOs can have broader impact, Robert Chambers, a pioneer in applying participatory approaches to development, states that:

"An $\mathcal{X G O}$ can achieve wider impacts in many ways including expanding its operations; introducing or developing technologies which spread; developing and using approaches which are then adopted by other XGOs and/or by government; influencing changes in government and donor policies and actions; and gaining and disseminating understanding about de velopment." 16

In looking at the HIV/AIDS epidemic specifically, it is evident that NGOs have operated in each of the above pathways to exert influence over the general thinking about and approaches to HIV/AIDS. The emphasis on and need for home care, for example, was initiated by NGOs, as was the emphasis on the ethical need to combine counselling with voluntary testing, and indeed the whole notion and promotion of 'safe sex' (O'Malley et al 1996). Similarly, it is largely due to successful NGO advocacy that an increasing number of donors now recognise the need to support and finance AIDS care and treatment, as well as prevention, which they were previously reluctant to do. It is also thanks to the efforts of NGOs that policy-makers have a greater understanding of the social determinants of the epidemic and its effects on communities and individuals. Yet, as stated above, much of this impact has been spontaneous, rather than a reflection of deliberate strategy.

Within the context of development thinking generally, a number of authors have recently addressed the question of deliberate strategies to increase scale and widen the impact of NGO activities. John Clark, for example, formerly of OXFAM but now working at the World Bank on NGOs, argues that there are essentially three pathways available to NGOs: project replication, building grassroots movements and influencing policy (Clark 1991; Clark in Edwards and Hulme 1992). Howes and Sattar (in Edwards and Hulme 1992) make the useful distinction between organisational or programme growth as opposed to achieving impact by means of transferring programmes to, or supporting other

\footnotetext{
${ }^{16}$ Drabek 1987 quoting from Robert Chambers, “Thinking about NGO Priorities” IDS Mimeo, 2 May 1987, p. 1
} 
organisations. Myers, in an analysis of scaling up early childhood development programmes, develops a terminology characterising the pace and nature of expansion; he uses the term planned expansion to refer to the process of implementing a particular model in a number of geographic areas once it has been pilot tested; explosion to denote the sudden initiation of a large-scale programme or intervention without any policy or organisation preparation beforehand, and association to mean expanding programme size through common efforts and alliances among a group of organisations, each of whom develop similar programmes but tailor them to the needs of specific communities or populations.

Other authors have pointed out that it is not the content of services alone that can be replicated or expanded, but underlying approaches or ideas, and this is particularly relevant to work on HIV/AIDS. Robert Chambers, for example (in Edwards and Hulme 1992) refers to what he calls "self-spreading and selfimproving strategies" whereby good practice (such as participatory approaches) is gradually extended through other organisations, in effect transforming their approach. ${ }^{17}$ Van Odenhoven and Wazir (1998) use the term "concept replication" to denote a similar process.

In the early 1990s, Edwards and Hulme, noting the lack of analyses of NGO efforts to scale up in developing countries, convened a number of workshops under the auspices of the University of Manchester and the Save the Children Fund. These brought together a diverse range of case studies of scaling up by both Northern and Southern NGOs, and include the presentation of a number of think-pieces on scaling up strategies more generally. ${ }^{18}$ In their efforts to synthesise the findings from these studies, they developed a three-fold conceptual framework: namely additive strategies which imply an increase in the size of a programme or organisation; multiplicative strategies - which do not necessarily imply growth but achieve impact through influence, networking, policy and legal reform or training; and diffusive approaches where spread tends to be informal and spontaneous.

\footnotetext{
${ }_{17}$ The book Who Changes? by Blackburn and Holland, inspired by Robert Chambers' work, entails a series of case studies of increasing the scale of the practice of participatory rapid assessment precisely through this approach.

${ }^{18}$ See Edwards and Hulme 1992; 1996; 1997
} 


\section{$9 \quad$ A Proposed Typology of Scaling Up with Application to HIV/AIDS}

To our knowledge, however, there has been no such analysis of approaches or philosophies to scaling up specific to the HIV/AIDS sector. In an effort to distil the findings from the above analyses of scaling up development NGOs more generally to processes relevant to HIV/AIDS, the following framework has been developed (summarised below in Figure 6). Five different types of strategies are envisioned, which can be represented on a continuum along which the original organisation that initiates the scaling up effort becomes less and less involved. The continuum also presents a gradation of strategies that become increasingly abstract in nature, and it is thus difficult to measure their impact.

This typology does not represent evolution of organisations, and indeed they may employ several of these strategies simultaneously with different types of HIV/AIDS programmes as appropriate to particular time-periods, geographic areas or social groups.

Figure 6 - A Proposed Typology of Scaling Up in HIV/AIDS

\begin{tabular}{|c|c|c|c|c|c|}
\hline & $\begin{array}{l}\text { Strategy } 1: \\
\text { Organisational } \\
\text { Expansion }\end{array}$ & $\begin{array}{l}\text { Strategy 2: } \\
\text { Catalysing Role } \\
\text { a) Technically } \\
\text { 6) Financially }\end{array}$ & $\begin{array}{l}\text { Strategy 3: } \\
\text { Diffusion }\end{array}$ & $\begin{array}{l}\text { Strategy } 4: \\
\text { Influe ncing } \\
\text { policy }\end{array}$ & $\begin{array}{l}\text { Strategy } 5: \\
\text { Mains tre aming in } \\
\text { Development }\end{array}$ \\
\hline $\begin{array}{l}\text { Main } \\
\text { objectives: }\end{array}$ & $\begin{array}{l}\text { Diversify: } \\
\text { - } \quad \text { Geograpfical } \\
\text { area } \\
\text { - } \quad \text { Social groups } \\
\text { - } \quad \text { Functions }\end{array}$ & $\begin{array}{l}\text { Expand range of } \\
\text { services provided }\end{array}$ & $\begin{array}{l}\text { Spread: } \\
\text { - } \quad \text { Concept } \\
\text { - } \quad \text { Approach, } \\
\text { or } \\
\text { - } \quad \text { Technology }\end{array}$ & $\begin{array}{l}\text { Influe ncing policy } \\
\text { climate }\end{array}$ & $\begin{array}{l}\text { Legitimise discussion } \\
\text { of } \mathcal{H} I \mathcal{V} / \mathcal{A} I \mathcal{D S} \text { of } \\
\text { sexuality Groadly }\end{array}$ \\
\hline $\begin{array}{l}\text { Type of } \\
\text { organisation } \\
\text { involved }\end{array}$ & $\begin{array}{l}\text { Initial } \\
\text { organisational only }\end{array}$ & $\begin{array}{l}\text { - Government } \\
\text { (service) } \\
\text { - Private sector } \\
\text { - Otfier NGO } \\
\text { - CBOs }\end{array}$ & $\mathcal{A} n y$ & $\begin{array}{l}\text { - Government } \\
\text { - Donors } \\
\text { - } \mathcal{N G O s}\end{array}$ & $\begin{array}{l}\mathcal{A l l} \text { de velopme nt } \\
\text { ins titutions }\end{array}$ \\
\hline
\end{tabular}




\subsection{Strategy 1: Organisational Expansion}

This category refers to the simplest form of scaling up activities, which reflects the effort of one organisation, rather than attempts to work with others. It entails increasing scale either by reaching a greater number of people, social groups or geographic areas, or expanding the functions or activity of the organisation. This may include, for example, developing a pilot project that is then expanded to a greater geographic area, or the opening of branches of the same organisation in different places.

Among the most famous examples of this first strategy is the Bangladesh Rural Advancement Committee (BRAC), which began in 1972 and is now one of the largest Southern NGOs with a staff of over 12,000, a budget of close to $\$ 23$ million and reaching over 3 million people. BRAC has achieved this scale through careful expansion of both the types of activities it undertakes (diversifying from economic activity into child survival and women's health for example) and by moving into different geographic regions of Bangladesh. According to one analysis of this scaling up process, quality was not sacrificed (Howes and Sattar in Edwards and Hulme 1992) perhaps owing to its careful process of experimenting through pilot projects, learning from them and then replicating them on a greater scale (Uvin 1995).

Extending to other population groups has been an explicit orientation of the scaling up objectives of a number of HIV/AIDS organisations. For example, Colectivo Sol, an NGO based in Mexico City, started by focusing its efforts towards self-identified gay men, but initiated educational programmes and other services for a wider group, including young people and other NGOs. ${ }^{19}$ Similarly, staff at ASI felt the need to extend their clinical services to children and babies. Their expansion of the programme was driven by increased demand for their services, projections of an impending rapid increase in the epidemic, and their perception that they either had to close or expand to cope with their rising case load. Similarly, the Family Health Trust has successfully reached out-of-school youth through its scaling up process, although it is much more costly and difficult to gain access to these young people than those in school.

\footnotetext{
${ }^{19}$ Chris Castle, personal communication.
} 


\subsection{Strategy 2: Catalysing Other Organisations a) Technically and b) Financially}

This strategy refers to efforts on the part of one organisation to work deliberately with other organisations either within the same sector or different sectors to influence the nature or scope of their service provision. This could entail developing relationships with government (particularly in terms of their service provision, not policy), the private $\operatorname{sector}^{20}$ or perhaps most usually, with other NGOs. For example, an organisation may develop a model, which the government is then persuaded to take over.

One successful example of this strategy is the strengthening of counselling capacity in government services with the involvement of SIAAP. Existing government STD facilities were not attracting patients - particularly women -- due to lack of a receptive atmosphere. SIAAP saw an opportunity to introduce counselling to break communication barriers between doctors and patients. In this case, government clearly saw the advantage of potentially increasing demand for their services. An arrangement was agreed whereby the government pays the salaries of counsellors who are trained and supervised by SIAAP. In the latter's judgement, the effort has been successful, and they have received requests from governments in neighbouring states for similar assistance.

Alternatively, an NGO may persuade another NGO to adopt an HIV/AIDS programme within its health or developmental activities. ${ }^{21}$ This category would encompass the work of NGO support organisations, which see their main contribution as offering technical, financial and social support to smaller organisations. This may entail providing expertise or guidance based on greater experience in HIV/AIDS, or may be of a more organisational development nature. An explicit part of KANCO's mandate, for example, is to assist member organisations in strategic planning, organisational development and financial accounting.

In some cases, such organisations may begin as direct service providers but either begin by or move subsequently into supporting other organisations financially. ${ }^{22}$ Such efforts can be hampered by unequal power relations between the more professional-oriented NGOs offering assistance in capacity-building and

\footnotetext{
${ }^{20}$ For example, the Thai Business Coalition, an NGO, aims to increase the scale of impact by increasing the involvement of business leaders in workplace AIDS programmes and to guide the development of AIDS policies in business settings (Sittitrai 1994).

${ }_{21}$ This has also been referred to as "grafting" whereby, for example, a programme for adolescents is added to existing services which failed to reach adolescents (Smith and Colvin 2000) and could also apply to links with governmental services

${ }^{22}$ Other examples of such types of organisations include TASO and SIAAP.
} 
programme design and the organisations receiving such support, in terms of access to finance, information and differential input into setting the agenda for the programme. SIAAP in South India, for example, at one stage began to support other NGOs financially but found it changed the nature of the relationship between the respective organisations and then restricted its support to technical issues. Nonetheless, where careful attention is paid to redressing such imbalances and where credit for success is fairly given, the results can be extremely positive.

The experience of KIMIRINA was almost the opposite to that of SIAAP in that when they only provided technical support the commitment to HIV/AIDS was relatively weak (Margarita Quevedo, personal communication). They found that even with large organisations with significant budgets, having an earmarked budget for HIV/AIDS, even if modest, generates a higher level of commitment. In their view, only once an organisation has a high level of awareness and strong commitment will technical support be enough.

The International HIV/AIDS Alliance employs this strategy at an international level. It sees its broad mandate as scaling up community response to HIV/AIDS internationally - working through "linking organisations" which it supports both financially and technically. These organisations in turn reach out and support local NGOs in their settings technically, organisationally and through exchange of information and sharing experience within and between countries.

A number of organisations provide technical support to other organisations by arranging for exchange visits, both within a country or internationally. This approach is critical to the Program Support Group's training to community volunteers in Southern Africa, for example.

HIV/AIDS prevention efforts may be most effective if integrated into existing infrastructures which already operate at a large scale across a range of sectors and thus NGOs may seek to "catalyse" those existing services to address HIV/AIDS. Indeed, seeking ways of combining HIV/AIDS interventions with delivery in other sectors, rather than focusing on scaling up individual HIV/AIDS interventions independently, may yield "economies of scope" whereby lower costs and greater efficiency are achieved than through separate delivery (Kumaranayake 2000). Yet, as Watts and Kumaranayake (1999) argue the potential for integrating HIV/AIDS programmes into other services, whether in education, reproductive health, family planning or sex education is often not fully exploited. They argue that in the short term, effective activities that can be scaled up quickly need to be identified, including using private sector (work 
places, unions) and informal networks involving religious and community groups. This could help increase the access of different social and geographical groups to specific activities (Watts and Kumaranayake 1999).

\subsection{Strategy 3: Diffusion}

The third type of strategy represents the effort to broaden impact by encouraging other organisations to adopt a particular concept, approach or technology. Diffusion is explicitly more abstract than previous strategies because it does not entail expanding one's own or influencing others' specific programmes or activities but rather spreading ideas or methodologies. Included among this set of strategies would be, for example, spreading the concept of peer education or community counselling or the promotion of male and female condoms (as technologies). This can entail either planned or spontaneous effort but by and large the initiating organisation is less directly involved in the implementation of the programme and works instead through influencing others. Outside the field of HIV/AIDS, this strategy has been very effective in promoting, for example, community-based rehabilitation approaches or reproductive health (particularly in influencing family planning organisations that previously provided highly vertical programmes).

The notion of community counselling in HIV/AIDS was foreign to India, for example, before SIAAP initiated a diffusion strategy to spread and legitimise the concept. Lacking expertise in India, they initially sought technical input from a number of international institutions. As a result of their efforts "SIAAP's counselling programme has been acknowledged and appreciated by the established medical system and endorsed by the Indian government." (Case study, p. 12).

At the international level, the Salvation Army's HIV/AIDS programme seeks to help communities to cope with the epidemic, and facilitates exchange visits across regions and countries to share experience and in which "facilitation teams" explore key concepts related to the epidemic with local stakeholders. In so doing, the organisation has endeavoured to diffuse the concept of communities measuring their own change in terms of having greater willingness and capacity to address HIV/AIDS (Case study, p. 16).

The Family Health Trust has also used this strategy to diffuse the model of the Anti-AIDS clubs to other schools in other locations. And ASI, which was the only 
clinical service in Guatemala providing integrated services to PLHA, made an explicit part of their strategy for scaling up to influence other clinical services to incorporate a similar approach.

\subsection{Strategy 4: Influencing Policy/Legislation}

At a yet larger scale, organisations may seek to engage deliberately the policies or legislation of government or of influential donor organisations. They may do so via efforts to shape the public debate on a particular issue, such as for example through outreach to the media so as to increase the understanding of the social determinants of HIV/AIDS or its impact. Or, they may seek influence via coalitionbuilding and knowledge exchange to increase the collective demands of civil society on the state within the arena of HIV/AIDS. For example, KANCO - a national network of NGOs, CBOs and religious organisations concerned about HIV/AIDS in Kenya, - aims both to complement government responses and to push for a more conducive policy environment. It provides capacity building to member organisations and operates as a clearing-house to provide accurate and up-to-date information on HIV/AIDS. Similarly, ASI and members of a coordinating body of 28 organisations in Guatemala have been lobbying for a more humane HIV/AIDS law, and their efforts bore fruit with the passing of that law in February 2000. And in the Philippines, an NGO coalition has lobbied for the full implementation of the existing HIV/AIDS law (Ruthie Libatique, PHANSuP, Horizons/Alliance Seminar). NGOs have also used this strategy in influencing governments and pharmaceutical companies by creating national, regional and international alliances or coalitions to lobby for price concessions and greater access to treatment.

Among the strategies thus far, this is the most explicitly political. Moreover, trying to influence policy or legislation may necessarily require a confrontational approach. For example, the organisation SIAAP began through efforts to obtain the release of HIV-positive women illegally imprisoned in South India, and it did so through legal challenges in the courts, as well as by raising awareness among the public at large (Shyamala Nataraj, SIAAP, Horizons/Alliance Seminar). Similarly, the fact that the social security system in Guatemala now offers care and treatment was achieved through lawsuits (Annie Hirschmann, ASI (AGPCS), Horizons/Alliance Seminar). A number of initiatives of scaling up harm reduction have also relied on legal strategies and efforts to keep the police at bay (Jeff O'Malley, HIV/AIDS Alliance, Horizons/Alliance Seminar). 
Some organisations may not initially engage in advocacy activities when they start work, but advocacy may become an explicit part of the scaling up process over time as they encounter obstacles or particular opportunities or needs. For example, the International HIV/AIDS Alliance based in the UK began to find ways to influence donor policies. And KIMIRINA, after several years of existence focusing primarily on catalysing small community-based organisations, began to initiate some advocacy activities as it increased its scale of operations and established a more solid institutional base (Horizons/Alliance Seminar).

\subsection{Strategy 5: Mainstreaming in Development}

Related to yet going beyond the fourth set of strategies, is the effort to permeate all development sectors with concern for and attention to HIV/AIDS and its implications. The explicit objective of such strategies is to widen the narrowly sectoral approach to HIV/AIDS by engaging the decision-making bodies and organisations across relevant sectors as well as seeking channels of implementation beyond the health sector alone. More of a development focus to AIDS efforts may also encourage a greater public understanding of the social context that puts individuals at risk of HIV/AIDS, including poverty, lack of education, ill health and the less tangible and more hidden problems such as inequitable gender relations, including women's economic dependence on men, poor self-esteem or lack of control over how and when sex (and conception) take place. For although one needs to change social norms more broadly to slow the spread of the disease, often the poorest communities are most affected by it. ${ }^{23}$

NGOs focusing on AIDS often find themselves ill equipped to deal with this broader development context of the pandemic. ${ }^{24}$ Conversely, development NGOs often do not take on HIV/AIDS efforts because they see it as a health problem outside their own area of expertise, a problem affecting only particular individuals rather than communities as a whole, or they may lack the financial and technical resources to do so (Sittitrai 1994). This is not to say, however, that HIV/AIDS specific NGOs should be advised to take on development activities previously not in their mandate. A more effective strategy is likely to be influencing nonHIV/AIDS specific NGOs to address HIV/AIDS so that, in the words of Kevin Orr of the Alliance "they don't make the same mistakes we did."

\footnotetext{
${ }^{23}$ This was one of the conclusions of the UK NGO AIDS Consortium report 1996

${ }^{24}$ The HIV/AIDS Alliance conducted participatory assessments in 1994-5 on the needs of local AIDS service NGOs in 12 developing countries, and found that: "The NGOs surveyed in most of the countries also cited the need for more action on the contextual (societal) factors which increase vulnerability to HIV, such as gender inequality." (O'Malley et al 1996: 346).
} 
The International HIV/AIDS Alliance has implicitly adopted this strategy in the majority of countries in which it works by choosing broad development organisations, rather than AIDS-specific organisations as linking organisations. Out of the 220 organisations the Alliance had supported by 1996, for example, 200 were general health or development organisations (Alliance Case study, Appendix C). However, although the Alliance found this strategy more effective, it notes that the associated costs of working with organisations not specialised in HIV/AIDS is often higher, at least initially. AMSED in Morocco, a development $\mathrm{NGO}$, is an example of an Alliance linking organisation. It is in turn collaborating with income generating organisations because they are already mobilised and Morocco lacks organisations working in communities across the country which have expertise in HIV/AIDS. Finally, PACT (in collaboration with the Alliance) specifically helps NGOs involved neither in health nor HIV/AIDS to address AIDS in Ethiopia.

Such a strategy is not without criticism, however. Ainsworth and Teokul (2000) argue, for example, that in poor developing countries with high prevalence of HIV/AIDS, where resource constraints are most evident and state capacity weak, encouraging non-health ministries to address HIV/AIDS may be spreading resources too thinly and may not be cost-effective. "AIDS mortality may strike every sector of the economy; however, this does not necessarily imply that adding AIDS prevention and mitigation to every ministry's programme will be a cost-effective way of reducing the epidemic." They argue instead that a selective number of interventions should be scaled up to national level by governments and pursued vigorously for achievable outcomes. However, their argument emphasises governmental strategies and is not specifically applied to NGOs. ${ }^{25}$ Moreover, they do stress the importance of integrating HIV/AIDS into poverty reduction strategies.

It should be noted that any one organisation may engage in a number of the above strategies simultaneously, and there may be overlap between the various categories. Moreover, the staging of the continuum is not intended to imply a chronological progression, as individual organisations may, after assessing their own comparative advantage and their environment, decide that any one of these broad categories of scaling up may be the most appropriate place to start.

\footnotetext{
${ }^{25}$ Interestingly, the same article notes that: "In many instances, the tendency of international agencies to work through
} NGOs has the effect of marginalizing the government" (Ainsworth and Teokul, The Lancet, $2000-$ p. 58). 


\subsection{TASO: An Example of The Evolution of Scaling Up Strategies}

The efforts of staff of $\mathcal{T}$ he $\mathcal{A I D S} S$ upport Organisation (TASO) in Ulganda to increase the scale of its activities and to widen its impact could be represented as an evolution of scaling-up strategies as presented in this publication. Their changing strategies reflected their response to the rapidly expanding epidemic and evolving policy context, and therefore emerging needs in the external environment, as well as their own institutional learning of what strategies were effective and manageable.

TASO began in the late $1980 s$ as a support group of people infected and affected by $\mathcal{H} I \mathcal{V} / \mathcal{A} I D S$ in Ulganda which started meeting informally in 1987 (Kalee ba et al. 1997). It then grew into a formal voluntary organisation with a mission of "restoring hope and improving the quality of life of persons and community affected by HIV infection and disease."

At its inception, $\mathcal{T A S O}$ focused on sensitising health care personnel to the needs of people with $\mathcal{H} I \mathcal{V} / \mathcal{A} I D S$ and providing clinical services to those suffering from $\mathcal{H} I \mathcal{V} / \mathcal{A} I D S$ and counselling for $\mathcal{H} I \mathcal{V} / \mathcal{A} I D S$ clients and the ir families. Initial approaches to scaling up focused on strategy 1 above, organisational expansion, or what they refer to as "purposive duplication" (Case Study p. 3). By 1990, TASO had opened 7 centres in 7 out of 45 districts (Case Study).

Shortly after its inception, $\mathcal{T} \mathcal{A S O}$ staff realised that clinic services we re insufficient and that they were incapable of responding to increased de mand and were indeed risking creating a dependency on $\mathcal{T} \mathcal{A} S O$ services (Antivelink et af. In the early 1990s, the TASO Community Initiatives (TCI) were established after recognition of the need to help communities address $\mathcal{H} I \mathcal{V} / \mathcal{A} I D S$ at the local level. Initially piloted in a few places near Kampala, they were replicated to other sites including Entebbe, I inja and Mbale (Antivelink et al. 1996). 
By the end of 1993, TASO was operational in seven districts in Ulganda and was providing counselling, medical care and social support to a cumulative number of over 22,000 people with HIV/AIDS and the ir families (Kale e 6 a et al. 1997). Nonetheless, despite this substantial expansion within 6 years, there was still continued demand for services and in 1996, TASO revised its scaling up strategy. TASO then assumed a catalyst role (strategy 2 above) in moving from direct service provision to facilitating capacity building of other organisations. Thus a network of "TASO-like" services were created after 1996, while TASO centres continued to run as "model HIV/AIDS care centres" The aim of the strategy was to develop local capacity in existing health centres to provide $\mathcal{A} I \mathcal{D S}$ services medical care, counselling, $\mathcal{F P} / \mathcal{S} \mathcal{T} \mathcal{D}$ services, manage rial capacity etc. Because $\mathcal{T} \mathcal{A S O}$ worked through local district committees, it was able to ensure that there was local commitment to the objectives of their organisation. This strategy meant that the effective impact of TASO extended well beyond those districts where $\mathcal{T A S O}$ services were physically located and priority could be given to districts which lacked any type of $\mathcal{H} I \mathcal{V} / \mathcal{A} I \mathcal{D S}$ related services.

TASO provided limited resources to "TASO like services" although their own costs were more than expected because of the unanticipated need for supervision on the part of $\mathcal{T A S O}$ staff

An extensive participatory evaluation in 1996 prompted a revising of several of their strategies for scaling up (see Antivelink et al. 1996 and Kale eba et al 1997). Of the many lessons the organisation tookfrom the participatory review was the fact that "HIV/AIDS is not the only issue or need in the community" (Antivelinket al 1996) and the importance of $\mathcal{T} \mathcal{A S O}$ linking with organisations addressing other development needs such as famine, the social and legal vulnerability of women-particularly widows .. and orphans, and income generation (strategy 5 above).

By 1998, TASO had worked in 66 communities and trained over 2,500 community volunteers. Significantly, by this time $\mathcal{T A S O}$ was working with 41 organisations in partnerships (2 fospitals, 7 health centres, 32 CBOs). 
Despite the tremendous success of this innovative approach, however, TASO staff recognise that it encountered a number of challenges in scaling up its activities many of which have been observed among other $\mathcal{N G O s}$ during scaling up. These include the difficulty of monitoring quality and quantity due to lack of comple te or reliable data at least partly due to inadequate record keeping by volunteers and health workers. Their efforts were also constrained by the problem of volunteer drop out and irregular supplies of condoms and drugs. They also acknowledge the problems of having only a few trained counsellors covering a large geographic area. As with other efforts involving collaboration with public sector staff, there were also specific challenges, such as the additional work and responsibilities placed on the staff of district health facilities when there were no financial incentives attached. Moreover, high staff turnover rate at the local health units meant that there was a continual need for training of newstaff.

This case study illustrates that at different points of the epidemic, and on the 6 asis of experience accumulated by individual organisations, strategies for scaling up are likely to evolve significantly over time.

\section{Partnerships/Alliances}

Since all of the above strategies with the possible exception of the first, organisational expansion, involve some sort of relationship with other organisations, key questions that must be addressed would include: What incentives are there for the other organisations to take over or adopt the new activities? Is there compatibility between the two types of organisations? Are there salary differences between the different types of organisation that could affect the expansion from pilot to programmes of greater scale? For example, if the initial effort is established by an NGO and then transferred to government services where civil servant salaries are lower in relation to the NGO, how can sustainability be achieved? Will the initiating organisation eventually withdraw or transfer the programme to the other organisation and if so, when and how? In what follows, some aspects of these questions in light of the specific relationships involved will be examined. 


\section{Government-NGO Relations}

Co-operation between government and NGOs in HIV/AIDS depends both on the political context and the degree to which governments are open to such input, and whether NGOs perceive the benefit of interacting more closely with government. As HIV/AIDS prevalence rises rapidly, governments often look to NGOs for expertise in addressing the epidemic, and therefore may be more open to collaboration. But high prevalence is not a necessary condition for successful partnerships. Often, however, governments and NGOs tend to regard each other with mutual suspicion (see cartoon below), rather than seek channels of collaboration. NGOs are often frustrated with the inability of public sector delivery mechanisms to be flexible or innovative, or to respond to changing community needs. They may inevitably feel - depending on political context -- that unequal power relations between government and NGOs means that the NGO is inevitably the junior partner and government "calls the shots." (Geoff Foster, Family AIDS Trust, Horizons/Alliance Seminar). Similarly, governmental staff may be wary of involvement with NGOs whom they may regard as opportunistic and donor-driven, or representing the interests of particular social groups and not addressing the wider national picture. In many cases, mutual competition over resources and particularly donor funding can inhibit co-operation.

Figure 7 - Government - NGO Relations

Source - Illustration used in Cambodia presenting the challenges of starting up a joint Ministry of Health / NGO home care programme for local NGOs/CBOs involved in HIVIAIDS.

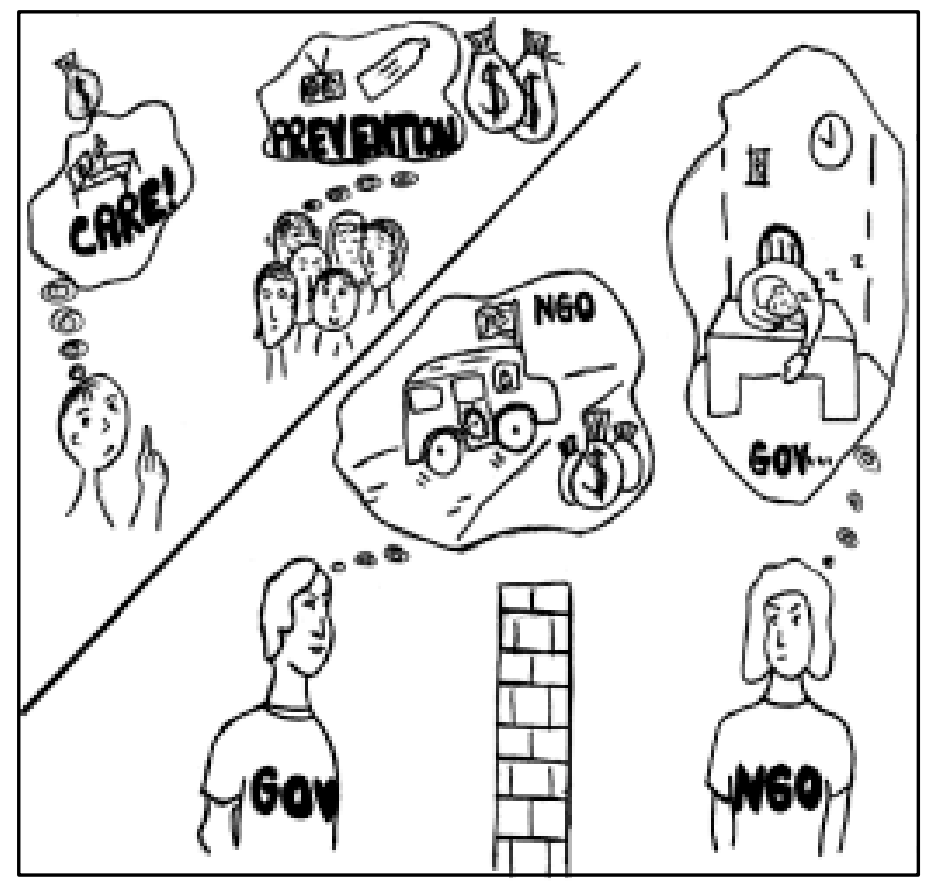


There are a number of clear advantages for both governments and NGOs to foster partnerships to increase the scale of HIV/AIDS activities. Government services have the advantage of greater coverage at relatively low cost (given low civil service salaries in most countries) but often lack the understanding of community dynamics and process approaches and risk being overly intrusive or directive. Here, NGOs can have a key role in encouraging more participatory methods as well as influencing the content of HIV/AIDS programmes.

Governments and NGOs may complement each other in terms of access to different social groups. On the one hand, governments may have sole or better access to groups such as the military or the police, both of whom are highly relevant to HIV/AIDS, and be able to reach them on a much larger scale than non-governmental organisations, such as through the public education system. Yet on the other hand, governments may be restricted in access to population groups engaged in illegal or stigmatised activities and have little political interest in working with the socially marginalised. One of the NGOs' comparative advantages lies in their ability and willingness to work with such groups.

NGOs may also have a particular contribution in broaching sensitive issues and then increasing the legitimacy of addressing this social problem, thus opening the door for government involvement. In other contexts, however, the fact that NGOs are active in some areas of HIV/AIDS may deter governments or let them off the hook from addressing these issues. It should be noted, moreover, that this is far from a one-way process in that not only might strategies described here influence government policy regarding the provision of public AIDS programmes, but policies can in turn have an impact on the environment in which NGOs operate as well.

Successful examples of NGO-governmental collaboration in development more broadly illustrate that strong relationships between individuals are critical (Edwards and Hulme 1992), even though political exigencies may bring unanticipated changes in personnel within governmental institutions, and staff turnover is often high in NGOs.

Within the field of HIV/AIDS a number of instances of successful collaboration were discussed at the Horizons/Alliance Seminar. In Cambodia, for example, the governmental HIV/AIDS programme has greater fears of cultural resistance and is more risk averse in trying new models, but once NGOs start and show a particular model can work, then the government may be more prepared to replicate it (Cambodia presentation and small group discussion, Horizons/Alliance Seminar). Participants in the Government-NGO collaboration 
for home-based care, described above, note that critical ingredients of its relative success is that both parties are aware of the benefits of partnership and respect and understand each other's systems and structures. In this case, the groups involved developed a joint mission statement and they operate as much as possible with full transparency (of funding and programme direction).

The government-NGO collaboration in Cambodia also successfully avoided a problem characterising many other community-initiated home-care programmes in their failure to institutionalise connections or referrals to existing governmental health services. As Wilkinson and co-authors note: "a home care programme which, at the onset, links grassroots organisations with existing public health services, and encourages shared ownership is more likely to achieve sustainability, impact and cost-effectiveness." (2000). This ingredient of a particularly successful collaboration illustrates a broader theme, which is the importance of NGO programmes being linked into existing HIV/AIDS related services and the dangers of NGOs assuming they can "go it alone."

In the Philippines there has been relatively smooth NGO-government cooperation in HIV/AIDS partly because the government recognises that it cannot do everything - that although there is a National AIDS Plan it would take a long time to implement it fully. One example is that NGOs initiated an effort to train public school teachers in HIV/AIDS, a model which the government subsequently adopted (Ruthie Libatique, PHANSuP, Horizons/Alliance Seminar).

A number of key lessons for fostering dialogue between NGOs and government emerge from the case study of KANCO. Allan Ragi noted that governments find collective networking threatening and therefore one has to actively look for opportunities to encourage the participation of government representatives. At the same time, governments will only respect the viewpoints and arguments of NGO coalitions if they authentically represent the views of grassroots organisations (Allan Ragi, KANCO, Horizons/Alliance Seminar).

NGOs note, however, that relationships or collaborations with government are not always sustainable. ASI found, for example, that having sought and developed a fruitful collaboration with government, with the change of government they had to start again and agreements made with previous administration were not upheld. Moreover, in Cambodia - where the government finances NGOs in home-based care, financial sustainability was not necessarily assured.

Surmounting these attitudinal and procedural barriers to greater co-operation between government and NGOs in HIV/AIDS is critical and has a potential for 
high returns. For ultimately, governmental services are unique in their national scope, and only governments possess full information of the situation at the national level as well as being accountable to the general public to a degree most NGOs are not.

\section{NGO-CBO Relations}

A number of successful efforts to scale up HIV/AIDS programmes have worked through collaborations between professional NGOs and small, community-based organisations (CBOs). The experience of FACT/FOCUS illustrates that it is feasible to build on existing community initiatives by volunteer and communitybased organisations. Their first pilot was established in 1993 in a particular region of Zimbabwe where communities were already addressing HIV/AIDS through a church. At its inception, 19 volunteers working in 19 villages led this effort. After 1 year FOCUS did an evaluation and found that the programme identified most orphans and targeted the neediest and most vulnerable in material terms. FACT/FOCUS then played a catalyst role to replicate the initiative to 9 sites (with the number of families reached increasing from 798 to 2764). In this case, the role of the NGO FACT/FOCUS was to supervise the existing programme, by providing both technical and organisational development assistance, assisting in the replications by the same CBO (strategy 1, organisational expansion) and by other CBOs (strategy 2, catalyst).

As noted above, however, the risk in relying solely on community initiatives is that there may be reluctance to address marginal social groups, or sensitive issues. In this case, the external agency may need to intervene to counter this resistance, while at the same time not undermining existing momentum. A similar dilemma was faced by the Family Health Trust when it found that the AntiAIDS Clubs tended to exclude young girls.

Another potential drawback of many such partnerships is the failure to ensure that the community initiatives are sufficiently linked into health and other service structures, whether public, private or charity-based. There is a danger that the effort may stimulate demand for services on a scale to which the supply of services (or commodities) is insufficient to respond. If a continuum of interventions - from prevention to care and support - is to be provided, fostering these links in advance of expansion is particularly critical. 
A number of examples of successful scaling up efforts by NGOs emerged out of collaborations with research institutions. The added benefit of this type of partnership is the opportunity to build into the NGO effort research and evaluation capacity that is rigorous. For example, the Program Support Group in Zimbabwe evolved from the University of Zimbabwe from a research project into a servicedelivery organisation. Staff at the university had been conducting an ethnographic study of HIV-vulnerable low income women in Bulawayo, Zimbabwe and the women who participated in the study requested STD/HIV/AIDS education and services (PSG Case study, p. 35). Research continues to inform the PSG programmes, although as their activities have expanded in three Southern African countries, they note a continual challenge entailed in maintaining the quality of their research.

In some cases, organisations found that there was particular value in affiliations to outside training and research institutions if national capacity in that particular area did not exist. For example, SIAAP, in its diffusion of the concept of community counselling, co-operated with a number of European institutions with expertise in that area since the concept was not known in India. This helped to increase the legitimacy of this field. And as noted earlier, ASI enlists medical students to assess the quality of its interventions.

As the above examples of successful collaboration in HIV/AIDS make clear, NGO partnerships may be essential in whichever scaling up strategy NGOs adopt. There is now increasing recognition - on the part of both NGOs and donors - that NGOs acting alone are not likely to make a dent in the epidemic, either in terms of preventing it or mitigating its effects, particularly in high-prevalence countries. Moreover, partnerships are often essential if a continuum of interventions from prevention to care and support is to be available. But such collaborations necessarily require time to develop, and each partner has to establish their reputation and legitimacy in the eyes of the other. As Annie Hirschmann of ASI notes, this inevitably means that NGOs need to anticipate slower processes. The rewards, as the Cambodian example described above illustrates, are potentially high. 


\section{The Importance of Context}

All of the above strategies are necessarily contingent on the context in which the organisation finds itself operating - such as the policy context and where the official government position on the HIV/AIDS epidemic lies on a continuum from complete denial to mainstreaming HIV/AIDS across all areas of development. The general political context will also play a determining role, whether in terms of the extent of state capacity, its accountability to public demands or the degree of transparency with which it governs. Political considerations would reflect the degree to which NGOs are given some autonomy within which to operate and the scope available for community organising without fear of repression. Many have argued, however, that even adverse political contexts do not necessarily mitigate against scaling up efforts (Myers 1992; Sittitrai 1994; Smith and Colvin 2000). Indeed, where governments are incapacitated for various political reasons - such as in complex emergencies - NGOs may find valuable opportunities for initiating activities at a greater scale. In these contexts, however, the most likely strategy is neither strategy 4 nor 5 above, but rather careful and low-key efforts to catalyse other organisations (strategy 2) and to diffuse community-based approaches to HIV/AIDS prevention, voluntary counselling and testing as well as care and support for those affected (strategy 3 ).

Capacity would also include the availability of government infrastructure and the degree to which government provides a minimum safety net for its citizens. This, of course, will in turn be affected by the economic situation prevailing in the country, and the adoption of macro-economic policies such as structural adjustment, which may severely constrain budgetary resources. Where economic or logistical constraints interrupt the supply of commodities - such as treatment for opportunistic infections or condoms, for example -- this can hamper the most successful models of scaling up as both the Program Support Group in Zimbabwe and TASO in Uganda have noted (Case study presentations). If capacity is very low, it is likely that there will be a ceiling to efficiency gains through expansion and at a certain scale of delivery, further investment in capacity and infrastructure will be necessary in order to be able to expand activities and exploit potential economies of scale (Kumaranayake 2000). Where state capacity and willingness to address HIV/AIDS are both low, for example, strategies of scaling up may focus on the NGO sector alone, rather than building bridges with government services.

The epidemiological context is also a key factor - including the stage and dynamics of the epidemic. Where, for example, governments are still in denial 
and the epidemic is still not significantly advanced into the general population, there are not likely to be many NGOs active in HIV/AIDS either on the prevention side or in care and support. Those that do exist are likely to be impeded in their access to communities and to the mass media. ${ }^{26}$ Thus, partnerships may need to be sought with organisations active in development to a broader degree, or through other entry-points such as reproductive health or gender issues. In some contexts, however, the fact of government denial may provide a window of opportunity for NGOs; for example, in Ecuador, precisely because the government does so little in HIV/AIDS many NGOs were created to respond to some of the needs of PLHA (Margarita Quevedo, personal communication). Nevertheless, despite the importance of the level of the epidemic, NGOs do not always articulate different strategies whether their countries or areas have high or low prevalence of HIV/AIDS. ${ }^{27}$

The feasibility of delivering scaled up interventions will also be conditioned by the intervention context and how difficult it is to reach population groups, both in terms of social and physical access. Thus, for example in contexts which have a relatively low level of urbanisation and in which populations are dispersed in remote rural areas, or among migrant communities scaling up is likely to be both resource- and time-intensive. Cultural considerations will dictate the degree of taboo surrounding the discussion of sex generally and the stigma associated with particular sexual orientations (such as homosexuality) or sexual activity (such as sex work) as well as with injecting drug use and other potentially high-risk behaviours.

\section{Decisions as to Whether or Not to Scale Up}

As the foregoing makes clear, the arguments for scaling up HIV/AIDS activities are strong on moral, epidemiological and cost-effectiveness grounds. Nonetheless, this should not be interpreted to mean that all institutions should scale up their activities or that all activities should be scaled up. The impact of many excellent small-scale programmes has been through the dissemination of their project experiences rather than scaling up itself (Boyce et al. 1997). Most countries have and need a diversity of types and sizes of organisations active in HIV/AIDS, which are complementary to each other. Thus both NGOs and government need to recognise their own comparative advantage within this larger

\footnotetext{
${ }^{26}$ This is the case in Egypt, for example, where despite significant capacity and a relatively good health infrastructure, there are few NGOs active in HIV/AIDS (professional experience of the author from working in Egypt 1992-99).

${ }^{27}$ Indeed, discussion of how the level of epidemic affects strategy was notably missing from the Horizons/Alliance Seminar.
} 
national picture. Moreover, not all organisations or activities are ready for scaling up, either in terms of financial capacity, internal organisational characteristics or programme maturity. Boyce and co-authors, in reviewing the scaling up of rehabilitation programmes, found, for example that it is often older organisations which are best prepared to scale up, given that they have established reputations and have the requisite community links (Boyce et al. 1997). Nonetheless, in the relatively new field of HIV/AIDS, "programme maturity" needs to be seen in relative terms.

At the Horizons/Alliance Seminar, a set of preconditions (see Figure 8 - below) to NGOs scaling up their activities was proposed by Baba Goumbala of the ANCS in Senegal.

Figure 8 - Six Preconditions for Scaling up

Source - Baba Gamboula, ANCS, Senegal (Horizons/Alliance Seminar)

- Evaluation is necessary before expansion.

- The desire and willingness to do more and better must come from inside the $\mathcal{N G O}$ and not be imposed from outside.

- The $\mathcal{N G O}$ must have the resources and capacity appropriate to the scaling up.

- The scaling up should be initiated at the $\mathcal{N G O}$ 's own rhythm and at the rhythm of the community.

- The NGO must control the know-how and direction of the scaling up transition process.

- The population(s) who will be reached must be the most appropriate regarding the ir vulne rability and the ir potential to act as vectors of social change.

While each of these preconditions was discussed extensively at the seminar, and is open to debate, consensus emerged that scaling up in HIV/AIDS need not always proceed at the "rhythm" of the community for many issues or groups may be disregarded or ignored if left only to the choice of communities themselves. Thus there may be an inherent conflict between the "rhythm" of the NGO and that of the community or communities concerned, and there is often a necessary role, it was argued, for outside agencies to stimulate action related to these sensitive concerns or marginalised social groups. 
If NGOs do decide to initiate scaling up processes, three elements become extremely important to contemplate in ensuring that the organisation is sufficiently prepared. The first is that time and resources are devoted to planning for the scaling up process. The second is that organisations analyse their own comparative advantage within the larger picture of activities within the HIV/AIDS sector. Thirdly, the institution must consider the internal implications of scaling up for leadership, management, staffing, structure and costs. The later internal dimensions will be further addressed in the final section of this publication, whereas the focus here is on questions of strategy and effectiveness.

A number of programmatic questions must be addressed before the scaling up exercise begins. These include the question of who to focus on, both in terms of the beneficiaries of interventions, as well as whether the scaling up exercise would be confined to the original organisation (strategy one above) or work with other institutions - NGO, private or governmental (strategies $2-5$ above). In terms of the beneficiaries, for example, should the scaling up focus on increasing the numbers of people reached in absolute terms, or concentrate on those most likely to affect the dynamics of the epidemic, or perhaps most likely to adopt behavioural changes? ${ }^{28}$

In some cases, NGOs that successfully scaled up their programmes present at the Horizons/Alliance Seminar did focus on the groups most vulnerable to HIV/AIDS. PSG for example, explicitly targets HIV/AIDS vulnerable and lowincome communities. Similarly, the Healthy Highways Project in India - an initiative of the UK Department for International Development and the Government of India including a number of NGO partners such as the Naz Foundation - specifically targets truck drivers (and their partners) as being most vulnerable to HIV/AIDS because of their mobility.

Such an approach based on epidemiological notions of risk is often highly effective but may tend to narrow emphasis on the target groups without looking sufficiently at their partners or the circumstances governing their sexual behaviour. For example, Allan Ragi of KANCO notes that neglected groups have been the wives of truck-drivers or secretaries in the companies for which they work.

If one follows a social model of health, and endeavours to understand the social processes driving the epidemic, then one may emphasise groups more likely to bring social change - that is, "vectors of social change" rather than the "vectors of

\footnotetext{
${ }^{28}$ Questions posed by Jeff O’Malley, email of 13 June 2000
} 
the epidemic" (the former term was favoured at the Horizons/Alliance Seminar). For example, SIAAP chose to work with an innovative target group of blind people. On epidemiological criteria alone, this may not seem an effective group to focus on given their relatively small population size. ${ }^{29}$ However, the fact that the blind are particularly disadvantaged in gaining access to HIV/AIDS material (most of which is written) or may be more stigmatised than most when purchasing condoms, for example, make this an important group to focus on in social terms, if one's objective is to counter stigma associated with HIV/AIDS.

Moreover, if one's objective in scaling up is to build on indigenous community initiatives, then of interest is how one can stimulate spontaneous links between and among communities. For example, the orphan support programmes that FACT/FOCUS has supported expanded through links between church groups to other communities.

The second key question is what to focus on in scaling up in terms of particular HIV/AIDS activities. ${ }^{30}$ This in turn will depend on a number of dimensions, including the feasibility of particular strategies - including technical aspects and questions of access to necessary resources (such as condoms or pharmaceuticals), costs as well as political considerations.

The second dimension would be the effectiveness of scaling up particular strategies, which points to the need for research to inform the strategies chosen. Yet NGOs often do not have the requisite information to assess effectiveness, either because they lack exposure to technical innovations or new findings or results of interventions tested elsewhere, or do not have the resources or orientation to undertake research themselves (Sittitrai 1994).

Finally, the strategy chosen would need to be based on assessment of the capacity of the organisation (or partner organisations) to undertake the scaling up. Questions of capacity should be assessed in relation to existing capacity within both the non-governmental and governmental sectors. The internal capacity of organisations is addressed in the final section of this publication.

\footnotetext{
${ }^{29}$ Their actual epidemiological risk has not been studied. C. Ramachandran of SIAAP notes that they may be at high risk because they tend to marry later, and often live in hostels or institutions for the blind (personal communication).

${ }^{30}$ See appendix B for a list of HIV/AIDS interventions from a public health perspective and Appendix: C for a description of the evolving focus of the HIV/AIDS alliance on different types of HIV/AIDS interventions in its support of community action in the field of HIV/AIDS.
} 


\section{What is the Motivation for Scaling Up?}

Within the literature on scaling up NGO efforts, there has been remarkably little attention paid to the motivation behind scaling up, ${ }^{31}$ with the lion's share of emphasis on the circumstances in which NGOs are pushed to increasing the scale of their efforts by donors making funding available deliberately for this purpose. While this clearly is a dominant model, in practice, however, there is a range of reasons that might motivate an NGO to undertake a scaling up effort of all or some of their programmes.

Expansion may be externally induced if the overall context in which NGOs operate changes, either because of the evolution of the HIV/AIDS epidemic itself (as it expands rapidly, and/or extends into other social groups or geographic areas, for example) or the natural history of the disease (with increasing proportions of the beneficiary community becoming symptomatic). The overall policy climate may change, either in a negative or positive direction due to changes in government stances regarding HIV/AIDS, or the activities of other organisations. Alternatively, the beneficiaries of an organisation may be the driving force behind expansion in that they may demand a greater scale in terms of the numbers of persons reached, geographic areas covered or the type of activities undertaken. In many cases increasing the scale of activities is part of a deliberately conceived research process, beginning with a pilot study and involving a staged programme of expansion. As noted above, the Program Support Group, for example, began as an ethnographic study in the University of Zimbabwe, and subsequently moved into service delivery. Research continues to inform their on-going programme.

In other instances, the introduction of new technologies - for example the female condom or microbicides - may drive efforts to expand the scale of activities. International pressure and advocacy or the evolution of ideas at the international level often play a key role in inspiring certain forms of expansion. As was evident at the International Conference on Population and Development for example, when a particular approach - such as integrating HIV/AIDS within reproductive health care - is endorsed at the international level, this can play a very influential role in the design of local programmes. The extent to which such integration is indeed desirable and is actually happening, however, remains debated (Mayhew 1996).

\footnotetext{
${ }^{31}$ Uvin and Miller (1996) refer to "push" factors for scaling up which are largely supply-driven - that is, where the impetus for scaling up comes from the programme providers themselves, usually NGOs or government; and "pull" factors where demands for scaling up emerge from the recipients or participants of the intervention programme. Nonetheless, there is a need to further disaggregate these categories. Moreover, in practice expansion is likely to result from a combination of motivations.
} 
The desire for expansion may have little to do with external factors but rather be entirely internally motivated, either at the initiative of a visionary and charismatic leader or through staff consensus. Funding is then sought to finance the planned expansion. Expansion may stem from observed success in smaller-scale activities and the desire to expand this effort. Alternatively, it may be driven internally by discovery of obstacles to successful programmes. For example, the Self Employed Women's Association, in Ahmedabad, India - a trade union with a membership of over 200,000 women - developed to represent the economic interests of disadvantaged women but expanded into health when staff found that the main reasons for defaults on loans were maternal mortality and health problems.

There may be personal motivation such as a desire for professional advancement, social recognition or prestige that provide the underlying impetus to programme expansion. In many cases, leaders of organisations stake their careers on the visibility, influence and indeed size (as measured in numbers of employees or in overall budgets) of the organisations they direct. The notion that NGOs need to increase in size in order to compete with other organisations for donor funding or influence is widely held according to participants in the Horizons/Alliance Seminar. As Jeff O'Malley notes in the case study on the HIV/AIDS Alliance: "It is rare indeed for an NGO of any size to conclude that it is doing enough, or that it has enough resources."

The degree to which the initiating organisation perceives itself to be in control of the process of expansion in large part reflects the nature of this motivation. In a workshop convened by the UK NGO AIDS Consortium, for example, many participants spoke of the involuntary nature of scaling up, in that they felt they were obliged to take on other activities because of overwhelming poverty and the lack of services in the face of a devastatingly rapid spread of the epidemic. In these circumstances, the lack of time, opportunity or resources to prepare for scaling up can have a detrimental effect on its ultimate effectiveness. In other situations where control is equally lacking - where expansion is induced by the exigencies of foreign funding, for example, scaling up may actually dilute effectiveness.

Similarly, selecting among strategies as defined above in the typology may not be a result of free choice, and indeed organisations may resort to certain strategies rather than others as a compromise. Where funding is not available to catalyse other organisations (strategy 2), for example, some might engage in policy 
advocacy with both government and donors in order to encourage them to provide the necessary funds to support grassroots activities. ${ }^{32}$

\section{Risks Entailed in Scaling Up NGO Efforts}

Over the last several decades, as the role of NGOs in social development has expanded considerably, there have been a number of criticisms of NGOs emerging. Among these are arguments that their impact would be greater if they looked self-critically at both their internal structures and processes as well as their comparative advantage relative to government in particular. These criticisms are instructive in thinking about a process of scaling up which would expand the role of NGOs even further. Some have criticised NGOs for increasingly taking on tasks more appropriate to the state, although they have recognised that this has often been prompted by the prevailing context of structural adjustment and indebtedness in many countries. Ironically, NGOs themselves are often critical of these macro-economic policies yet find themselves increasingly pushed into the role of large-scale service-providers, effectively substituting for the public sector (Edwards and Hulme 1992). Part of this may be attributed to the preference of donors to fund service provision that has concrete and visible outcomes, as opposed to the more political advocacy efforts whose impact is difficult to measure. Yet not only does this shift have a major impact on the institutional culture of the NGO, but it can put them in a very different political role nationally as well as divert the original aims of the organisation.

Perhaps more serious concern has been expressed about what many have observed to be a prevailing tendency for NGOs to become more accountable to their external funders than to their declared constituency. In their book entitled NGOs, States and Donors: Too Close for Comfort? Edwards and Hulme (1997) point to evidence that NGOs are "losing their roots" as they increasingly serve the interests of donors, and to a lesser degree governments, rather than the poor and disempowered whom they set out to help. And this tendency might only be exacerbated by scaling up. Pearce voices a widely held view that: "Without meaningful accountability to their "beneficiaries," scaling them up could seriously distance them from the poor and their own social structures." (Pearce 1993). Indeed, despite the rhetoric of NGOs that they represent the interests of their beneficiaries and respond to their needs, there are often few mechanisms to ensure that this is the case. For the most participatory oriented organisations, such needs make themselves felt precisely because the NGO faces the

\footnotetext{
${ }^{32}$ Sue Lucas, International HIV/AIDS alliance, personal communication
} 
community daily, but as the scale at which NGOs operate increases, such close interaction, and consequently the scope for participation, may be reduced.

Several authors have pointed to the fact that this increasingly influential relationship between donors and NGOs often creates processes whereby the structures and values of the NGO come to mirror those of the funding organisation (Charlton 1995; Fowler 1991; Edwards and Hulme 1997). For example, complicated reporting procedures may stimulate the expansion of departments within the NGO to respond to such demands, thus increasing the bureaucratisation of the organisation. Moreover, a premium may be placed on the employment of English-speaking graduates who are able to prepare polished proposals for donor consumption and this may distort the interaction with local communities, as well as the salary structure of the organisation. White ${ }^{33}$ observes that increased size of NGOs serving the poor in Bangladesh has "inevitably meant increased distance from the grassroots and the early pioneering vision has been replaced by an ethic of efficiency and professionalism."

\section{Special Challenges in Scaling Up HIV/AIDS Efforts}

\section{Donor Funding}

Many of the above critiques have also been levelled at NGOs active within HIV/AIDS. Although it is recognised, for example, that an increased level of donor support is necessary to increase the scale of operations, many have pointed to the damage created by a sudden influx of large amounts of donor funding. ${ }^{34}$ If sufficient reflection has not taken place internally regarding the strategic use of the funds - such as in a thoughtful process of preparing for scaling up - the influx of money is likely to diminish creative effort within the organisation and may jeopardise the effectiveness of its programmes. Moreover, as organisations increasingly compete in chasing donor funds, this is likely to create jealousies and rivalries with other organisations that should be natural allies in efforts to increase the impact on HIV/AIDS.

Some have noted that receiving an increasing scale of funds - particularly if available through official channels negotiated with the state - may make NGOs less critical of government policy, and inclined to shift away from an advocacy

\footnotetext{
${ }^{33}$ S. White (1999) "NGOs, Civil Society and the State in Bangladesh: the politics of representing the poor" Development and Change, Vol. 30, No. 2.

34 The dynamics created in PWHA organisations by greater donor funds being made available are particularly complex given the fact of the intrinsic conflict of interest where staff and beneficiaries belong to the same group (O'Malley et al 1996).
} 
role (Sittitrai 1994). This has been observed in Australia, for example, where the increasing official recognition of AIDS councils has prompted their expansion into large service-delivery organisations whose autonomy from the state is increasingly questioned. ${ }^{35}$

A less analysed feature of increased levels of donor support is how it may affect the local reputation of the organisation and community perceptions of its activities. Hyden and Lanegran (1991), in a "political mapping" of the AIDS epidemic in East Africa, argue that HIV/AIDS agenda setting within Africa has been overly dominated by international donors and Northern NGOs. According to them, this reinforces the perception among Africans of AIDS as foreign and reflecting outsider determination to prove that AIDS originated in Africa. Others within the HIV/AIDS sector, such as Decosas ${ }^{36}$ have argued that donor agencies have played too prominent a role in influencing HIV management in southern Africa.

A more recent concern has emerged that with increased commitment for donor organisations to work on HIV/AIDS and to increase their budgetary allocations to it, particularly since the Durban conference, there is a growing competition among donors for NGOs to support. ${ }^{37}$ There is also concern that in the desire to spend these larger budgets, donors seek to commit larger amounts of money at one time to non-governmental organisations. This has thereby increased attention to issues of NGO absorptive capacity. There is a risk that donor funding may proceed at levels beyond the existing absorptive capacity of NGOs, and thus stifle their existing good efforts. To avoid such problems, clearly NGOs themselves need to refine tools for assessing their own capacity. ${ }^{38}$ The ultimate risk is that the need of donor agencies to disburse larger amounts of money to local organisations may distort their original objectives or capacities. As Decosas, who has voiced this fear and is critical of the preoccupation of international organisations with scaling up, notes: "A scaled up local response is no longer a local response, it becomes something else." (Decosas 2000).

\footnotetext{
${ }^{35}$ Geoffrey Woolcock and Dennis Altman cited in O'Malley et al 1996. This has also been found in Brazil where the fact that a World Bank project brought an increasing scale of funding to NGOs made them less critical of government policy (according to Richard Parker and Jane Galvao as cited by Chris Castle, personal communication).

${ }^{36} \mathrm{~J}$. Decosas (1994) "The answer to AIDS lies in united commitment" AIDS Analysis Africa 5,1,3-4 quoted in Campbell and Williams 1999

${ }^{37}$ Chris Castle, personal communication

${ }^{38}$ A report commissioned by USAID on measuring absorptive capacity within the population and health field (Brown, Lafond and Macintyre 2000) notes that the available literature suggests that efforts to measure the outcomes of capacity building are at a very early stages of development, although there is a wealth of experience described in the grey literature. The availability to developing country organisations of the latter literature, which documents, for example, a range of measures for self-assessment of organisational capacity, is however unclear.
} 


\section{Cultural and Political Resistance}

One of the greatest obstacles to HIV/AIDS prevention is the extent of stigma surrounding the disease, with its attendant association with "illicit" or "immoral" sex, fatal disease and death (Herek 1999; Gilmore and Somerville1994). While cultural perceptions of the origin of the disease vary, such stigma has been identified across cultures (Goldin 1994). ${ }^{39}$ Stigma itself creates resistance to people in the general population recognising their own high personal levels of risk behaviour, since they feel the fact that they do not belong to a stigmatised "high risk group" makes them safe.

Given the sensitivity and stigma surrounding HIV/AIDS it is not amenable to the simpler strategies of scaling up, such as the process which Myers refers to as explosion, which is more characteristic of, for example, immunisation or literacy campaigns. While in some relatively non-controversial areas such as blood safety, "explosion" may be possible as an approach, in most aspects a slower pace and less visible nature of expansion may be more appropriate in HIV/AIDS. The stigma surrounding HIV/AIDS may make it difficult, moreover, to mobilise sufficient demand for scaled up services, rendering it particularly important to communicate the aims of the intervention as scaling up proceeds. In some cases where stigma is particularly strong, NGOs have learned that it may be more appropriate to promote services for the general population, rather than making it explicit that it is for people with HIV/AIDS - such as, for example, expanding access to care for the chronically ill. ${ }^{40}$ Similarly, peer educators working in HIV/AIDS may prefer to be seen as community health educators because of the stigma associated with HIV/AIDS (Horizons 2000b).

As stated above, while NGOs are able to deal with stigmatised groups, often they are able to do so because they operate on a small enough scale to be nonthreatening on religious, cultural or political grounds. Yet if they choose to expand their activities with such groups (strategy 1), they may perversely increase the latter's vulnerability to state repression or social prejudice. If their scaling up strategy aims to catalyse other organisations (strategy 2) and they choose deliberately to work with government, they may well confront political and legal restrictions in working with these groups. In Egypt, for example, the National AIDS Programme cannot work with sex workers, since commercial sex work is illegal there. ${ }^{41}$ Similarly, in Pakistan, homosexuality is against the law.

\footnotetext{
${ }^{39}$ See for example Nnko '98 on Tanzania

${ }^{40}$ Chris Castle, personal communication

${ }^{41}$ Professional experience of the author in Egypt, 1992-99
} 
At a political level, governments may be reluctant to draw national or international attention to HIV/AIDS because of the fear of tarnishing their national image or a detrimental effect on crucial economic sectors such as tourism. Moreover, they may be averse to the kinds of alliances and networking among NGOs which scaling up necessitates. This depends on the degree to which the political climate is one that discourages or encourages the role of NGOs generally, and what legislation exists regarding oversight of their activities.

\section{Greater Visibility}

In many respects, increasing the scale of HIV/AIDS activities may bring greater visibility or prominence to specific organisations but perhaps more importantly to their constituencies. Depending on the political and social context in which NGOs operate, this may be beneficial or detrimental. In cases where it increases stigma associated with HIV/AIDS or risks increasing discrimination against marginal social groups - such as sex workers or drug-users, this visibility may have very negative effects. By contrast, in the case of some low-prevalence settings, such as Ecuador and the Philippines, this may be a necessary step to increase public awareness and give groups involve greater negotiating power (Margarita Quevedo, KIMIRINA and Ruthie Libatique, PHANSuP, Horizons/Alliance Seminar).

\section{Promoting “Community Participation"/Facilitating Community Response}

The foregoing has argued for the need for careful attention to be paid to participatory processes which give beneficiaries a clear voice in defining directions and activities of HIV/AIDS organisations, and involving affected communities and individuals in the design of interventions. These needs are made all the more acute by the scaling up process. Yet, those who are members of the "community" of interest in HIV/AIDS may well be diffuse, not organised along geographic or social lines, and may themselves resist efforts to promote their "participation." Asthana and Oostvogels (1996), in a cogent analysis of the obstacles to community participation in HIV prevention among female sex workers in Chennai (formerly Madras), India, for example, found that sex workers there came from diverse social backgrounds, worked in a range of establishments and had varied access to support structures. Their ability to organise is therefore "limited by the fact that they are locked into unequal power relationships with brothel-owners, madams and pimps and often too isolated and 
powerless to act individually or collectively" (ibid.: 133). Yet, in the end the women prefer to rely on such patrons - no matter how unequal the relationship because it is a "least risk strategy in extremely precarious circumstances" (ibid.: 146).

\section{Incorporating Diversity}

Scaling up HIV/AIDS programmes beyond the borders of particular communities inevitably brings organisations into contact with a greater diversity of "beneficiaries" whether in terms of social class or background, educational levels or income (Smith and Colvin 2000). Given how social attitudes about HIV/AIDS are often closely tied to such background variables ${ }^{42}$ developing messages and approaches that are suitable to this new diversity is challenging. Where initial activities against HIV/AIDS began in primarily urban, middle-class movements, for example, efforts need to be made to transcend this narrow focus. This constraint would argue for a phased programme of implementation, rather than a sudden expansion or explosion, to give the organisation time to adapt to and learn from the diverse settings and how best to work with constituencies from a wider range of socio-economic backgrounds.

\section{The Pace of Scaling Up}

The rapid spread of the HIV/AIDS epidemic calls for urgent measures to expand the scale of all activities to stem the progress of the epidemic. It is clear that the challenge for NGOs in HIV/AIDS is to find a balance between moving at an appropriate pace to mobilise demand and adapt the intervention to local social contexts and often highly stigmatised groups, while at the same time generating enough momentum and sufficient political commitment to sustain the effort. The pace of expansion, however, is not usually set by internal or micro-level concerns alone, but rather by the overall context in which NGOs operate. For example, as argued in the discussion of motivations, often the rapid spread of the epidemic, or economic and political factors can play a key role in calling for a more rapid response in face of growing need. On a positive note, however, where there is a surge in political commitment at the national level, or internationally, as was the case following the International Conference on AIDS in Durban in July 2000, the pace of scaling up is likely to quicken. As will be discussed below, however,

\footnotetext{
${ }^{42}$ For example, Klouda (1995) cites a study in Abidjan which found that $26 \%$ of patients from the lowest socio-economic group reported having been rejected, blamed or isolated by their families as opposed to none in the highest socioeconomic group (Ingegno, A. et al "AIDS patients in Abidjan: social dynamics and care process" Int. Conf. AIDS 6-11 June, 1993 Abstract No. PO-D20-4014).
} 
there are dangers that higher levels of international funding for HIV/AIDS may dictate the pace of expansion at a rate faster than the capacity of NGOs to sustain that activity.

\section{Risk of Failure}

Perhaps the most poignant risk in scaling up HIV/AIDS programmes is that of failure, with disappointed expectations on the part of beneficiaries, NGO staff and funding institutions. As Avina notes, failed expansion has been the reason for the demise of many NGOs (Avina 1993). It is with this risk in mind that sound choices need to be made by organisations deciding to scale up whether they have the capacity to do so, the programmatic maturity and sufficient funding to sustain a greater scale of intervention. Some of these internal dimensions will now be addressed. 


\section{iii. Institutional Implications of Scaling Up}

16. Internal Dimensions of Scaling Up

\section{Preparing for Scaling Up}

In most analyses of scaling up processes, emphasis is placed on the external, programmatic dimensions with much less attention paid to the internal, organisational questions which are perhaps equally important. Indeed, the reasons behind failure to scale up may lie more within the organisation, in terms of inappropriate leadership, management or structures, than outside. The little published literature there is on these concerns focuses on the experience of Northern, rather than Southern NGOs (see for example Hodson; Billis and MacKeith in Edwards and Hulme 1992).

This deficiency applies equally to analysis of the internal implications of scaling up for NGOs active in HIV/AIDS. Evidence from case studies presented the Horizons/Alliance Seminar on scaling up indicates that very few organisations actually prepare their staff or internal processes for the demands of scaling up. The experience of KANCO is exceptional and instructive in this regard. Having made the shift from a voluntary to professional organisation, and having established an office in 1993-4, they rapidly expanded and successfully received a higher level of funds. However, they began to see some of the bigger programmes collapse, and therefore went through a period of institutional reflection to analyse what was happening within the institution. They developed a questionnaire for staff concerning the goals of the organisation, achievements and what people enjoyed in working for the organisation. This process informed a thorough strategic plan that laid the basis for a re-organisation. Among the new procedures introduced were job analysis and evaluation, new financial and personnel procedures, a staff appraisal system and more attention to sustainability.

Bob Grose, a representative of DFID at the time of the inception of the Healthy Highways Project in India targeting truck drivers and their partners, noted at the Horizons/Alliance seminar that scaling up is a type of transition and as such should be considered a project. Like any project, he argued, scaling up needs a clear plan, with objectives, indicators for achieving objectives and a plan of activities. Indeed, several participants in the Horizons/Alliance Seminar noted that because they did not consider the scaling up process as that, they lacked 
indicators for evaluating it. But Grose and other participants agreed that not all aspects can be planned in the real world, where one often has to respond to the sudden emergence of opportunities, needs or even threats.

Whether an organisation has the time to reflect on internal and external prerequisites for scaling up, however, partly depends on the nature of its funding. If the entire scaling up process is financed from a single donor, often its pace may be dictated by that particular donor's demands. PSG in Zimbabwe has a policy of maintaining funding from five diverse donors, partly in order to ensure the requisite programme and institutional autonomy.

\section{Changes in Institutional Culture and Processes}

Institutional culture and structures are inevitably affected as organisations expand the scale of their activities. Changing roles of staff and board in the process of scaling up can be very threatening, and may lead to loss of staff. Decisions formerly made on the basis of trust and informality may give way to more formal structures and increased hierarchy (Hodson 1992) and involve different people (Horizons/Alliance Seminar). How managers help staff of their organisations to weather these dramatic changes is critical to the success of the scaling up. Staff may be used to a process of ownership and participation that is possible in a smaller organisation but may not be sustained as scaling up proceeds (Billis and MacKeith 1992). Expansion may also require an increased functional specialisation between parts of the organisation, increased capacity to raise resources (Edwards and Hulme 1992) and standardised delivery mechanisms to reduce unit costs (Edwards and Hulme 1996). Increased emphasis on professionalism and efficiency may come to replace the "value consensus" and mission goals that motivated the establishment of the NGO in the first place (Hodson 1992).

These processes may be particularly true of organisations addressing HIV/AIDS where staff's personal commitment to the aims and particular approaches to HIV/AIDS which they feel are rare may inspire a particularly strong sense of staff ownership, and thus resistance to change. The greater diversity within the organisation and the increased proportion of professional staff as opposed to volunteers, as organisations expand into service-delivery organisations, for example, can sometimes limit the ability to work with affected communities. ${ }^{43}$

\footnotetext{
${ }^{43}$ This risk has been cited by Woolcock and Altman in the case of Australia (O'Malley et al 1996).
} 
Both of these trends may jeopardise the former commitment of the organisation to providing labour-intensive personalised care.

When, as is often the case, only certain programmes of an organisation are scaled up, there may be a sense of resentment and competition over resources from staff of other programmes. This was true of the experience of both SIAAP and $\mathrm{Naz}$, for example. In the former case, the counselling programme expanded much more rapidly than the others did, and in the latter, the Healthy Highways initiative began to command a greater amount of resources and attention internally.

\section{Involvement of Volunteers}

Many of the organisations that expanded their HIV/AIDS activities did so through the explicit recruitment or increased involvement of volunteers. AMSED, for example, in Morocco saw this as a key strategy for reaching more people. Since volunteers usually come from the communities with which NGO are working, are aware of existing services and often know the community-members well, the clear benefit is the increased sense of community ownership over the project the involvement of volunteers brings. This was also the case for ASI, where volunteers with HIV/AIDS contributed both time and materials towards the building of a new clinic - a step that ASI sees as critical to the legitimacy of the effort. Similarly, PSG describes its programmes as almost entirely based on volunteers: "PSG's prevention and mitigation activities share a common approach. They both work with community volunteers to deliver large-scale, economical, locally relevant services that increase community response capacity". (Appendix A, Case study page 46). In Cambodia, volunteers in the Home-Care programme described above are "well-placed to facilitate links with other community activities, to ensure access and accessibility of Home Care Teams, and are a major source of referral of new patients to the Home Care Teams". (Wilkinson et al 2000).

Often volunteers work as peer educators, who have been shown to be highly effective in a variety of settings in terms of fostering behavioural change, and also in generating demand for HIV related services such as voluntary counselling and HIV testing and management of sexually transmitted infections (Horizons 2000b).

Nevertheless, the contribution of volunteers may need to be formalised as the scaling up proceeds. ASI found that a critical step that improved their 
effectiveness was the recruitment of a manager to whom the volunteers report. The formalisation of the contributions of volunteers or donated commodities will mean that the costs associated with scaling up may be significantly different (and substantially larger) than the costs of running projects at current scales of activity. The costs, for example, of peer education programmes are often much higher than expected given the need for training, support, supervision and to provide them with resource material and compensation (Horizons 2000b).

Several organisations present at the Horizons/Alliance Seminar note that volunteers play a key role in collecting data useful for monitoring projects. However, the same organisations have also noted the problem of quality entailed in relying solely on volunteers to collect data. Clearly, also, the frequently high turnover of volunteers can be detrimental to institutional learning. ${ }^{44}$

\section{Leadership}

Many innovative NGO efforts are led by charismatic, visionary leaders who pay relatively less attention to the establishment of participatory internal structures of governance (Edwards and Hulme 1992; Fowler 1991) and this has also been true of those active in HIV/AIDS (Sittitrai 1994). Yet the demands on leadership necessarily change as the organisation enlarges its scale of activity. The question is then raised as to whether the leader who pioneered the scaling up process is appropriate to lead the organisation through the next stage (question from Horizons/Alliance Seminar).

In order to sustain expansion of the organisation, it is imperative that consensus among staff is reached about the objectives and approaches to scaling up. Moreover, in order to scale up operations, managers increasingly have to delegate to lower levels of staff and to leaders within the beneficiary community. Are they willing to give a prominent role to subordinate staff members and for example, sex workers, in directing activities and will due credit be given to them? And is attention being paid to the need to develop a second generation of leadership given that the scaling up process is likely to take a long time? The leadership of any organisation undertaking scaling up is likely to feel tension between the often conflicting processes of achieving efficiency for operating at a larger scale, encouraging participatory processes within the beneficiary

\footnotetext{
${ }^{44}$ Although, as noted by Jeff O'Malley at the Horizons/Alliance Seminar, turnover of volunteers is not necessarily a bad thing, particularly given the high risk of "burn-out" associated with such stressful work.
} 
community and sustaining employee aspirations and motivations as the organisation undergoes change (Hodson 1992).

\section{Capacity}

Scaling up may necessitate the hiring of new categories of staff or enlisting new board members with diverse skills, or the retraining of existing personnel, which may be very costly. One key area that needs to be addressed is the avoidance of high staff turnover, given the need for institutional continuity during what is often a time-consuming scaling up process. This may be a particular problem for organisations that have relied on volunteers, or where salary levels are not sufficient to keep talented staff. While NGOs in most fields face difficulties in maintaining continuity and retaining skilled and experienced staff, those in HIV/AIDS face particular constraints since "the epidemic is so close to the people who are working in the epidemic" (Loughran 1995: 6) This has been the experience, for example, of the Cambodia home-care programme which has lost a number of key staff to HIV (Horizons/Alliance Seminar). Where an NGO loses key staff to HIV, it may take a long time for the programme to regain momentum.

There is also a need for staff to maintain good working relations with the often diverse organisations with which they will come into contact in the scaling up process, whether other NGOs or governmental bodies. Staff will need to document the processes and obstacles to scaling up and be able to communicate these lessons more broadly to stakeholders.

Once agreement has been reached on the objectives of scaling up, there needs to be careful attention paid to creating appropriate incentives for staff - or personnel of the organisations one is trying to influence (strategy 2) - to meet them. This is a particularly challenging task in sensitive areas such as HIV/AIDS where, because of the deep stigma associated with it, there is a need to instil changes in attitude and approach. ${ }^{45}$ An example of the difficulty of inspiring such attitudinal change is provided by the case of reproductive health in India. Following the International Conference on Population and Development the Indian government undertook a strong commitment to shifting the orientation of their population programmes from a vertical orientation to family planning to the wider and more comprehensive concept of reproductive health. Yet one of the main constraints to implementing this strategy is the difficulty of changing the approach of family planning cadres who are entrenched in ways of working that

\footnotetext{
${ }^{45}$ Smith and Colvin 1999 has extensive analysis of this point as well in relation to adolescent services.
} 
stress the goal of increasing contraceptive prevalence rates, rather than the process-oriented approach of eliciting and addressing often sensitive reproductive health problems (Health Watch 1998).

As several participants in the Horizons/Alliance Seminar noted, however, the process itself of expansion - although it may require change in attitude and in ways of working - can be a morale boost for staff, in conferring a sense of greater visibility, prominence and effectiveness (PSG, ASI, KANCO).

\section{Documentation and Evaluation}

Often overlooked in the haste to expand the scale of activities is the importance of building capacity to collect data as well as to document the experience of scaling up or the indicators used to evaluate it. Greater attention to documentation of the process of scaling up is important not only as a motivating factor for staff, but also provides the opportunity to share success with others, thereby widening perception of need, widening constituencies involved and even stimulating new action.

To be meaningful, however, the data collected must inform the scaling up process and not be collected for its own sake. As noted above, PSG is exemplary in analysing the impact of each intervention in terms of behavioural change and cost to draw lessons for application elsewhere. And ASI uses volunteers to collect data that have - as shown above - identified dips in quality and prompted a revision of strategy. Much more can be done in general by NGOs to collect routine information on their activities and their impact to inform assessment of effectiveness. ${ }^{46}$

In some cases, even where there is desire to collect such information, it is not available because the programme approach is so new. Geoff Foster (FACT/FOCUS case study, p. 24) noted about the experience of establishing a community support programme for children affected by AIDS in Zimbabwe that when it began, there were no known models of community support to children affected by AIDS. Therefore staff had no information on which to set targets for coverage, impact and sustainability. Similarly, Margarita Quevedo noted about the organisations Kimirina supports in Ecuador that most tend to lack access to data, and are weak in documenting their own programmes or conducting evaluations, and therefore scaling up tends to be a trial and error process.

\footnotetext{
${ }^{46}$ Lilani Kumanarayake (personal communication) notes from her experience with colleagues trying to estimate the impact of NGO prevention activities in a number of countries that even routine monitoring on measures such as the number of people being reached may not always occur.
} 
It is evident, however, that much more effort and time could be invested by NGOs themselves in developing criteria for assessing their own programmes. In evaluating the effects of scaling up, it is important that one relies on a range of indicators to give a fuller picture of change. Since reported sexual behaviour change is so subject to bias, use of other criteria of change may be particularly necessary. For example, the Family Health Trust's initiative in supporting AntiAIDS Clubs in Zambia has found that there was no change in reported sexual behaviour among club members (Dixter Kaluba, Family Health Trust, Horizons/Alliance Seminar). However, there has been an increase in young people reporting to health centres for screening and treatment of STDs (Case study).

Moreover, soliciting the views of beneficiaries in the evaluation of scale up is essential. For example, the FACT/FOCUS programme found that the initial efforts of communities to respond to the problem of orphans was successful in that: "Community-based organisations were able to identify a high proportion of orphans living in their area, target those most in need, and provide regular visits and material support." But when the orphans' own views were asked, they stated that they had understood that their guardians, rather than themselves, were being visited and assisted through the programme.

\section{Implications for Donors and NGO-Support Organisations}

The above discussion suggests that it is not only organisations that are interested in scaling up who need to reconsider the nature of their operations and internal management structures. Donors and AIDS-support organisations also need to adapt to be able to support the complex demands that the process of scaling up places on the institutions they support.

The level of funding needed to enable a process of scaling up to occur is perhaps the most obvious prerequisite. Yet few donors are willing to sustain commitment to an organisation as they undergo the "trial and error" process of expanding their operations, and these challenges are arguably more arduous in the field of HIV/AIDS. Indeed, the proliferation of highly visible pilot projects that the World Bank (1999) among others criticises, is at least partly due to the lack of available funding to replicate these on a larger scale. But equally important as the level of funding is the time-scale of support, if one considers the time needed to prepare for scaling up, including conceiving and communicating ideas, encouraging 
participation of beneficiaries, adapting to diverse contexts and preparing the organisation for change. Given the time demands and major institutional change scaling up requires, there is a need for donors to shift from short-term project finance to more longer term institutional support. ${ }^{47}$ Uvin refers to the simultaneous need to "scale up the grassroots and scale down the summit" (by which he means international organisations) - that is, that they should "adopt structures and modes of operation that allow local communities and NGOs to build their conceptual, operational and institutional capacities" (Uvin 1995). This suggests the importance of providing sufficient resources and time to encourage reflection and learning, even when these do not necessarily translate into shortterm, demonstrable outputs. Funding for expansion should take into consideration not only the external, programme context but also the institutional prerequisites to scaling up, and the kind of intensive internal work required, such as conducted by KANCO, for example.

In many cases, the nature of donor funding may even complicate and undermine the scaling up process of NGOs. For example, it may contribute to the lack of planning of scaling up by making a sudden rash of funds available that has to be spent in a finite period. As the director of ASI put it: funders caused "chaos" with the rapid pace of expansion they imposed on that organisation. The experience of ASI suggests that donors did not envision the scaling up process as such, leading to a "feast and famine" financial situation at ASI. As they put it: "There were periods of rapid growth and periods of no growth due to erratic funding...A more comprehensive evaluation of the scaling up process was difficult because no funding was available for the process itself. This made it difficult to assess the overall progress at the early stages."

In some cases, where organisations receive funds from more than one donor, which may be the best way of reducing the risk of relying on a sole source, there may be competing objectives of programming imposed on the organisation. This was noted, for example, in the case study of the International HIV/AIDS Alliance.

A more fundamental critique of donors - and indeed other external agencies - is that they may ignore existing community initiatives to address HIV/AIDS and even - unknowingly or not - undermine them (Foster papers). The risk of such a trend is, if anything, greater with the increased influx of resources devoted to HIV/AIDS.

\footnotetext{
${ }^{47}$ This view is endorsed by the latest World Bank report on HIV/AIDS in Africa which states that: "Sporadic or isolated activities are ineffective unless they are evaluated as pilot activities and revised and expanded based on what has been learned. To maximise their impact, programmes should be implemented for long periods based on need rather than on funding cycles." (World Bank 1999: 24)
} 
At the same time, the pressure to scale up should not be applied indiscriminately across the board. As mentioned earlier, not all organisations or aspects of programmes are amenable to scaling up. Donors and NGO-support organisations should not necessarily focus on selecting the most professional organisations for support, but should recognise that a range of types and sizes of organisations are complementary to one another and thus a portfolio of different types of investments at varying levels may be more effective. ${ }^{48}$ Similarly, within individual organisations it is conceivable that certain activities are more amenable than others to scaling up or require different time-frames for scaling up. Instead of concentrating all its resources and staff time on scaling up all interventions, an organisation could, for example, scale up a particular intervention while leaving time, energy and creativity to experiment at a pilot-level with other activities. Thus, while there are synergies to be gained in scaling up several HIV/AIDS programmes together (UNAIDS 2000), which may also yield greater economies of scope, these may be better gained through complementarities among organisations rather than single organisations scaling up several demanding activities simultaneously. ${ }^{49}$

That said, however, there are risks that donors may also fragment an organisation's integrity by only emphasising scaling up of individual strategies or interventions, and not recognising the synergies between them. This suggests that more flexible funding that allows organisations to allocate resources across interventions would be most effective.

\section{Conclusion}

As the HIV/AIDS epidemic continues its rapid spread bringing individual tragedies and social upheaval, the inadequacy of existing programmes is increasingly a subject of debate. This publication has asked the question whether organisations active in the HIV/AIDS arena, and perhaps most particularly NGOs, have done enough in thinking about scaling up their activities. It explains, however, that scaling up in the context of HIV/AIDS is a challenging and complicated process.

The extent to which NGOs can be proactive in scaling up, with sufficient time for reflection and planning in order to maximise impact and safeguard their organisational mission is critical. Not all NGOs should scale up and nor should NGOs scale up all of their activities simultaneously, and thus choices as to which

\footnotetext{
${ }^{48}$ I am grateful to David Hulme for suggesting this "portfolio" approach.

${ }^{49}$ This discussion draws on comments on this publication by Chris Castle.
} 
aspects of NGOs work to scale up with maximum impact have to be considered carefully. To the extent that it is possible, organisations need to prepare their own structures and staff for the scaling up process. If they are merely responding to donor demands or the evolution of the epidemic, they will command little control over the scaling up process and ultimately perhaps have less effect. At the same time, however, NGOs may need to sacrifice some elements of the quality of the programmes they run for the sake of broader coverage. This in turn points to the need for more information on the quality and impact of NGO programmes.

While definitions of scaling up vary according to the perspective of the individual and organisation, consensus exists over the need to define objectives in terms of impact on either preventing the epidemic or mitigating its effects. A narrow understanding of impact, however, based only on reducing the number of new infections, without looking at the synergies between prevention, care and support and the broader social change needed to address HIV/AIDS, is misleading. NGOs - based on the many successful but often undocumented experiences of scaling up - need to express their own notions of the impact of their efforts, and to communicate these to a broader audience.

In both effectiveness and efficiency terms, integrating HIV/AIDS efforts into development processes and institutions more broadly is desirable to address the structural and social determinants of the epidemic and take advantage of existing infrastructure. Yet such efforts should not lose sight of the experience accumulated by specialised AIDS-service organisations (O'Malley et al 1996).

Scaling up the programmes of NGOs in HIV/AIDS entails much more, however, than finding avenues for reaching wider coverage. If scaling up is seen as a process, as described here, the dynamic relationships between impact, coverage and quality of programmes mean that at different stages of the process, different objectives become paramount. Moreover, scaling up that is sustainable in social, as well as financial and programmatic terms necessitates understanding, strengthening and catalysing the existing response of individuals and communities to the complexities of the epidemic.

Finally, truly scaling up will require that NGOs do not work in isolation but forge much stronger and workable alliances with other NGOs, research institutions and with government. To do so will inevitably require compromises and conflicts of institutional culture, but will be well worth the effort in the broader aim of stemming the epidemic and mitigating its devastating effects. 


\section{Appendix Section Appendix A:}

Case Studies from Scaling Up Seminar Sponsored by HORIZONS and the International HIV/AIDS Alliance

[Note: The following case studies of NGOs which have scaled up aspects of their programmes in HIVIAIDS were written by authors from the institutions concerned and edited by HORIZONS staff. All edited versions were then checked for accuracy and content by the authors of the case studies and their organisations]

Scaling-up Asociacion de Salud Integral (ASI)

\section{Implementers}

The Asociacion de Salud Integral (ASI) is a local non-governmental organisation (NGO) established in Guatemala City, Guatemala in 1987. Originally known as Asociacion Guatemalteca para la Prevencion y Control de SIDA (AGPCS), the organisation was founded by a group of physicians and other health care personnel who were concerned about the lack of information on HIV/AIDS available to health care workers.

ASI seeks to reduce the impact of HIV/AIDS in Guatemala through education, research and treatment.

The organisation has grown from a staff of six, running one programme in a single public hospital, to a staff of 40 running seven projects, aided by a large group of volunteers.

\section{Background}

The decision to scale up was based on the dramatic increase in need for the services provided at the ASI clinic, and the expectation that the peak of the AIDS epidemic was still to come. By 1996 the organisation had grown and expanded its projects, but had no formal direction or strategic plan. There was at this stage a staff of 20 , but the growth in demand for services was already taxing.

ASI decided to focus its efforts to scaling up counselling and treatment. Neither 
the government nor other NGOs were providing this sort of comprehensive approach in a clinical and community setting. But in order to ensure that the level of care would be sustained and expanded to meet the rising need, it would be important to establish alliances with other groups.

Scaling up would require additional trained staff to counsel and treat patients and expanded physical space for the clinic itself.

\section{Objectives and activities}

The objectives of the scaling up programme were to:

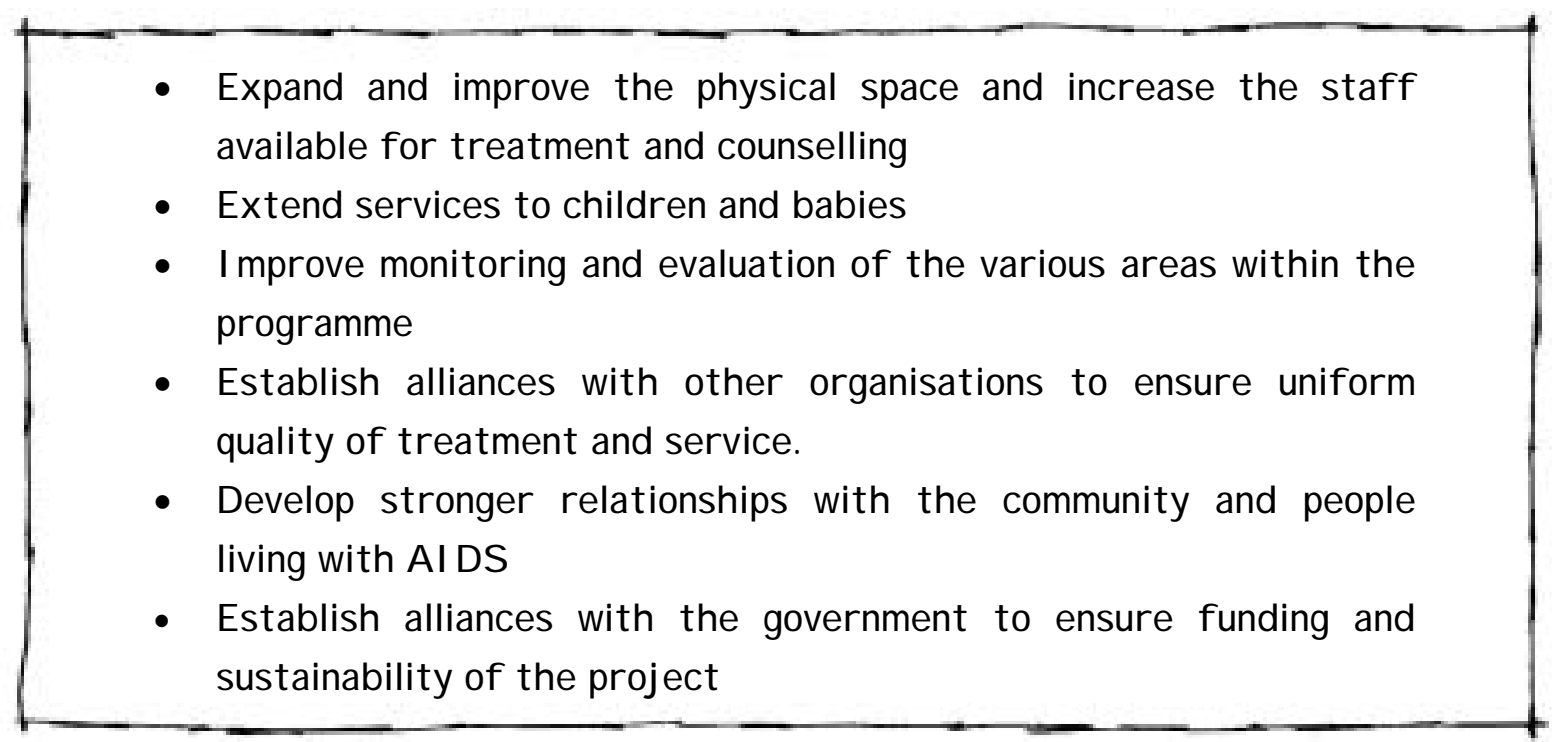

The programme was conceived as part of a five-year strategic plan beginning in January 1997.

\section{Resources and timeframe}

AsI had grown dramatically in both size and number of projects since it began in 1987, but had not developed a formal direction or strategic plan to guide future growth. With assistance from the Dutch government, ASI hired an external consultant to help develop the five-year plan for restructuring and expansion.

The Dutch government offered funding for the first three years to support core staff in this time of strategic planning. This money was not intended to fund any of the specific scaling up efforts, but to allow ASI time to search for sources of 


\section{Appendix: A Page 3 of 53}

long term, sustainable revenue.

The process of obtaining funding has been very difficult. While there is strong national support for the programme, there is not always money available. Because of this, the process has been slow, and often stalled. Local donations did enable ASI to open a new and larger clinic in July 1997, but there was no money to hire additional staff to handle the increase in patients until January 1998. During this lapse, the staff was overworked and stressed.

Community support is essential to the programme. When a local family that was respected in the community lost a son to AIDS, they contributed financially to the programme, but more importantly, their support helped remove barriers within the larger community.

\section{Outputs/outcomes}

Initially, the clinic expected to see an average $15 \%$ yearly increase in-patients. This was the case for the first two years, but the year 2000 has already produced an increase of over $100 \%$. The huge increase is partly due to expanded availability of services at the new clinic, including a new counselling programme, but probably more a result of an accelerated phase of the epidemic in Guatemala. The anticipation of a dramatic increase in affected populations was a key reason for the scaling up.

Since the strategic plan is still underway, evaluation is limited. There is an important initiative just beginning to form a strategic alliance with the Ministry of Health to establish a national AIDS unit to treat people from all over the country. There is also a movement to pass a national AIDS law.

\section{Internal organisational implications}

The primary difficulty in the scaling up process was the need to balance the limited funds and resources between existing programmes and developmental projects. The scaling up process required more technological equipment, specialised staff for evaluation, and other specialised staff not contemplated in the original plan. Although some funding was provided, there was still a drain on resources. ASI absorbed these additional costs, but it caused some tension within the organisation. 


\section{Appendix: A Page 4 of 53}

While the staff understood the need to expand the programme and was supportive of the effort, it also felt that resources were being diverted from existing programmes. Directors held several sessions with the entire staff to keep the line of communication open.

Volunteers were very supportive of the expansion. A special research programme was established within the clinic, recruiting university students to assist professional staff while working on their medical studies. These volunteers were especially valuable in collecting data for monitoring and evaluation.

The effort to form strategic alliances with other groups, particularly organisations of people living with HIV/AIDS has helped improve the quality and impact of care.

\section{Evaluation}

The monitoring of the scaling up process was not a formal process, although reviews were conducted twice a year to evaluate the progress. Before the scaling up process, the clinic recorded basic demographic information as well as medical records on treatment.

A more comprehensive evaluation of the scaling up process was difficult because no funding was available for the process itself. As previously mentioned, there were periods of rapid growth and periods of no growth due to erratic funding. This made it difficult to assess the overall progress at the early stages.

In January 2000, additional staff was hired specifically to work on evaluation.

\section{Lessons learned}

The scaling up process for ASI was essential. The caseload was increasing so rapidly that either the capacity grew or the programme would have no longer been functional.

It was clear from the beginning that forming strategic alliances with other NGOs and government organisations was essential to the success of the expansion.

The initial process of scaling up, in which the clinic space was physically expanded, went well because ASI already had a good relationship with the 


\section{Appendix: A Page 5 of 53}

hospital where the clinic was located.

Community support was invaluable. The acceptance of the programme by prominent families and community leaders greatly increased general support.

The strategic alliances with NGOs have worked well, but the process has been slow. The division of labour and the shared search for funding from a limited pool of resources will always be a strain on NGO alliance relationships. Initially, some organisations saw no need for working together, but as the scope of the epidemic has increased, the importance of alliances has become clearer.

In countries with limited resources, strategic alliances are a key factor in the success of scaling up any programme. The search for funding placed an ongoing burden on administrative staff. An alliance with the government is expected to allow for a steady income and the survival of the programme.

The involvement of government has been slow, but as the number of people affected continues to increase sharply, the Ministry of Health has begun to look for organisations with experience for help.

Organisations of people living with HIV/AIDS must be involved in any scaling up programme from the beginning. This generates trust and a sense of empowerment within the community and makes people more willing to participate in education and prevention programmes, and to accept treatment.

This small, ongoing scaling up process in the ASI treatment and counselling programme has allowed the organisation to gain experience and plan more effectively for the future. 


\section{Family Health Trust - Zambia}

\section{Implementers}

The Family Health Trust (FHT) is a Zambian NGO dedicated to preventing the spread of HIV/AIDS while offering care and support to those already affected. The group was formed in 1987 and focuses most of its efforts on programmes for young people.

The Anti-AIDS Project was established in 1987 as a one-person operation and has since expanded to include 9 full-time staff and 77 part-time community-based peer educators. Students themselves at David Kaunda Secondary School generated the idea of an Anti-AIDS club after hearing a talk by a doctor about HIV/AIDS.

Students who are trained as peer-educators lead the Anti-AIDS clubs and are supervised by adult facilitators under the direction of Zonal Co-ordinators and a central office.

\section{Background}

The HIV/AIDS epidemic has had a particularly devastating effect on children living in Africa. Many have been left orphans. They are especially vulnerable since the communities that traditionally provided support have also been weakened. There is also an alarming increase of new infections among young people.

The decision to scale up the Anti-AIDS Club programme was based on the need to educate young people about the spread of HIV/AIDS and empower them to take control of their own lives. The success of the original programme and the growing desire among young people to take positive action prompted FHT coordinators to expand the project.

The specific objectives were to reach more young people by building Anti-AIDS clubs throughout the country. 


\section{Objectives and main activities}

The clubs rely on peer-educators to promote interactive learning through the use of role-playing, focus group discussions, games and individual discussions. The objectives of the scaling up were:

- To intensify outreach to non-members and to retain interest among existing me mbers.

- To develop effective new educational materials

- To consolidate the field support to the clubs through a programme of training and supervision based on the development of Regional Co-ordination and Zonal Leaders.

\section{Resources and timeframe}

The peer education approach has proved the most effective way of reaching young people. The adult facilitators are volunteers, either teachers or leaders of church, youth or community groups. They co-ordinate club activities with the Anti-AIDS Project and ensure that the clubs are registered. They act as a link between the school administrations and the clubs and help club members develop action plans. They may also help develop links between the clubs and other local or government organisations.

The FHT central office provides training to Regional Co-ordinators at least twice a year. It also encourages participation in workshops organised by collaborating organisations.

FHT receives funding and other resources for all its programmes from NORAD, CIDA-SAT, UNICEF and Christian Aid, HIVOS, and the World Food Programme. Funding is given on a three year contract for NORAD and a one year contract for CIDA-SAT and UNICEF. These contracts are renewable depending on satisfactory performance of the projects. The Peer Education Programme receives funding mainly from UNICEF and CIDA-SAT. Christian Aid funds the production of IEC materials. 


\section{Outputs/outcomes}

There are now 2,561 clubs registered with the Anti-AIDS Project. $45 \%$ of the clubs are in Primary/Basic and Secondary /High Schools, $43 \%$ are serving out of school youth and young adults and $12 \%$ are in community schools.

\section{Internal organisational implications}

An increase in community participation has strengthened the sense of community ownership.

Since peer-educators are paid per diem, the budget has been stretched to supply educators to all the new clubs.

New clubs are often widespread within zones, especially in rural areas, so Zonal Co-ordinators find it difficult to reach them all, as they travel primarily on bicycles.

The growth of the Peer Education Programme has always depended on the willingness of the donors to increase the funding to enable increased coverage. However, there has been an extension each year since 1995 when the programme was initiated. The number of active clubs has increased from 251 in 1995 to 717 in the year 2000. The programme has also grown from one to three regions in the country.

\section{Evaluation}

Because the Anti-AIDS clubs were a new programme, there was little upon which to base an initial evaluation. Since the scaling up began, FHT has seen an increase in community participation. More young people are involved in the initiation and formation of new clubs. There has been in increase in the variety of educational activities, and in youth participation of the club newsletter. More young people now report to health centres for screening and treatment of STDs. There is more direct support given to orphans and other vulnerable children by Anti-AIDS clubs. For instance, in Kasusu, 22 orphans are being supported by income generated through club activities. It is difficult to determine how much funding the clubs generate because they are not accountable to the project for this activity. The project only monitors the performance of these programmes and ensures that they are running effectively and at an acceptable standard. 
Appendix: A Page 9 of 53

\section{Lessons learned}

- Peer education is an extremely effective way to educate young people about ways to prevent $\mathcal{H} I \mathcal{V} / \mathcal{A} I \mathcal{D S}$.

- Continued support is needed after clubs are formed, to maintain activities and prevent boredom.

- It is difficult to organise out of school youths because there are no mone tary rewards.

- There are other clubs that offer material incentives that lure young people away.

- Gender imbalance remains high in the clubs, with more boys than girls on average .

- Community involvement is essential. 


\section{South India AIDS Action Programme (SIAAP): It's Role, Growth and Development in Meeting the Challenge of HIV/AIDS}

\section{Implementers}

The South India AIDS Action Programme (SIAAP) was formed in 1991 with the goal of involving existing NGOs in South India in an effort to increase AIDS awareness in the region and to help develop and implement effective education and prevention programmes.

The creation of SIAAP began in 1988, when 30 HIV positive female sex workers in the city of Chennai were jailed. By the time their case went to trial, nearly 900 women were imprisoned in the state of Tamil Nadu. In July 1990, the court ordered all the women released and recommended that no person should be detained on the basis of HIV infection. Shyamala Nataraj, a journalist covering the trial and other AIDS issues in India, discovered there were no support services available for people with HIV/AIDS. Using personal contacts, she established a link with Voluntary Health Services in 1991 to bring existing NGOs together and help them develop strategies for dealing with the epidemic. This led to the founding of SIAAP as an independent NGO.

\section{Background}

In the early 1980s India was beginning to see the results of a long struggle to provide better health care for its people. Infant mortality rates were decreasing and average life spans were increasing. Indian citizens in both urban and rural areas had better access to health care in district hospitals and public health centres. When HIV began to emerge as a national health problem in 1986, however, government and health care agencies, like those in most other parts of the world, were unprepared to deal with it. Prejudice and misinformation contributed to a sense of panic.

It was clear that HIV interventions had to include education on safer sex practices including condom use and improved treatment access for sexually transmitted diseases. But it was also important to reduce prejudice and empower people. Counselling had to be understood as fundamentally different from simply giving out information. In India, counselling and therapy were generally conducted in an official medical setting and considered limited to psychiatry. There was little 


\section{Appendix: A Page 11 of 53}

experience in providing counselling at the community level, especially with issues of sexual behaviour.

Through experience with various projects, it became clear that a primary need in the region was to develop full-time trainers and counsellors outside the established medical system who could deal effectively on a community level with issues of sexual behaviour, empowerment and HIV education.

\section{Objectives and main activities}

SIAAP recognised the need for trained non-medical counsellors who could work outside the large institutional frameworks on a community level.

The objective of the scaling up was therefore to train full-time counsellors to be placed in government health clinics throughout the region.

\section{Resources and timeframe}

SIAAP's first project, funded by the local NGO Madras Christian Council of Social Services (MCCSS), was designing an AIDS education programme in the slums where MCCSS was already working. In 1992, SIAAP launched an education project directed at truckers. They opened a booth at Puzhal, one of the busiest check posts near Chennai, where they distributed information, free condoms and lists of referral centres for the treatment of STDs. These early projects led to the development of a comprehensive three-year action plan that would expand educational programmes, particularly those dealing with truckers and women in prostitution (WIPS). HIVOS and the Ford Foundation funded this proposal.

Having largely succeeded in its attempts to get NGOs and governments to address HIV issues, the SIAAP management began to consider the future direction of their organisation. In the fall of 1996 HIVOS invited the SIAAP director to visit the Gestalt Foundation in the Netherlands where they consulted with Harm Siemans, a trainer and therapist. Siemans visited the region in November 1996 and issued a report supporting SIAAP's proposal for increased counselling services and recommending that SIAAP take primary responsibility during the initiation phase. The Gestalt Institute offered training and supervisory support for the first two years. 


\section{Outputs/outcomes}

By the end of the project period in 1996, SIAAP had fulfilled many of its objectives. A total of $42 \mathrm{NGOs}$ throughout the region were incorporating AIDS education and prevention into their existing programmes, as well as developing specifically targeted new projects. The NGOs were funded by a variety of agencies including USAID in Tamil Nadu, and HIVOS in Karnataka and Andhra Pradesh. The Department for International Development (DFID) UK supported a7national trucking programme, which absorbed many of the existing interventions in Tamil Nadu.

Despite the problems in scaling up, the results were still positive. By June 1999, forty-five community groups were meeting sporadically and by January 2000 these had stabilised at 18 sangams (those in the villages with whom SIAAP was working). Of these, two have been running intensive HIV intervention programmes for 4 years. In February 2000 a combined community meeting for solidarity brought together 700 people from across the state and culminated in a resolution demanding protection of human rights.

\section{Internal organisational implications}

From the beginning of the first training session in April 1997, organisational resources remained minimal and were stretched far too thin. There was no startup period, no pre-planning and few people available to take responsibility for the details of what was becoming a huge and complex enterprise that had to provide counselling, training and service in the states of Tamil Nadu, Karnataka and Andhra Pradesh.

In April 1998, the Dutch trainer responsible for the Tamil Nadu programme left without warning and was not replaced by the Gestalt Institute. Two Indian trainers stepped in on a part-time basis but the remaining trainer found it difficult to meet all the demands.

The first group of counsellors graduated in September 1998 and a second group followed in June 1999. When the arrangement with the Gestalt Institute came to an end in August 1999, a full time Indian supervisor took over. 


\section{Lessons learned}

The process of scaling up showed that while SIAAP's technical skills were considerable, its organisational and administrative capacity were inadequate. Staffing, organisational structure, training and supervision needed to improve as well.

Other important lessons:

- Community organisations require a great deal of support.

- Setting up advocacy structures and recruiting adequate personnel needs to be a priority.

- Appropriate peer training and supervision is essential.

- Counsellors recruited from affected communities perform significantly better than those not from these communities, even when they enter the programme with less education or experience.

- Client centred counselling, as a specific process of individual empowerment, is a relatively new discipline in India.

- Community based counselling along with hospital-based counselling provides a good balance.

SIAAP's community counselling programme has been acknowledged and appreciated by the established medical system and embraced by the Indian government. SIAAP has decided to focus on evolving as a training institution and transfer programme implementation and responsibilities to the sangams. 


\section{Cambodia Home Care Programme}

\section{Implementers}

In 1998 as part of the response to the growing HIV/AIDS epidemic, the Cambodian Ministry of Health (MoH) established a partnership with a group of NGOs to develop and implement Cambodia's first HIV/AIDS home care programme. Financial and technical support were provided from $\mathrm{WHO}$ and the UK Department for International Development (DFID) in the pilot phase, and from Khana, World Vision and Mary Knoll subsequently.

The Home Care Network Group (HCNG) plays a vital role in the continuum of care by providing education and support services, counselling and nursing care to people living with HIV/AIDS (PLHA) in their homes and communities. Hospitals make and receive referrals, and provide monthly medical supervision in the field. The teams (now 10) are co-ordinated by the HCNG, which includes representatives from the NGOs and the MoH. Teams in two areas of Battambang Province are adapting this home care model for use in rural areas.

\section{Background}

Home care is particularly important in Cambodia where a severe shortage of hospital beds, general inability to afford current prophylactic drug therapies and poor nutrition put PLHA at greater risk of opportunistic infections. By allowing PLHA to remain in the community, it also fosters better understanding of HIV/AIDS, correcting misunderstandings about both prevention and care as they arise.

The pilot project launched in February 1998 had a dual purpose; to implement home health care programmes and to determine sustainable ways in which NGOs and government could act in partnership.

In December 1998, a two-week evaluation of the project was carried out by a WHO consultant, who reported that home and community care was essential and recommended that the project be strengthened and expanded. 


\section{Objectives and main activities}

While the initial home care programme is successful in the city of Phnom Penh, there are many factors to consider in expanding to the more rural provinces. The evaluation of the programme recommended the following objectives for expansion:

- To develop a well-resourced and supportive Home Care $\mathcal{N e t w o r k . ~} \mathcal{H C} \mathcal{N}$ groups should be established to co-ordinate teams, possibly on a provincial 6 asis. The mechanism for national co-ordination has not yet been discussed

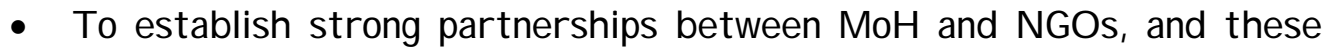
partnerships may well include other ministries, pagodas, etc.

- To expand the number of volunteers and providing appropriate training.

- $\mathcal{T}$ increase community involve ment and owners fip

- To provide adequate technical and financial resources and support

- To establish a supportive system of medical and management supervision

\section{Resources and timeframe}

Partnerships between $\mathrm{MoH}$ and NGOs have enabled scarce resources to be shared and contributed to the cost effectiveness of the programme. The average cost of providing urban home-based care services is estimated as $\$ 9.28$ per home care visit and $\$ 14.60$ per visit for rural services. This estimate includes all administration, personnel and technical support costs, and this compares favourably both to other home care programmes and to outpatient service. 


\section{Outputs/outcomes}

The review of the pilot phase concluded that the majority of objectives had been met within the timeframe. Patients, NGO and government partners, health staff and community leaders all reported a high level of satisfaction with the teams' activities. The evaluation conducted in June 2000 showed that this had been built on during the post-pilot year.

\section{Internal organisational implications}

The Home Care Teams (HCTs) rely on a large number of volunteers, many of whom are PLHA. Volunteers play a number of important roles in the home care programme and are likely to be a key component in the expansion programme. There has been a high turnover of volunteers, sometimes because they take up paid employment, but often because of illness or death.

Volunteers generally work more than the 10 days per month for which they receive expenses. Most live in the community in which they work in home care and some feel that they are potentially always "on call." Volunteers receive 60 hours of initial training and also on-the-job training. They expressed the need for more training in the areas of stress management and in handling work-related situations that may threaten their personal security.

While some HCTs are expanding their links within the community, this will become increasingly important during expansion. It is suggested that the HCNG develop itself as a more autonomous institution that can then respond to the changing needs of the home care service in a co-ordinated way.

\section{Evaluation}

Community response to the programme was overwhelmingly positive. PLHA reported that after home care visits they felt better able to look after themselves. By focusing on better nutrition and early treatment of infections, PLHA enjoyed both better health and more positive outlooks on the future. Family members had an improved sense of confidence. The home care programme has also provided households with significant benefits in terms of financial and time savings.

In addition there is a documented cost saving as compared with hospital stays. 
Appendix: A Page 17 of 53

\section{Lessons learned}

- Monthly HCNG meetings provide valuable feedback co-ordination and support to the $\mathcal{H C T}$ s and are an important component of the home care programme.

- $A$ competitive selection procedure for $\mathcal{H C T}$ s to ensure the right staff with the right set of attitudes toward $\mathcal{P L \mathcal { H }}$ is important to ensure quality home care provision.

- $A$ good team requires people with the right balance of skills and experience, who receive comprehensive training and supportive supervision.

- Volunteers play a key role and support from community leaders is critical.

- Participatory reviews and responsive management have played an important role in helping to shape and guide the home care programme.

- Strong $\mathcal{N G O / g o v e r n m e n t ~ p a r t n e r s h i p s ~ a r e ~ i m p o r t a n t . ~}$ 


\section{The Salvation Army's "Concept Transfer" Approach to Scaling-up}

\section{Implementers}

The Salvation Army provides regionally based support to local field programmes in the areas of HIV/AIDS, health, and development. A key mission has been to support and expand local community capacity development for care and prevention, while influencing policy at multiple levels through sharing the meanings of community capacity and experience. The focus of this case study is the Salvation Army's work through its Africa Team in 12 African countries.

\section{Background}

Based on an integrated home-based care and community prevention approach that started in 1987 at Chikankata Hospital, Zambia, the Salvation Army developed a process of "concept transfer" as the foundation for further expansion. This is an approach to promote the response to HIV/AIDS at the local community level, and the process lies at the heart of much of the work that the Africa Team is conducting throughout the continent.

The concept transfer process breaks new ground in capacity building and scaling up for HIV/AIDS programming. From 1990 to January 2000, this approach has been used worldwide by the Salvation Army to develop 88 programmes in 37 countries, with estimated coverage reaching 3.5 to 4 million people.

The approach is based on the use of international and regional "facilitation teams" that work with local stakeholders to explore such key concepts as participatory caring, community as "belonging," change, leadership, and hope. Using such concepts rather than a "one size fits all" programme design model, the teams work with the local Salvation Army and others in the context of local communities, so that responses are based on the community's capacity for addressing HIV/AIDS prevention, care, and support. The aim is to improve and expand the impact both of the response within communities (defined by the Salvation Army as scaling out) and within and between organisations (defined as scaling up). The approach is non-prescriptive regarding protocols and planning tools, yet appropriately supports understanding of development planning cycles and processes within each setting. 


\section{Appendix: A Page 19 of 53}

The teams are involved in three "learning pathways": programme-to-programme visits, attachment or "loaning" of team members to organisations, and courses focusing on health-related community development.

\section{Objectives and main activities}

The overall goals of the program include:

- Increased community capacity to cope with and take responsibility for $\mathcal{H} I \mathcal{V} / \mathcal{A} I \mathcal{D S}$ and its impact.

- Improved quality of life for individuals, family, and community members affected by $\mathcal{H I V} / \mathcal{A I D S}$.

- Decreased transmission of the virus, measured through befraviour change at the community level.

- Capacity development through the sharing of lessons learned and transfers of ide as and linkages with other organisations.

- Development of a pool of skilled people from within field programmes who can facilitate vroaramme develovment in other locations.

Major activities include assessment and relationship building, participatory programme design and support, participatory evaluation, documentation, coordination of programme-to-programme visits, regional and sub regional consultations, inter-organisational sharing for increased capacity development and influence on policy development/formation, reflection and application of lessons learned from HIV/AIDS to other areas of health and development work, analysis of the processes that facilitate change, and sharing of lessons learned.

The process of expanding the Afric an community response has included:

- Demonstration that local community programmes fiave the capacity to act, to measure the ir own change, and to transfer concepts to other communities.

- Support from the Salvation Army's International Headquarters Health Services for te am formation.

- A consultation workshop to solicit input on the facilitation team process from field people and some le aders, as well as UNICEF.

- Responding to an increasing volume of requests from the field and from national le aders.

- Appointment of an Africa-based co-ordinator in 1995 and a co-co. ordinator in 1996. 


\section{Appendix: A Page 20 of 53}

Regional programme activities in Africa for 1999 included development of a participatory evaluation process with clinic teams in Ghana, a community counselling workshop in Malawi, and health management consultations in Zimbabwe and Ghana

\section{Resources and timeframe}

While the Salvation Army cannot support entire funding of the programme, the 25 percent component is symbolically significant to signify ownership and to motivate external donors.

\section{Internal organisational implications}

The team facilitation approach has required the Salvation Army to redefine all of its core functions in order to become a real and meaningful resource in the countries where it works. It has also meant that there is a constant need to look outwardly and develop new perspectives that put local community capacity at the moral and spiritual centre of all of the work. Recruiting new people to facilitation teams and becoming involved with new partner organisations also expands the organisation's perceptions and functioning.

Staff and volunteers have been energised by the evolution of such new approaches, although the experience can sometimes be confusing and even threatening because there is some loss of central control. Yet as this form of control has diminished, the organisation has gained in influence. Because of the clear benefits of this approach, organisational commitment to expansion is strong and plays a key role in sustained involvement.

Overall, the Salvation Army has gained important experience in community capacity development approaches involving health and other development issues, new perspectives on facilitation and local participatory approaches, and successful mutual learning pathways. Budgetary concerns have become less important as "participation" becomes more important than "provision." 


\section{Evaluation}

Monitoring activities include on-site visits by the international team to each regional team, regional and international consultations, and mutual accountability and support. Evaluations are also done on a local basis using a participatory design, with the help of a multicultural facilitation team.

\section{Lessons learned}

Overall, programme experience-affirmed by an external evaluation conducted in June 2000-demonstrates that local participatory design and evaluation done with the help of a multicultural facilitation team can be very successful. Such success has led to growing quality in resource pool development, the greater involvement of local and regional leadership, and smoother inter-organisational sharing.

Important barriers to progress remain, though. Some resistance to these concepts is still evident among leaders and some institutional based programmes. Areas that require improvement include the further development of team leadership and "decentralisation" from the two co-ordinators, with even greater leadership involvement, and greater understanding of the external evaluation process. The team approach needs to involve a highly developed sense of collectively shared consciousness and vision, and refers to the responsibility and presence of team leadership. 


\section{Appendix: A Page 22 of 53}

Other key lessons learned include the following:

- Successfulcommunity-to-community transfer is an incentive to other local communities.

- During the early stage of an activity, it's important to identify leadership among team members from the resource pool stage and to commit to intensive activity.

- The scaling up process is helped by a shared vision of local community capacity development and developing complementary ways of working that serve local responses.

- It's critically important to include local implementers in planning cycles and to involve service be neficiaries.

- Discussing leadership and personal security issues strengthens teams and helps 6 ond the team to local stakefiolders.

- Frequent policy discussion based on concept and process analysis is necessary and must include field implementers and members of the community. 


\section{Naz Foundation (India) Trust: An Implementer's Perspective of the Healthy Highways Project}

\section{Implementers}

The Naz Foundation (India) Trust, based in New Delhi, was established in 1994 to serve community needs that were not being met by Government or other agencies. Naz India is committed to reducing the spread of HIV/AIDS through education and to providing support to those living with the virus, their families and communities. There are currently six programmes at Naz India: the Care and Support Programme, the Healthy Highways Project, the National Level Master Training Programme, the Men Who Have Sex With Men Programme and the Women's Sexual Health Programme.

The organisation consists of teams of programme officers and outreach staff headed by co-ordinators. These co-ordinators report to Programme Managers, who are under the supervision of an Executive Director, who is accountable to the Board of Trustees of Naz India.

\section{Background}

In December 1997 Naz India conducted a study of the risk behaviours and spread of HIV and STDs among truck drivers, their crews and their sexual partners. This study found overall lack of knowledge and high level of myths and misconceptions surrounding sexual practices and the risk of STDs, which left the truckers at a high risk of contracting STDs including HIV. There was also a lack of treatment programmes for STDs, as well as a high social stigma associated with these diseases.

In response to the findings, the Healthy Highways Project opened the Top Gear Clinic in Azadpur Transport Mandi, one of the largest transportation centres in Asia. This trucking service centre, or "mandi", houses between 4,500 and 5,000 trucks at any time. The adjoining wholesale fruit and vegetable market brings in many more thousands of people.

The demand for services at the centre grew so quickly that the programme had to be scaled up almost immediately. This required hiring an additional doctor and counsellor and doubling the number of outreach staff. Outreach staff also determined that services should be extended to the nearby village of Bharola, 


\section{Appendix: A Page 24 of 53}

where truckers frequently went for casual/commercial sex. Project co-ordinators requested an additional 2 female outreach workers, one female doctor, and one female counsellor for this expansion.

Outreach also expanded to the fruit and vegetable market centres where there was a high level of MSM (men who have sex with men) activity.

\section{Objectives and main activities}

The primary objective of the scaling up was to increase the capacity of the clinic and its related outreach programmes so that more people could be served.

On an average day, 30 to 40 people came to the clinic. This number increased to more than 60 on days when staff put on mobile exhibitions. Even though the clinic focused on treatment of STDs, it could not exclude people seeking treatment for other medical problems, at the risk of generating resentment and further stigmatisation.

\section{Resources and timeframe}

From the beginning, the Department of International Development (DFID) has funded nearly 30 Healthy Highways Projects throughout India. State AIDS Control Societies (SACS) are taking over the projects in phases and DFID will not in future have any financial or administrative control.

The primary obstacles in the scaling up process were financial. There was a lack of resources to train the additional community outreach workers needed, and lack of funding to increase condom distribution outlets. Some simple but essential material goods were lacking, such as boots needed for outreach staff during the rainy season.

DFID did not fully understand and agree with the projected budget for the scaling up. The expanded Women's Sexual Health Programme in Bharola received funding for only one female outreach worker and no female doctor or counsellors.

Under the new guidelines of the National AIDS Control Organisation (NACO) and State AIDS Control Societies (SACS), doctor's salaries would be cut in half. 


\section{Appendix: A Page 25 of 53}

Medicines that were initially distributed free of cost are now charged to the clients, exempting only women, children and the elderly.

\section{Outputs/outcomes}

Truck drivers are a highly mobile population, but also form a fairly close community of their own. Truckers get most of their information, or misinformation from other truckers. Those who have visited clinics or received outreach counselling through the Healthy Highways Project are likely to tell their friends. The outreach staff at Azadpur regularly encounter men who have come in for the first time, often with a vast amount of misinformation.

The programme has been successful in dispelling many myths and providing factual information about the transmission of STDs and HIV/AIDS. This change is reflected in the information documented by outreach staff in their daily reports.

Because the clinics do not refuse those seeking treatment for general ailments, they were not stigmatised. Truckers may come in with some other medical problem, and then feel comfortable requesting STD treatment. Since the beginning of the project there has been a considerable behaviour change about condom use as awareness about proper usage has increased.

Another issue with the truckers is the high level of drug and alcohol addiction. Most cases of unprotected or risky sex are reported to occur while under the influence of alcohol. Staff now regularly refers cases to the de-addiction centre run by the NGO Sharan based in New Delhi.

The original targets of the scaling up have been far exceeded:

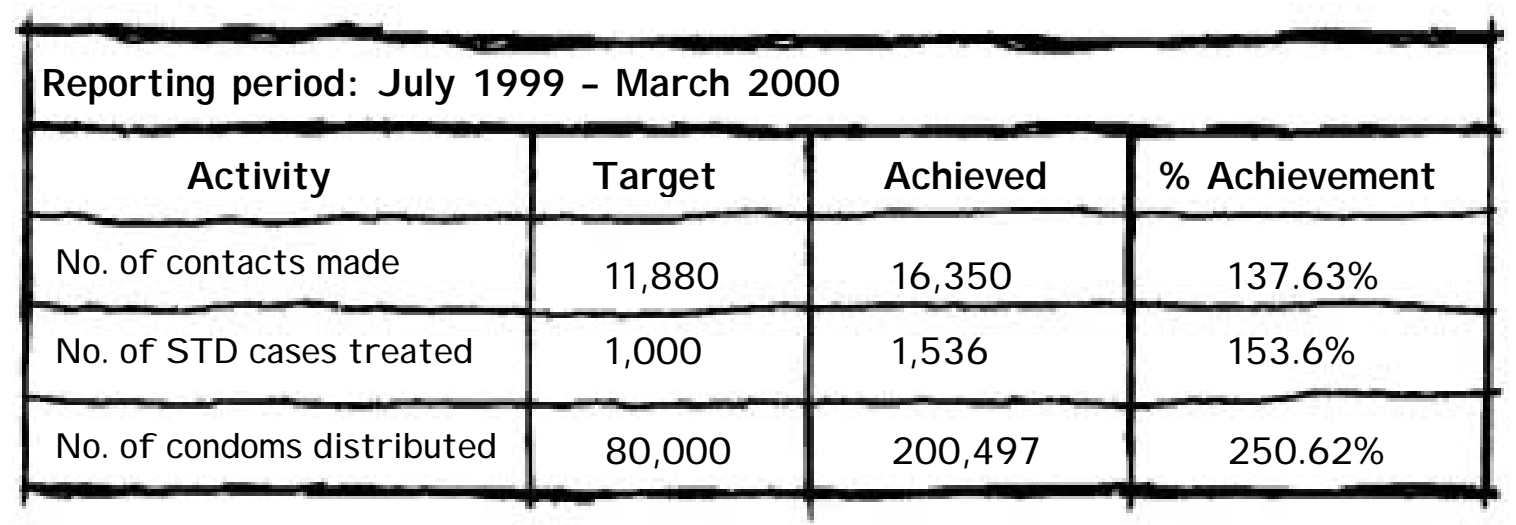




\section{Appendix: A Page 26 of 53}

Co-operation from secondary stakeholders like truck owners associations and police has largely increased as well, but individual truck company owners have not been generally co-operative. They do not consider the health problems of their employees as their business or concern.

Sustainability of the project remains a big issue, as the reliance on community resources must increase.

\section{Internal organisational implications}

Staff and peer educators welcomed the scaling up as they could now respond adequately to the needs of the community. The scaling up did, however, strain the already limited resources, forcing transfer of funds from some other programmes.

\section{Evaluation}

No formal evaluation was done before scaling up, but the Naz Foundation does have a very strong ongoing monitoring system within every programme. All outreach and other activities are extensively documented at the end of the day. The programme team meets weekly to review the performance of the past week. Every month there is general staff meeting to share programme experiences, seek input from other teams and discuss future plans. This system of internal monitoring has been functioning effectively for the last five years. 


\section{Lessons learned}

- Befiaviour change, though often slow, is the only effective way of reducing the transmission of $\mathcal{S} \mathcal{T} \mathcal{D}$ s including $\mathcal{H} I \mathcal{V} / \mathcal{A} I \mathcal{D S}$.

- Groups at particular risk such as the women of Bharola village are eager for education and support. Women accessed the clinic even without a female doctor.

- Befiaviour change communication (BCC) materials are an extremely effective way to reach clients.

- $\mathcal{A}$ successful programme for this particular population must include treatment for drug and alcohol addiction.

- Clients who receive effective counselling and treatment encourage their partners to participate.

- There must be great care not to stigmatise the treatment of $\mathcal{S} \mathcal{T} \mathcal{D}$ and $\mathcal{H} I \mathcal{V} / \mathcal{A} I D S$. Truckers are feeling increasingly alienated as they are perceived as a high-riskgroup. 


\section{Scaling up the FOCUS Programme of Family} AIDS Caring Trust

\section{Implementers}

Family AIDS Caring Trust (FACT) is a Zimbabwean NGO, established in 1988 with offices in Mutare and Chiredzi. FACT works with a variety of NGOs and CBOs to promote quality HIV/AIDS interventions.

The Family, Orphans and Children Under Stress (FOCUS) programme, established in 1993, works primarily with church-based CBOs to provide support to children affected by AIDS. They identify households where children's basic needs are unmet and help develop a sustainable plan to improve their quality of life.

\section{Background}

In 1991, FACT Director Dr. Geoff Foster was alarmed at the growing number of malnourished orphans he encountered during his work as a paediatrician at a government hospital. FACT then sponsored a research study to count the number of orphans, examine how communities and extended families were coping and determine how best to support their efforts.

The first FOCUS programme was established with a church group near Mutare in 1993. One year later, the group had succeeded in identifying a large population of orphans in the target area, prioritising the most needy households and mobilising the community to provide regular visits and support to these households.

The process of scaling up might actually be better described in this case as scaling out. As other churches heard about the success of the pilot project they asked FACT, the facilitating NGO to help them establish similar programmes. By 1998 FACT supervised 9 FOCUS sites with 178 volunteers providing regular visits to 2,764 orphan households. 


\section{Objectives and main activities}

The objectives of the FOCUS programme are:

- To identify all orphaned children in each project's area and prioritise those house holds with the greatest needs.

- To visit these housefiolds at le ast twice a month

- To provide these housefiolds with material support.

- To involve other community groups, le aders and organisations in all aspects of the operation.

- To enable these groups to work toward more autonomy and controlover the ir own local programmes, eventually reducing the ir de pendence on $\mathcal{F A C T}$.

- $\quad \mathcal{T} o$ identify early new problems affecting orphans.

As the FOCUS programmes expanded so quickly, FACT had to develop a new type of support model. It became necessary to re-evaluate decision-making systems and structures within the programme. There were attempts to enhance collective decision-making and encourage site supervisors to become more actively involved in planning activities and budgeting. An annual management meeting was introduced so supervisors of different sites could plan activities together with the FOCUS staff.

It became clear that:

- The capacity of the FOCUS staff to supervise new sites was limited.

- Identifying emerging problems was better achieved when attention could be focused more intensely on fewer sites, rather than more broadly on many.

- Community ownership made a project much more sustainable,

- $\quad \mathcal{F O C U S}$ should begin to limit its activities to community mobilisation and tecfinical support. 


\section{Appendix: A Page 30 of 53}

\section{Resources and timeframe}

The initial funding for baseline research was provided by Plan International (Mutare). A start-up grant for the FOCUS programme was provided in 1993 by Save the Children Fund (US). Since 1993, Plan International has provided most of the funds, with some additional support from UNICEF.

No specific budgets were set for the scaling up process in the beginning. FACT administrators believed that the expansion could be carried out using existing resources. When the new sites began to develop rapidly, additional money was requested and granted.

Because FOCUS relies so heavily on volunteers from within the community, the cost of establishing and maintaining a new site is a fraction of the total cost of running the programme. An assistant co-ordinator was hired at the beginning of the first scaling up in 1996, but no additional staff was added after that. Fixed programme costs such as Co-ordinator's salary, office rental and administration costs remained basically unchanged as the programme grew.

Additional costs of training, transport and support to communities represented less than $20 \%$ of total costs.

There were however, definite changes in the financial situation as the programme expanded:

- While the amount spent on material support increased with programme expansion, the actual number of housefiolds supported increased at a faster pace, resulting in reduction of support provided to each fouse fold.

- In 1997, due to limited capacity of FOCUS staff, a decision was made to reduce the frequency of site support visits in established programmes from monthly to 6i-monthly. In alternate months, FOCUS site supervisors attended training and support meetings at $\mathcal{F A C T}^{\prime} s$ offices. This increased supervisors' responsibility and provided peer support.

- The reduced availability of FOCUS staff for training of volunteers at sites was compensated for by establishing exchange visits for volunter ers betwe en sites. These visits proved to be popular and beneficial. 
- The reduction in the amount of material support and supervision provided by $\mathcal{F A C T}$ to $\mathcal{F O C U S}$ sites actually encouraged the CBOs to become more autonomous. Some developed additional resources within their own communities, or independently recruited from outside. One CBO obtained external donor funding and was able to employ its own staff, develop a Board of directors and become an $\mathcal{N G O}$ in its own right.

\section{Outputs/outcomes}

Although scaling up was assumed in the original project design, there were no specific targets set concerning coverage, impact or sustainability. Initially, there were no known models of community support to children affected by AIDS. Since the pilot programme, targets have been developed for new sites.

Few aspects of the original model were lost or diluted in the scaling up process. Though FACT was able to provide less material support to the newer FOCUS sites, this did not affect the functioning of the programmes and may actually have enhanced community ownership, decision-making and contributions. When community groups were challenged to make more decisions about their future development, they matured and became more empowered.

The flow of monitoring data to FACT has become less efficient however, as a result of reduced supervisory visits to FOCUS sites. 


\section{Internal organisational implications}

Overall, the process of scaling up was advantageous to the FACT organisation.

- The additional work for $\mathcal{F A C T}$ staff in supervising several FOCUS sites was offset by an increase in mutual support from site supervisors and volunteers.

- The FACT organisation was able to gain a strategic understanding of the mechanisms involved in an effective scaling up process.

- Innovations introduced by community-based partner organisations will be helpful to $\mathcal{F A C T}$ in developing future programmes.

- $\quad \mathcal{F A C T}$ decided in 1999 that they would not directly support any new FOCUS sites, but would supply technical support and training without formalised monthly visits, allowances or material support.

\section{Evaluation}

The pilot programme was evaluated in January 1995, one year after commencement. The findings have been published as a peer-reviewed article, Supporting children in need through a community-based orphan visiting programme, G. Foster et al, AIDS Care, 4:389-404, 1996. Among the findings:

- Community-based organisations were able to identify a high proportion of orphans living in their area, target those most in need, and provide regular visits and material support.

- These programmes can provide support to large numbers of affected families .

- The FOCUS model was targeted, effective and replicable. 
Another major evaluation was carried out in 1999. These findings included:

- FOCUS programmes enjoyed high levels of volunteer retention and sense of community ownership.

- There was a need to diversify the FOCUS model so it could operate with lower levels of external support.

The most challenging aspect of evaluating the scaling up has been maintaining a balance between the requirements for FACT to supervise programme sites, obtain monitoring data and understand emerging problems, while also ensuring autonomy to the communities and fostering their sense of ownership.

\section{Lessons learned}

The success of the FOCUS programme is most clearly demonstrated by the mechanism by which it proliferated. Local leaders and pastors saw tangible benefits being provided to a community in need and sought, through their own initiative, to establish the programme in their own communities.

Despite the acknowledged success, the scaling up process could have been much more effective with more outside support. The FOCUS programme expansion received little support from outside agencies, government departments, international children's organisations or policy advisory groups. 
There are a number of factors that appear to inhibit effective partnerships between large organisations and NGOs

- Unrealistic reporting require ments

- Lack of fle xibility

- Lack of trust

- Partis an agendas

- Inability or reluctance on the party of large organisations to embrace the ide a of community ownership, empowerment and eventual autonomy of a project 


\section{Pact AIDS Corps}

\section{Implementers}

$P$ act is an international NGO with 30 years of experience working with networks of NGOs and civil society organizations. Pact's AIDS Corps was created to help other NGOs and community organizations more effectively battle the spread of HIV/AIDS.

Pact's headquarters are in Washington D.C. and there are country offices throughout Africa, Southeast Asia and in Peru and Nepal.

The goal of Pact is to keep international attention focused on the epidemic and mobilize resources to help fight it.

\section{Background}

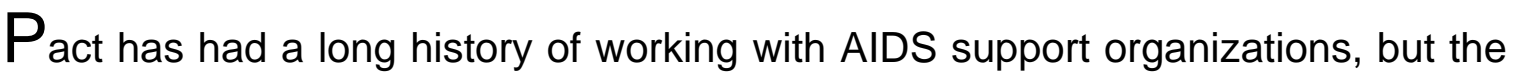
increasing impact of the HIV/AIDS epidemic in Africa motivated the organization to find a way to escalate their efforts and broaden their approach. The AIDS epidemic is more than just a health crisis. It affects all aspects of a community. Pact believes that a social movement led by those most affected is needed to revitalize hope and galvanize cooperation.

Pact is drawing on the expertise of existing staff and has engaged additional fulltime staff and consultants.

\section{Objectives and main activities}

The Pact model of expansion is based on the complex interdependence of the rain forest. The web is comprised of community and national leaders, NGOs, government and private sector organizations. This model requires participants to rethink their ideas of traditional boundaries and eliminate the sense of competition between various organizations. 
The strategic objectives include:

- Advocating for increased attention and resources.

- Strengthening the capacities of organizations and communities to focus, intensify and sustain the ir efforts.

- Increasing the diversity of people giving voice to the needs of their communities.

- Developing and disseminating cross-sectoral programs that include aspects of economic and social development.

- Coordinating diverse networks of organizations for maximum impact.

Pact has convened four AIDS Corps meetings so far, with a network of over 100 individuals and organizations. Two meetings in September will include leaders of US foreign aid policy, religious leaders and representatives from pharmaceutical companies and Johns Hopkins University.

\section{Resources and timeframe}

The AIDS Corps was inaugurated in January 2000 when Pact provided unrestricted funding to establish the movement and develop country strategies in Ethiopia, Zambia, Zimbabwe, Mozambique and Madagascar.

From April to October, Pact is working with the Africa Bureau of Democracy and Governance Support to develop cross-sectoral approaches to HIV/AIDS, focusing on increasing democratic principles and practices in community-led solutions. In the fall of 2000, Pact will be working with NetAID on country programs in Ethiopia, Zambia and Zimbabwe. Plans are now underway to work with UNAIDS in Ethiopia in early 2001.

\section{Outputs/outcomes}

It is too early to have specific information about targets and goals. The evaluation process is ongoing as the projects continue to develop. The response from participants, both within the various organizations and among the populations affected, has been positive. 


\section{Internal organizational implications}

Pact has had to develop a global AIDS Corps Team to deal with the complex communications involved in working with diverse organizations, countries and international partners.

On of Pact's three strategic pathways is peer partnership in which AIDS Corps can soar internationally and nationally.

Internal support for the AIDS Corps movement is being built. Pact is a project and service oriented organization. Launching a social movement, no matter how compelling, is a different way of doing business at Pact.

Self-fulfilling prophecy- the diverse array of Pact partner NGOs made it a natural to respond to the realization that AIDS has crossed all development sectors.

Pact's culture is rich in pioneer spirit and risk-taking. The passion of AIDS Corps demands commensurate fundraising, a harrowing challenge.

\section{Evaluation}

The project is still in the early stages, no significant evaluations have been made.

\section{Lessons learned}

Even though most people now agree that the the HIV/AIDS epidemic involves more than just a health care crisis, it was difficult for some in the health-care organizations to accept Pact's interest since it did not have a background in this arena. Several groups were also concerned about replicating existing efforts and diverting resources away from projects already underway.

The tradition among NGOs has been to direct resources to specific efforts in one sector, and it will take some effort to broaden this view. Pact would like to see funding integrated in support of cross-sectoral approaches. 
Appendix: A Page 38 of 53

Pact has to build on the already good work being done. It has to extend the hand of connectivity and bridge builder. It must demonstrate its skills in coordination and resource mobilization. 


\section{The Kenya AIDS NGOs Consortium (KANCO)}

\section{Implementers}

The Kenya AIDS NGOs Consortium (KANCO) is a coalition of some 600 NGOs/CBOs and religious organizations that deal with HIV/AIDS/STI activities in Kenya.

\section{Background}

KanCO was founded in 1990 by a group of seven health and development NGOs that had added an HIV/AIDS component to their existing programs. The consortium's goal is to improve the response to the epidemic by enhancing NGO networking and collaboration among NGOs, religious, institutions, and the Kenyan government, as well as to promote leadership and solidarity.

In 1997, KANCO identified the need to expand and strengthen services, enhance its visibility, and increase capacity on the district level without creating field offices. To accomplish this, the consortium developed an implementation plan to deliver services in districts where there are many KANCO member organizations. This process is described below, under "Internal organizational implications."

\section{Objectives and main activities}

KanCO's efforts are designed to complement the government response to HIV/AIDS to ensure a positive policy environment for HIV/AIDS/STI prevention, care, and support; promote capacity building; and provide broad access to HIV/AIDS/STI information and materials. 


\section{Appendix: A Page $\mathbf{4 0}$ of $\mathbf{5 3}$}

The consortium's key activities include:

- Establishing and facilitating a networking system to provide forums for sharing resources and enfrancing collaborative efforts both at the national and district levels. Maintaining a resource center to collect and disseminate $\mathcal{H} I \mathcal{V} / \mathcal{A} I \mathcal{D S}$ information, education, and communication materials; the center currently handles a monthly average of 350 enquiries.

- Promoting capacity building among members to improve quality of services and respond to the epide mic more effectively

- Working to complement the government in developing and articulating national policies for $\mathcal{H I} \mathcal{V} / \mathcal{A} I D S$ prevention, care, and support.

\section{Resources and timeframe}

KANCO has been supported by several donors, including the U.S. Agency for International Development, the Department for International Development of the UK, and others.

\section{Outputs/outcomes}

KaNCO's commitment to national policy development on HIV/AIDS has led to several important initiatives. The consortium has built strong ties with government agencies involved in policy formulation and health programming, such as the National AIDS and STD Control Programme (NASCOP) and the National AIDS Control Council (NACC). The executive director of KANCO sits on the NACC, which coordinates HIV/AIDS activities in the country, to promote the perspective of Kenya's NGOs. KANCO's policy initiations contributed significantly to the development of the 1997 Sessional Paper No. 4, "AIDS in Kenya." KANCO has also sponsored several symposia to build the capacity of members of Parliament to respond to the epidemic in their constituencies. 


\section{Appendix: A Page 41 of 53}

\section{Internal organizational implications}

In late 1997, KANCO invited consultants in organizational development (OD) to assist in designing a strategy to better support member organizations and other clients, particularly at the district level. Rather than force KANCO to strictly adhere to linear planning procedures toward this goal, KANCO leaders saw OD as a process that would allow the consortium and the organizations within it to consciously manage their growth and development without sacrificing KANCOs' organizational knowledge and culture. OD became a valuable tool that has allowed KANCO to identify constraints or crisis points in its structure and to decide whether it needs to shift to different ways of organizing itself to improve effectiveness.

The OD intervention helped KANCO examine areas that regular planning rarely touches, yet that are extremely crucial for organizational well-being. These include such issues as values, identity, image, relationships, and organizational culture. In strategy making, for instance, an OD inter-vision will take longer than conventional linear planning approaches but will help the organization as a whole become more conscious of the values that drive its mission and the norms that keep it alive. This also helped to bring values and norms into alignment with internal capacity, structure, administration, and communication. The process also helped KANCO to acknowledge problem areas, some of which involved deep emotions and change.

The first step was a "belief session" designed to introduce staff to OD and answer questions about the process. Next came a comprehensive survey to help assess existing organizational capacity and infrastructure within KANCO. This two-day effort, facilitated by the consultant, focused on interviews with individual employees, including the director and all staff working in the administration, policy and advocacy, and resource center departments, as well as organizational diagnosis questionnaires. These sought to explore why individual staff chose to work at KANCO, whether personal objectives are achievable at KANCO, and how staff perceive KANCO objectives. They revealed that most staff are confident about their skill levels, have high regard for KANCO's networking orientation, feel pride that they work for a high-profile organisation that has enjoyed success in its field, and are confident in KANCO's financial management. The surveys were followed by a diagnostic workshop made up of staff, board members, and volunteers that focused on analyzing and summarizing the results of the diagnosis questionnaire. 


\section{Appendix: A Page 42 of 53}

Next steps included participatory development of a five-year strategic plan, which concentrated on five key questions. Key components of this planning process included allowing participants to express expectations and fears; introducing a planning framework to enable the entire team to understand the planning process; analyzing KANCO stakeholders and prioritizing commitments to them; reviewing KANCO's mission and organizational vision; analyzing the external environment of factors likely to influence KANCO in the future and envisioning future factors; examining internal competence, strengths, and weaknesses; and developing strategic goals in a participatory process. These efforts lead to three key goals for KANCO:

- Goal 1: A competent secretariat capable of responding to the technical needs of members and $\mathcal{H} I \mathcal{V} / \mathcal{A} I \mathcal{D S}$ issues.

- Goal 2: Functioning national and district networks capable of providing regular forums for experience sharing and access to information.

- Goal 3: Enhanced advocacy capacity for members to respond to $\mathcal{H} I \mathcal{V} / \mathcal{A} I \mathcal{D S}$ policy issues effectively.

Key outcomes from the OD process have included:

- $A$ job analysis and evaluation, involving staff-wide job analysis questionnaires and a job evaluation exercise, which led to development of a grade level system based on evaluation results.

- A salary survey, which provided the basis for recommendations on a salary structure and prompted creation of a staff pension and medical scheme.

- Creation of finance and personnel policy manuals.

- Development of a sustainability plan, including technical assistance to improve financial management and staff benefits, and a working committee on sustainability.

- Astaff appraisal system.

- More staff training to, among other things, enfance KANCO's ability to respond to donor requirements for financial management, analysis, and reporting.

- Project management meetings.

- Joint donors'meetings to explain $\mathcal{X A N C O}$ activities, constraints, and future plans. 


\section{Appendix: A Page $\mathbf{4 3}$ of 53}

The benefits to KANCO of the OD process are numerous. The consortium now enjoys increasing transparency within the organization, an overall change in perspectives and attitudes, new learning processes, internalization of the organization's mission, and a new sense of ownership by staff and members of the organization, leading to greater effectiveness. 


\section{Project Support Group (PSG)}

\section{Implementers}

The Project Support Group (PSG) is a regional non-profit organization founded in 1986 to provide training and support to community organizations. PSG works in eight Southern African countries: Zimbabwe, Zambia, South Africa, Malawi, Botswana, Swaziland, Lesotho and Mozambique. It has branches in Zimbabwe, Zambia, South Africa and Malawi and a strong academic collaboration with the Universities of Zimbabwe, Zambia and Pretoria. These partners share responsibility for project management, training and field support. PSG has national and regional governing structures.

PSG defines its mission as building bridges between knowledge and application, i.e. applying state-of-the-art knowledge to implementation and generating stateof-the-art knowledge that will improve practice. It integrates professionalism and voluntarism, adding value to altruism. It also develops approaches that link formal health systems to informal community-based AIDS prevention and mitigation initiatives.

PSG seeks is to develop economical, effective methods that build partners' capacity to deliver economical, effective AIDS prevention and mitigation services. PSG's approach to capacity building is based on the conviction that effectiveness derives from partner ownership, a results orientation, continuous support, rather than one-off training, provision of tailored materials and emphasis on how to do rather than what to do.

\section{Background}

In 1987, the University of Zimbabwe began an ethnographic study of HIVvulnerable, low-income women in Bulawayo, Zimbabwe's second largest city. The women who participated in the study requested STD/HIV/AIDS education and services, which the Bulawayo City Council agreed to provide, initiating STD/HIV/AIDS project for HIV-vulnerable communities of women and men in 1989. With the University of Zimbabwe's support, other health authorities and community organizations in Zimbabwe followed the Bulawayo City Council's lead, developing projects for HIV-vulnerable communities of women and men PSG evolved from the University of Zimbabwe, as a service delivery arm, to complement research activities. As the number of partners seeking its assistance grew, PSG became increasingly formalized and structured. To manage its 


\section{Appendix: A Page $\mathbf{4 5}$ of 53}

increased responsibilities, in consultation with partners and stakeholders, PSG became a regional non-profit organization in Zimbabwe, Zambia, South Africa, and Malawi, strengthened its institutional governance structures in each country and developed an overall regional governance framework, with equal representation from South African, Zimbabwean, Zambian and Malawian partners.

PSG recruited additional staff and formed an associate group of 20 experienced field coordinators to provide training and support to regional partners.

In order to support its growing network of partners, PSG developed a structured training program, based on horizontal training approaches. Partners complete a structured training cycle. New partners first attend a skills building workshop, which provided an overall conceptual and skills-based framework. This is followed by a practical internship, in which new coordinators visit experienced coordinators for a practical, field-based orientation. Thereafter, field support visits take place, in which experienced coordinators visit new coordinators to provide on-site practical assistance. Through these reciprocal visits and interactions, coaching and mentoring partnerships evolve, in which new and experienced partners form ongoing "parenting" or coaching relationships.

As its number of partnerships has grown, PSG has sought to make its training approaches as structured as possible. It has two training suites, a management training suite with 10 modules and a coordinators' training suite with six modules. PSG and partners have also developed five core training courses: a project managers' course; a prevention coordinators' course; a mitigation coordinators' course; a peer educators' course; and a care supporters' course. Thus, the organization has significantly increased its structure and capacity in order to manage its increase.

PSG also needed highly structured standardized approaches. We did these through modules, manuals and structured participatory approaches. The World Bank and the World Health Organization have commended the PSG approach. 


\section{Objectives and main activities}

PSG's overall goal statement is: "To assist Southern African government, municipal, non-profit and church partners to develop, manage and sustain optimally efficient, effective, evidence-based HIV/AIDS prevention and mitigation projects". Its unifying theme is community-based HIV/AIDS prevention and mitigation approaches, utilizing carefully trained and supported community volunteers to deliver services.

The organization does not support institutional approaches to HIV/AIDS prevention and mitigation, which invest in physical plant or institutional facilities. The regional project believes that the scope of HIV/AIDS prevention and mitigation needs is too great for formal, institutional approaches and that only through the fullest possible involvement of community members can services of sufficient scope be introduced.

The Project Support Group has two project areas: STI/HIV prevention and HIV/AIDS impact mitigation. PSG's prevention and mitigation activities share a common approach. They both work with community volunteers to deliver largescale, economical, locally relevant services that increase community response capacity.

PSG develop systems to train and support community volunteers effectively. In prevention, volunteers serve as peer educators, providing training, behavior change communication and condoms to their communities particularly low income, HIV-vulnerable communities. In mitigation, volunteers work as care supporters, training and supporting community members to care effectively for family members with HIV and orphans.

Concerning an illustrative example of prevention, in Mutare, Zimbabwe, community peer educators, organize thousands of community meetings, reaching men in workplaces, bars and nightclubs and women in homes and markets. They use participatory approaches to stimulate community debate and to shape safer sexual norms. They also distribute condoms through their social networks and at hundreds of fixed distribution points throughout Mutare. They give low-income women STI treatment cards, to enable them to secure free, high-quality treatment. Through participatory dialogue to foster safer sexual norms, largescale condom promotion and distribution, and improved STI care, the project has sharply reduced STIs, and by implication, HIV. 


\section{Appendix: A Page 47 of 53}

An example of PSG's work in mitigation can be seen in Masoyi, South Africa, where church members have volunteered to serve as care supporters. They are trained provide home care and to train family members to offer palliative care. Once trained, they visit their neighborhoods to identify families with terminally ill patients. They assist the family to gather firewood, sweep their yards and clean their houses, bring food and simple medicines, assist the family to care for the patient and above all, train the families to provide high quality palliative care. The care supporters have trained, equipped and supported hundreds of families in Masoyi to care for terminally ill patients.

PSG has three major activities: implementation research, project training and field support, and on-grant management. The first stream is implementation research, to identify, refine effective prevention and mitigation strategies. PSG is currently involved in five studies in three countries; Zimbabwe, Zambia and South Africa. Two studies are evaluating alternative approaches to reduce STI/HIV transmission among HIV-vulnerable adults. Two studies are evaluating school STI/HIV prevention approaches. One study is evaluating the coverage, economy and quality of community AIDS care

The second stream is project training and field support. Through national and regional grants, PSG provides training and field support to approximately 130 projects, including 60 in South Africa, 40 projects in Zimbabwe, 22 in Zambia, 4 in Malawi, 1 in Botswana, 1 in Lesotho, 1 in Swaziland and 1 in Mozambique. An estimated $60 \%$ are prevention projects and $40 \%$ are mitigation projects, but the percentage of mitigation projects is growing fast. Project training and support involves site visits, to foster interest, and regular skills building workshops, to learn and reinforce concepts. Each year, PSG co-facilitates 10 skills building workshops in South Africa, 6 in Zimbabwe and 4 in Zambia. It also involves internships, with experienced projects, to learn practical skills, mentoring partnerships, in which experienced projects coach emerging ones.

The third stream is on-grant management. PSG currently contributes national and regional on-grant funds to 60 partners, including 40 in South Africa, 10 in Zimbabwe, 4 in Zambia, 3 in Malawi, 1 in Lesotho, 1 Swaziland, and 1 in Mozambique. PSG and its partners have developed comprehensive on-grant management systems, including project application packages, review forms and financial and progress reporting manuals and forms. 


\section{Appendix: A Page 48 of 53}

\section{Resources and timeframe}

PSG try to have at least five sources of funding in each program for diversity and sustainability. These include private sector contributions in cash or in kind, particularly in South Africa, with its large, cash-rich corporations. It also includes community contributions, such a community and household training and meeting facilities and community members' volunteer time. It includes government contributions, such as personnel, grants, medical supplies and services, condoms and IEC materials. It also includes multilateral/bilateral contributors, who provide funds. Finally, foundations play an increasingly important role.

The organization's regional programs have a current time frame of five years.

PSG has adequate resources and staggers its expansions in relation to resources available, on a phased, country-by-country approach. It keeps its per project costs low and its administration particularly low, by having a very small management nucleus. PSG passes on in direct grants fully 90 to $92.5 \%$ of all resources received. It believes that the proportion of resources disbursed to those retained is the only meaningful measure of administrative costs. All other indicators can be embellished, usually by re-profiling administration as capacity building or implementation support services.

The efficiency and economy of the PSG is evidenced by the fact that despite this sustained growth in activity, full-time program staff now number only five persons, supported by a finance manager. They are assisted by 10 part-time associate members (primarily partner project managers and coordinators of excellence), who assist in the training and mentoring of new coordinators. PSG believed in the principle of co-funding for sustainability and most funders accepted the motion.

The costs of scaling-up during the initial period in new countries are relatively high. They also varied from country to country, in keeping with cost of country operations and economies of scale in respective countries. For example, operations in Zambia and Mozambique are significantly more expensive and project costs in Zimbabwe have grown and infrastructure and productivity have declined.

Donors agreed with the organization's timeframe because they were familiar with its budgets. PSG also identified donors with a long-term focus and those who were willing to work regionally. PSG then complemented its core donors with 


\section{Appendix: A Page 49 of 53}

additional funds from donors with a shorter-term perspective. However, it was careful not to position funds from shorter-term donors at the core of any program activity. PSG kept administration both monetary and office staff costs low.

The organization developed project management systems to support its work. In particular, project application, management, monitoring and reporting packages were developed, to assist projects to prepare applications, monitor progress and provide progress reports.

\section{Outputs/outcomes}

All 20 Zimbabwean projects held 750,000 meetings, reached 24 million people (including repeat attenders) and distributed 100 million condoms. These outputs have been delivered within exacting cost targets. Bulawayo's unit costs (excluding opportunity costs and donated condoms) average US $\$ 1.2$ per outreach meeting, US $\$ 0.02$ per person reached and US $\$ 0,01$ per donated condom distributed. In Lusaka, Zambia, unit costs average US $\$ 7.48$ per outreach meeting, US $\$ 0.38$ per person reached and US $\$ 0,05$ per condom distributed. These unit costs far surpass economies achieved in other health promotion projects.

Through large-scale activities, high coverage has been achieved. Nine projects have conducted community coverage surveys. In Bulawayo, $80 \%$ of 705 sex workers have attended peer education meetings and $91 \%$ of these had received condoms during meetings. In Mutare, $98 \%$ of 204 sex workers and $92 \%$ of 508 clients had attended peer education meetings and $93 \%$ of sex workers and $84 \%$ of clients had received condoms during meetings. In Mutare, a survey showed that peer educators were the primary source of condoms compared to bars, health centers family planning clinic and friends.

High coverage has provided a basis for behavior change. In Bulawayo, condom use in sex work rose from $18 \%$ at the outset to $72 \%$ within two years. Condom use was closely related to intervention coverage and exposure. Condom use in the last commercial sex act was reported by $27 \%$ of those who had attended no meetings, $46 \%$ of those who had attended one meeting and $77 \%$ of those who had attended two or more meetings.

Behavior change appears to have contributed to reduced STD/RPR rates. In Zimbabwe project sites, STD/RPR rates fell by $48 \%$ in Bulawayo, $52 \%$ in Mutare, 


\section{Appendix: A Page 50 of 53}

$63 \%$ in Kariba, $71 \%$ in Chitungwiza and $74 \%$ in Masvingo. In Zambia project sites, RPR rates fell by $77 \%$ in George, $78 \%$ in Kanyama and $47 \%$ in Matero.

The projects' impact have been independently evaluated by international universities, including the London School of Tropical Medicine, Johns Hopkins University, University of Michigan, University of North Carolina and Amsterdam University.

The most challenging aspect of scaling up was trying not to dilute quality and building country support mechanisms in each country. It was also a challenge to preserving research quality in many sites more than half of the sites had no research expertise.

\section{Internal organizational implications}

The core organization has become more involved in management. It has increasingly delegated training and support to downstream partners, particularly associate group members.

Expansion improved morale, because staff and volunteers felt part of a growing, expanding, evolving organization. In addition, the organization has become more skilled and focused, greater breadth, capacity and overall professionalism.

\section{Evaluation}

PSG has powerful project impact data from Zimbabwe, Zambia and South Africa, which gives confidence that the approach works.

The organization has made significant progress towards the development of a project monitoring and evaluation framework.

The prevention and mitigation components have both developed monitoring forms, for peer educators/care supporters, coordinators and project managers. These forms are included in the project information packages. The prevention component has developed baseline and follow-up behavioral surveillance surveys for priority groups. These surveys have been translated into Shona, Ndebele, Zulu, Sotho and Nyanja. Community coping and quality of care surveys have been developed, to assess baseline and follow-up coping capacity and quality of support. 


\section{Appendix: A Page 51 of 53}

PSG has developed a comprehensive framework for evaluating projects. The framework encompasses inputs, outputs, unit costs, coverage, behavioral outcomes and STD/RPR trends.

The framework has a detailed, logical results chain. The results chain is as follows: Inputs lead to outputs. These outputs are achieved within specified costs. Through large-scale outputs, high coverage is achieved. Coverage is imperative for change: a project cannot modify behavior unless it actually reaches communities. Through high coverage, important behavioral outcomes especially increased condom use and improved STD symptoms knowledge, suspicion, recognition and care seeking behavior, occur. These behavioral outcomes lead to reduced STD/RPR rates, which are the best measure of the projects' "real world impact".

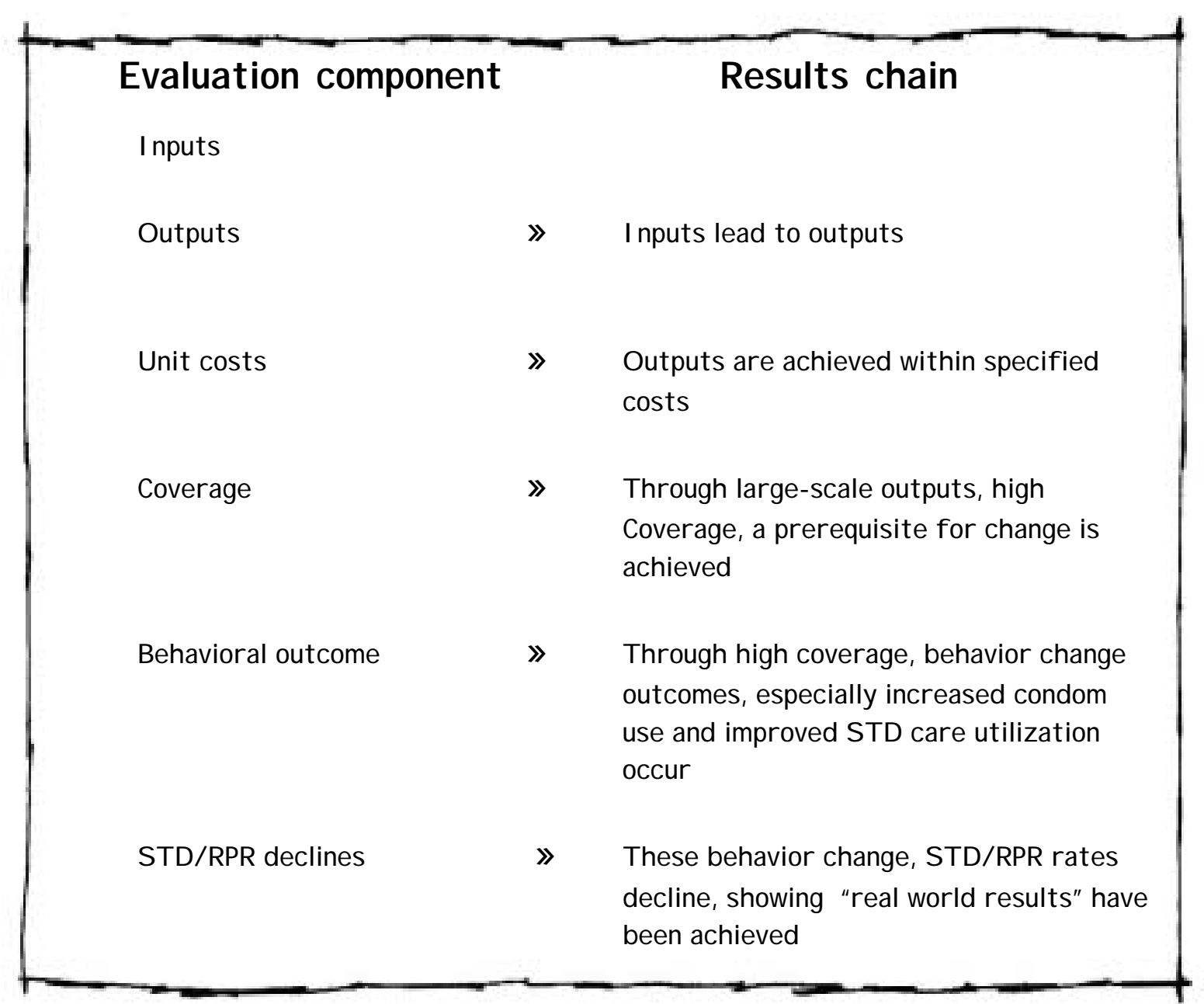




\section{Appendix: A Page 52 of 53}

PSG's inputs include: a suite of 10 program management modules, available in English and Portuguese, a suite of six peer educator training manuals, over 100 participatory outreach activities, an average of 10 training courses annually and over 500 person days field support annually. These inputs have contributed to significant outputs. Since 1987, the oldest project, in Bulawayo (population 900,000 ) recruited 80 peer educators, held 250,000 outreach meetings, reached 10 million people (including repeat attenders) and distributed 32 million condoms.

\section{Lessons learned}

PSG has managed to build in-country training and support mechanisms. It expanded without run-away administration costs. This was because it was able to develop a structured, standardized approach that could be replicated in each of its focal countries. Each country is unique and there are slight differences and challenges during implementation of the projects.

One of the major drawbacks that the PSG encountered was the failure to access sufficient STI care, home care medicines and food and condoms as needs grow. Current need and /or use of condoms are about 100 million annually. Many partner countries are experiencing drug and condom stock outs. Home care programs are critically short of food.

To have a successful program one needs a structured, standardized approach, with supporting modules and packages. In short, an organization needs to build its systems as rapidly as the growth of the organization. There is need to develop horizontal training approaches, through site visits, internships, mentoring partnerships as projects are being implemented.

If PSG were to go through the process of scaling up again, it would try to develop fully standardized materials more rapidly. It would also establish the horizontal training school earlier.

In all its projects there has been no major resistance. However, early partnerships resent the loss of attention and uniqueness as scaling-up proceeds. Before replication of any projects in any country, PSG consulted with beneficiaries on expansion plans in each region. Their expertise was used to identify sites and approaches that were appropriate in the relevant countries. 


\section{Appendix: A Page 53 of 53}

The larger impact of scaling up was expanded coverage and scope of services. This led to truly district (Zambia), provincial (SA) and national (Zimbabwe) coverage.

Above all, projects must have a commitment to structured, methodical approaches and to a rigorous results orientation. Process cannot be a substitute for structure or results. 


\section{Appendix: B}

Potential Target Groups for HIV/AIDS Interventions and Prevention, Care and Support Activities According to Need, Complexity and Cost

The following two tables are included to provide more information about specific HIV/AIDS Interventions. It should be noted, however, that the interventions are listed from the perspective of a national agency delivering services, rather than that of NGOs as described in this paper.

Source: WHO/UNAIDS 2000: "Key Elements in Care and Support" (draft working document) as cited by Lamptey, P.R., Zeitz, P., Larivee, C. (Eds.) (2001) Strategies for an Expanded and Comprehensive Response (ECR) to a National HIV/AIDS Epidemic. Draft of July 10. MODULE 6: Technical Considerations of an Expanded and Comprehensive HIV/AIDS Response. Family Health International (Washington, D.C.) 
Appendix: B Page 2 of 3

\section{Table 1: Potential Target Groups (PTG) for HIV/AIDS Interventions and Activities}

\begin{tabular}{|c|c|}
\hline Activity/Intervention & Potential Target Group \\
\hline $\begin{array}{l}\text { School Youth interventions } \\
\text { Out of school youth }\end{array}$ & $\begin{array}{l}\text { Male and female youth enrolled in primary schools (age 6-11) } \\
\text { Male and female youth enrolled in secondary schools(12-16) } \\
\text { Male and female youth aged 6-11 not enrolled in schools } \\
\text { Male and female youth aged } 12-16 \text { not enrolled in schools }\end{array}$ \\
\hline Sex worker interventions & Sex workers in urban are as \\
\hline $\begin{array}{l}\text { Strengthening public sector } \\
\text { condom distribution }\end{array}$ & $\begin{array}{l}\text { Protection by condoms for all casual sex acts and of sex acts in } \\
\text { regular partnersfips (proportion of sexacts in regular partnersfips } \\
\text { set at } 2 \% \text { for the analysis) }\end{array}$ \\
\hline $\begin{array}{l}\text { Condom social marketing } \\
\text { (including female condom) }\end{array}$ & $\begin{array}{l}\text { Protection by condoms for all casual sex acts and proportion of sex } \\
\text { acts in regular partne rsfips (proportion of sex acts in regular } \\
\text { partnerships set at } 2 \% \text { for the analysis) }\end{array}$ \\
\hline $\begin{array}{l}\text { Strengthening } \mathcal{S} \mathcal{T} I \\
\text { services }\end{array}$ & $\begin{array}{l}\text { Men (15-49) with curable symptomatic } \mathcal{S} I \text { Is and access to health } \\
\text { services } \\
\mathcal{N} \text { (on-pregnant females (15-49) with curable symptomatic STIs and } \\
\text { access to health services } \\
\text { Pregnant women with syphilis and access to health services }\end{array}$ \\
\hline $\begin{array}{l}\text { Voluntary counselling and } \\
\text { testing }(\mathcal{V} C \mathcal{T})\end{array}$ & Current sexually active population \\
\hline Workplace interventions & $\begin{array}{l}\mathcal{H} I \mathcal{V} \text { prevention activities: all males and females in formal mployment } \\
\mathcal{S} \mathcal{T} I \text { treatment: same groups as those for strengthening } \mathcal{S} I \text { se rvices, } \\
6 \text { ut limited to workplaces that have } \mathcal{S} \mathcal{T} I \text { treatment. } \\
\text { Condom distribution: the number of sex acts requiring a condom (set at } \\
100 \% \text { causal and } 2 \% \text { of regular partnerships) for those in formal } \\
\text { employment }\end{array}$ \\
\hline $\begin{array}{l}\text { Strengthening 6lood } \\
\text { transfusion services }\end{array}$ & Units of blood used in transfusions \\
\hline Prevention of $\mathcal{M T C} \mathcal{T}$ & $\begin{array}{l}\text { Screening }(\mathcal{V C T}): \text { Pregnant women } 15-49 \text { with access to ante-natal } \\
\text { services. } \\
\mathcal{A R V} \text { treatment for pregnant women testing positive and formula for } \\
\text { infants. }\end{array}$ \\
\hline Mass me dia & National campaigns for entire country \\
\hline Palliative care & For $\mathcal{P L W} \mathcal{H A}$ who are symptomatic \\
\hline $\begin{array}{l}\text { Clinical manage ment for } \\
\text { opportunistic illness }\end{array}$ & For $\mathcal{P L W} \mathcal{H} \mathcal{A}$ with access to he alth services \\
\hline Home-based care & For $\mathcal{P} \mathcal{L W} \mathcal{H A}$ with access to health services \\
\hline Clinical care for children & $\begin{array}{l}\text { Includes palliative care for all children who are } \mathcal{H} I \mathcal{V} \text { positive and } \\
\text { symptomatic, and clinical care for children who are } \mathcal{H} I \mathcal{V} \text { positive and } \\
\text { symptomatic with access to health services }\end{array}$ \\
\hline $\begin{array}{l}\text { Prevention of } O \mathrm{Is} \\
\text { (cotrimoxazole and } \mathcal{T} \mathcal{B} \\
\text { preventive the rapy) }\end{array}$ & For $\mathcal{P} \mathcal{L W} \mathcal{H A}$ who are symptomatic and have access to health services \\
\hline Support for orphans & All $\mathcal{A} I D S$ orphans less than 15 years old \\
\hline $\begin{array}{l}\text { Psycho-social support and } \\
\text { counselling }\end{array}$ & For $\mathcal{P} \mathcal{L W} \mathcal{H A}$ who are symptomatic \\
\hline 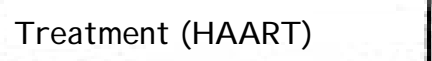 & For $\mathcal{P L W} \mathcal{H A}$ who are symptomatic and have access to health services \\
\hline
\end{tabular}




\section{Table 2: Care and Support Activities, by Need, Complexity and Cost}

\begin{tabular}{|c|c|}
\hline \multicolumn{2}{|c|}{ Care and Support Activities, by $\mathcal{N e e d , ~ C o m p l e x i t y ~ a n d ~ c o s t ~}$} \\
\hline $\begin{array}{l}\text { Essential } \\
\text { activities }\end{array}$ & 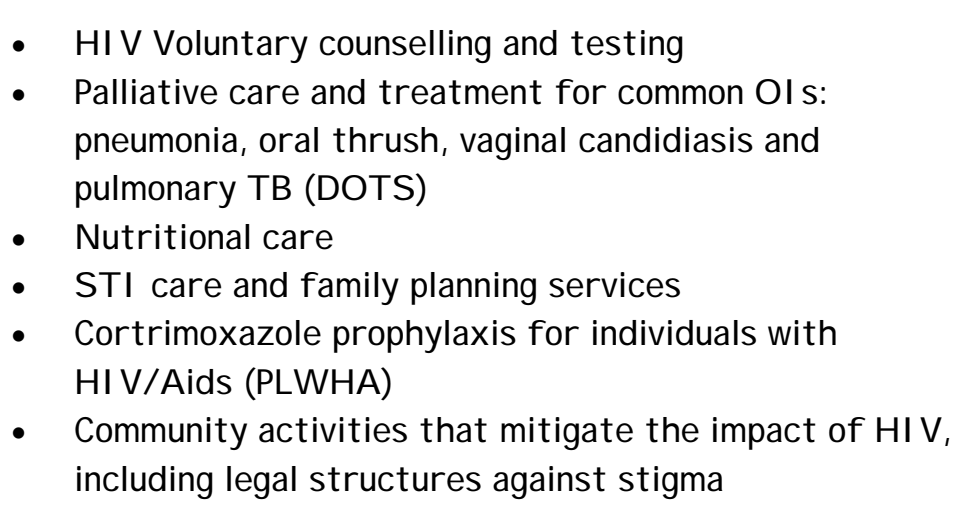 \\
\hline $\begin{array}{l}\text { Interme diate } \\
\text { complexity and } \\
\text { cost }\end{array}$ & 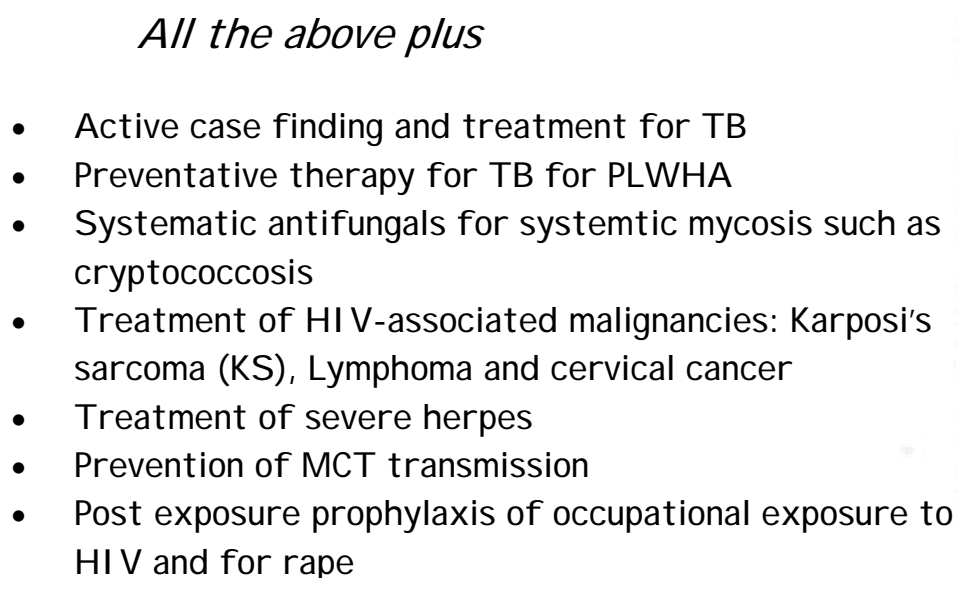 \\
\hline $\begin{array}{l}\text { High complexity } \\
\text { and cost }\end{array}$ & $\begin{array}{l}\text { All the above plus } \\
\text { - } \quad \text { Triple antire trovial the rapy } \\
\text { - Diagnosis and treatment of difficult to diagnose } \\
\text { OIs and expensive to treat OIs such as drug } \\
\text { resistant } \mathcal{T} \mathcal{B} \\
\text { - } \\
\text { - } \text { Public services to reduce the economic and social } \\
\text { impacts of living with } \mathcal{H} I \mathcal{V} / \mathcal{A} S\end{array}$ \\
\hline
\end{tabular}




\section{Appendix: C}

Case Study, International HIV/AIDS Alliance, 1993 - 2000 Jeff O'Malley

The development of the International HIV/AIDS Alliance since its foundation in 1993 illustrates a continual process of scaling up through a number of the strategies identified in the paper. For this reason, and also because different approaches to HIV are also illustrated through the Alliance experience, this substantial case study is included as an appendix in its own right.

The Alliance was formally established in December 1993 and its first staff person took up responsibilities in January 1994. The initiative had begun in 1991 with a series of discussions among a group of individuals from northern donor agencies about how to increase support to, and therefore the coverage of, community responses to AIDS in developing countries. These initial discussions were followed by a series of needs assessments, project design activities, and two country-level pilot projects leading to a proposal for support to create "The International Alliance Supporting Community Action on AIDS" (to be renamed the "International HIV/AIDS Alliance"). The following quotation from the original proposal for support captures much of the thinking that informed the Alliance's creation:

Effective HIV/AIDS prevention, care and community support programmes require changes to individual attitudes and sexual behaviour which can only be brought about by a sustained and massive mobilisation of communities which, whilst small individually, together add up to a large-scale response. To effect this, financial and technical resources have to be made available at village and neighbourhood level on a vast scale and used to supplement existing community resources to implement programmes in education, condom distribution and $S \mathcal{T D}$ prevention, and in innovative care and community support programmes. The intention of the International Alliance Supporting Community Action on AIDS (IASCAA), is to support nongovernmental organisations to implement both small- and large-scale interventions which can have a rapid and significant impact on the spread and effects of AIDS. ${ }^{50}$

${ }^{50}$ Cliff Lenton, "The International Alliance Supporting Community Action on AIDS (IASCAA) Proposal for Support", 12 November 1993, pp 3 -4, 


\section{Appendix: C Page 2 of 17}

The Alliance was established with a clear strategy to act as a catalyst and to support action on HIV/AIDS by other organisations - NGOs and CBOs operating locally in developing countries. The core function was to identify or establish national mechanisms (later to be called "linking organisations") and provide them with technical and financial support. These linking organisations would support NGOs already working on HIV/AIDS in their country to scale up; catalyse new groups to begin responding to AIDS for the first time; and support both those new to HIV/AIDS and those already engaged through providing organisational and technical support. This reflected a commitment to community action by NGOs and CBOs, (later changed to community action by local NGOs and CBOs), rather than a commitment to expanding any particular type of programme or intervention.

From the Alliance's inception it was anticipated it would support the expansion of these other organisations through "organisational expansion", as well as through "mainstreaming in development" 51 .

The key target adopted for the first three years was to establish and support "NGO support mechanisms" in 14 countries with an anticipated funding level of approximately US $\$ 21$ million of unrestricted funds. These would be channelled to a central fund, approximately $80 \%$ of which would be invested in programme expenditure, for which the Alliance itself would develop technical criteria. The funding would cover international and local technical support, linking organisation running costs and grants to NGOs and CBOs. Costs needed to provide technical support from an international base were estimated, but no projection was made of the relative cost of supporting linking organisations vis-à-vis investment in local implementation of prevention, care and impact mitigation activities. No targets were articulated concerning either the number of people to be reached, or the quality of activities to be supported.

The needs for organisational and technical support to linking organisations were far greater than initially anticipated. At first this was because the Alliance's model of supporting an indigenous organisation to raise funds, disburse funds and provide technical support was unusual not just in HIV/AIDS work, but development work overall. Support needs then increased with increasing pressure on performance and deviation from the original programme design (more donor restrictions requiring more complicated finance and programme

\footnotetext{
51 "The roles of the national mechanisms will be to help organizations already engaged in HIV/AIDS ... to expand and scale up their work....and to reach out to a wide variety of private sector groups not yet engaged in the prevention and management of the epidemic", Lenton, op cit, p. 3
} 
systems, more detailed requirements for monitoring and evaluation data, more emphasis on programme quality in addition to quantity).

The need for in-country technical support was recognised when the Alliance was established, but local technical support costs were not clearly differentiated from the costs of in-country service delivery. In the Alliance's initial business plan, no explicit acknowledgement was made of the very clear cost difference between supporting successful and capable organisations to expand, as opposed to convincing and supporting organisations with very little HIV/AIDS experience to begin, improve and expand work on HIV/AIDS.

Just over $10 \%$ of the anticipated funding was committed at the start of the programme. With further fundraising (a task not initially anticipated in the Alliance's business plan), an additional $\$ 9$ million was raised over the initial threeyear period. About $60 \%$ of this was restricted, with the majority of the restrictions requiring marked deviations from the Alliance's original plans. From the perspective of the Alliance's Executive Director, the Alliance's most significant mistake in its first two years was its failure to convene stakeholders to agree a new business plan and new targets in light of real commitments and restrictions rather than original projections and hopes.

\section{Evolution of the Alliance's approaches}

\section{The start-up period: Alliance development from 1994 to 1996}

By mid 1996, the Alliance had worked with local partners to conduct national assessments of the NGO/CBO sector's response to HIV/AIDS, and the potential to expand and improve that response, in ten countries: Philippines, Bangladesh, Sri Lanka, Pakistan, Morocco, Senegal, Burkina Faso, Tanzania, Mozambique and Ecuador. To some degree this mix of countries reflected a strategy to test the Alliance's approach in both low and high prevalence settings and in countries with weaker and stronger NGO sectors; to establish a programme base in each of Asia, Africa and Latin America; and to avoid particularly complex settings such as India or Brazil in the start-up period. To a great degree, however, the mix of countries reflected donor restrictions on how funds could be used, including geographical restrictions which dictated, for example, the choice of countries in West Africa and the exclusion of the Caribbean. Funds covered assessments in Tanzania and Mozambique, but were insufficient for programme development. Programme development was suspended in Pakistan because there was no suitable in-country partner and the national government did not strongly support 
the initiative. The Alliance's first seven country programmes were thus developed in Ecuador, Senegal, Burkina Faso, Morocco, Sri Lanka, Bangladesh and the Philippines.

The Alliance's scale-up strategy finged on two levels of action,

- Community-level responses to prevention, care and (to very limited degree) alleviating the impact of $\mathcal{H} I \mathcal{V} / \mathcal{A} I \mathcal{D S}$

- National-level $\mathcal{N G O / C B O}$ support.

Community responses were developed in more than 50 sites. In each of these, a participatory community assessment was undertaken, leading to project design and community mobilisation. In general, these assessments were highly successful, both as a prelude to successful project design and as a means to cultivate community ownership. Following assessment, programme and project design included peer education programmes for young people, participatory prevention (largely adapted from the "Stepping Stones" programme of participatory community discussion groups), and interactive awareness raising activities. Self-help groups were also created and supported.

During 1994-1997, the Alliance also had limited experience of supporting pilot projects in areas such as peer education in particularly vulnerable populations (men who have sex with men, sex workers) NGO based sexual health delivery, NGO based care and support services and intensive community development with key vulnerable populations. In the start-up period, there was little or no involvement in a number of other possible programme areas related to HIV/AIDS, such as condom social marketing, in-patient care, mass media harm reduction activities and blood safety programmes.

National level NGO/CBO support included assessments of national $\mathrm{NGO/CBO}$ sector strengths and weaknesses, the establishment and management of grant making facilities, the development of a limited range of methodologies to identify and respond to NGO/CBO technical support needs, and partnership building and external relations for partner organisations. Little or no attention was paid in this period to some other NGO/CBO support functions, such as fundraising, either for implementing $\mathrm{NGOs/CBOs} \mathrm{or} \mathrm{linking} \mathrm{organisations:}$ development of skills in building partnerships; policy analysis and advocacy; formal operations research; epidemiological surveillance; production and/or dissemination of training materials and educational materials; or maintenance, development and promotion of resource centres or libraries. 
After two years of operation a donor-organised external evaluation team reviewed the Alliance's programme. The evaluation's broad conclusions were positive:

The Mission's unequivocal answer to the central question of the Evaluation is therefore that if donors wish to continue to develop the civil society response to the epidemic in the developing world, they should continue to fund the Alliance. ${ }^{52}$

By $1996,86 \%$ of the Alliance's expenditure, a higher proportion than originally anticipated, was allocated to technical assistance and funding for local programmes. In a total of seven countries, 220 organisations had received financial and technical support for HIV/AIDS work, 200 of which were general health or development organisations rather than HIV/AIDS groups. Although this scale of activity was obviously less than initially projected, most stakeholders recognised that it was a significant achievement, particularly in view of the reduced funding.

It was acknowledged that it was too early and too difficult to assess the impact of this work on the epidemic, but both the Alliance's own evaluation and other evaluations indicated that promising approaches were being promulgated at a community level, as reflected in these citations from USAID and EU documents:

When there is uncertainty about what contextual changes are appropriate or most significant, a valid strategy is to enable the people who are closest to the problem to decide, to experiment with different approaches, and to see what works. This is the methodological approach taken by the International HIV/AIDS Alliance, which offers one example of kow to develop contextual interventions in $H I V / A I D S$ prevention and care. ${ }^{53}$

Despite these overall positive assessments, however, the Alliance's external evaluation and other analyses and discussions pointed out some problems and

\footnotetext{
52 "Joint Donor Evaluation of the International HIV/AIDS Alliance", October 1996, p. 5

53 "Process evaluation of the AIDS Technical Support Project" of USAID, July 1996, pp $79-80$.
} 


\section{Appendix: C Page 6 of 17}

controversies with the Alliance's approach and performance. The three most significant were:

- Concern that a greater proportion of expenditure than anticipated was absorbed in support and operational costs of linking organisations, and that in some cases this exceeded the funds allocated to local NGOs and CBOs to carry out activities in prevention, care and impact mitigation. Different stakeholders cited different reasons for this. The Alliance external evaluation team believed that the Alliance had over-emphasised NGO support capacity as a goal, rather than seeing such capacity as a delivery cost. The Alliance secretariat countered that developing such capacity was a legitimate goal in itself, and that, as country programmes inevitably have a certain level of fixed costs, under-funding would increase the proportion of expenditure on "NGO support" vis-à-vis implementation.

- The international donor landscape had evolved considerably over the Alliance's first two years, with significant changes including a strong trend to devolving funding decisions to missions or delegations based in developing countries; the elimination of many HIV/AIDS specific budgets following the Cairo Conference consensus on integrated approaches to sexual and reproductive health; and the creation of UNAIDS to replace WHO/GPA. Together, these changes considerably challenged the Alliance's structure and model.

- It was unlikely that the Alliance itself could increase its operating budget significantly. Nevertheless, there was strong pressure to pay more attention to quality and impact of interventions and responses, and a strong desire for the Alliance to play an increased role in learning and influencing others. 


\section{Transition phase: 1997}

A new scale-up strategy was developed by the Alliance and endorsed by its donors in February 1997. Key features of this new strategy included ${ }^{54}$ :

- An emphasis on the Alliance's technical rather than financial contributions to scaling up community responses to AIDS. This led to a strategy of influencing existing initiatives (that already had secure funding) rather than supporting new programmes.

- An emphasis on catalysing rather than directly sustaining expanded responses, and reducing support over time

- A commitment to experiment with new methodologies - development and testing of tools, operations research, advocacy - to influence practice indirectly rather than directly

- New goalposts for performance measurement: mobilising new responses; improving the quality of responses; building capacity of NGOs and NGO support organisations; and learning and influencing.

The new strategy was based on the implicit assumption that, rather than being concerned about finding a global mechanism to deliver funds to community level, donors and multilateral agencies now had a growing appreciation of the Alliance's knowledge and experience of leveraging funds and improving community responses to HIV/AIDS. The Alliance's value-added was thus to be in learning, influencing and leveraging rather than funding.

With reference again to de Jong's proposed typology in this publication, the Alliance's post-1997 strategy depended strongly on "diffusion" approaches and explicitly introduced "influencing policy/legislation". Commitment was maintained to "catalysing other organisations", but with the emphasis on "catalysing" rather than "supporting in an ongoing manner". This distinction suggests that de Jong's "Strategy 2: Catalysing Other Organisations" might usefully be separated into two distinct strategies.

\section{Scaling Up: 1997-2000}

The Alliance's original design was informed by needs assessments, consultations and pilot projects with key developing country partners. In contrast, the strategies adopted in February 1997 to scale up impact were the result of

54 “The International HIV/AIDS Alliance Proposal for Support 1997 - 1999”, 28 January 1997 


\section{Appendix: C Page 8 of 17}

external evaluation processes and extensive consultations with donors. There was no formal or informal consultation with developing country partners, who almost certainly would have expressed concern about the implications. Linking organisations were informed of the Alliance's new goals and strategies and were required to change some of their own approaches to monitoring and evaluation but most key linking organisation staff and volunteers did not contribute to the shift in strategy and perhaps never fully understood it.

Depending on one's organisational perspective, the Alliance's strategic shift in 1997 could be represented as "more with less" or "less with more". For donors, by and large, the strategy offered "more with less": more countries influenced, more NGOs and CBOs influenced, more tangible products such as toolkits and operations research findings. For the Alliance's existing partners, the opposite held true: the Alliance secretariat and its budget grew, while funding for any particular country programme tended to remain steady or declined. Steady or declining funds from the Alliance accompanied increasing pressures: to implement particular kinds of activities with particular populations; to pay much more attention to strengthening quality and evaluation; to document and market success-stories; and to fundraise.

In 1998, within a year of adopting the new strategy, one of the Alliance's largest donors (USAID) introduced a new requirement for funding - to measure the number of people being reached. Although relatively straightforward, the measurement was at odds with the explicit goals of the new strategy and introduced conceptual difficulties to performance measurement and "ownership" (People reached with services financed by the Alliance? People reached by organisations influenced by the Alliance? People reached effectively or people reached at all?) More positively, despite redesigning the Alliance's overall strategy to increasing impact at low cost, donor funding increased considerably from 1997 to 2000 .

During this period the Alliance actively discouraged investment in broad public awareness raising, programmes designed to serve the general public, and income generation activities. In contrast, there was a growing awareness of the importance of concurrent community action to address supply of services and commodities for prevention and care and to stimulate demand for these services, while taking account of context issues such as gender roles and stigma. More support was therefore channelled into following up discussion groups with outreach programmes, home care initiatives which integrated prevention and referrals, and the promotion of the involvement of people with HIV/AIDS. Gender issues such as violence against women and creating a sense of responsibility 


\section{Appendix: C Page 9 of 17}

among men and boys, and STI service delivery including condom promotion were all emphasised. Peer education and community development activities with marginalized communities key to the dynamics of the epidemic were encouraged. New pilot activities included harm reduction and prevention of sexual transmission with people who inject drugs, community mobilisation linked to voluntary testing and counselling, and a response to the needs of orphans and vulnerable children. Links between care, prevention and impact alleviation began to be emphasised, and community based advocacy took a higher priority.

There have been some seemingly contradictory pressures on the Alliance from its donors - pressure to influence linking organisations to influence NGOs and CBOs to reach more people, pressure to increase quality of activities at the community level, and pressure to increase "influencing" and "advocacy" functions based on community lessons. The tension between these goals had resulted in many positive changes and an increase in the Alliance's impact. Most notably at the level of community implementation, a healthy balance has been found between intensive prevention and care work with populations key to epidemic dynamics, broader awareness activities, and partnerships with governments to reach larger numbers of vulnerable people, especially young people.

\section{Results to date}

From 1994 to 1999, mostly after the strategic shift in 1997, the Alliance raised approximately $\$ 23$ million from international donors to support its work. The target funding for its first three years was thus achieved over six years. Donors also provided $\$ 5$ - $\$ 6$ million directly to linking organisations or partner organisations. By the end of 2000, the Alliance had worked with NGOs or CBOs from 25 countries, and was supporting ongoing NGO/CBO support programmes in 13 countries. The linking organisations had provided technical and financial support to over 1,520 projects implemented by over 950 different NGOs and CBOs, about $85 \%$ of which were not AIDS groups - in fact about $70 \%$ of them became intensively involved in AIDS for the first time through the Alliance's support. Many of the linking organisations also became key institutions influencing their national policy environments

The Alliance has not had a comprehensive external evaluation since 1996, but evaluations of particular initiatives and ongoing monitoring point to the achievements of its current hybrid approach: 


\section{Appendix: C Page 10 of 17}

- In 1999 alone, almost 1.5 million people were beneficiaries of prevention, care and/or impact-mitigation programmes or services supported by the Alliance, at a cost of about US $\$ 2.50$ per person. Over 325,000 volunteers, mostly young people, were involved in intensive activities as "peer educators" or "care givers" in their communities. It is estimated that over 8 million people were reached in 1999 through Alliance-supported mass media and IEC initiatives.

- In depth evaluations of particular initiatives show these programmes as making a real difference in people's lives.

- An evaluation of a home care programme in Cambodia in early 2000 concluded, "It is reducing the suffering of people living with $\mathcal{H} I \mathcal{V} / \mathcal{A} I \mathcal{D S}$ $(\mathcal{P L H A})$ and improving the quality of their lives and the lives of their families and caregivers; it is increasing understanding of $\mathcal{H} I \mathcal{V} / \mathcal{A} I \mathcal{D S}$ and reducing discrimination against $\mathcal{P} \mathcal{H} \mathcal{A}$ in the community; it is helping to empower some of the poorest and most disadvantaged individuals and families in the community".

- An evaluation of prevention activities in Senegal in 2000 concluded, "ANCS has achieved remarkable results with relatively modest means ..ANCS has contributed significantly to the HIV prevention and care response in Senegal".

Perhaps most notably, the Alliance's shift in strategy in 1997 allowed it to maintain (and even expand to some degree) the development and support of incountry NGO support systems which in turn assist local NGOs and CBOs which in turn organise and facilitate prevention, care and impact-mitigation responses. These activities, however, are no longer the sole or even primary criteria against which the Alliance's performance is measured.

\section{Evolving ideas about scaling up}

The Alliance was established within a rhetoric of "scaling up community responses to AIDS". What did that mean to different stakeholders? If more attention had been paid to the phrase, more contradictions in approach amongst and within different sets of stakeholders would have been identified. There was a 


\section{Appendix: C Page 11 of 17}

broad agreement at the time that "scaling up" meant doing more, and in particular having NGOs and CBOs do more. There was relatively little explicit discussion at the time amongst NGO/CBO actors - or their supporters - of population-level impact, of priorities amongst different countries, of priorities amongst different technical approaches, or of how priorities might change at different phases of the epidemic. All of these are now understood as key issues.

In 1991 and 1992, many donors were concerned about investing available HIV/AIDS funds through the "multi - bi" channels of WHO/GPA, and were looking for a new mechanism to absorb and disburse resources. Although this situation had already started to change by the time of the Alliance's formal establishment in late 1993, it deeply informed the logic of the Alliance's creation. It is important to note that now, years later, a number of donor agencies seem to be once again concluding that scaling up means spending more money at community level. Hopefully some lessons have been learned.

In addition to Northern donors, the other key set of stakeholders involved in the Alliance's establishment were (mostly Southern) NGO and CBO activists. Amongst the most vocal and visible actors in the community response to AIDS, there was already some genuine debate in the early 1990s about what to do and how to do it. Key features of the debate at the time included pressure from community groups for more attention to care as opposed to a singular focus on prevention; more attention to marginalised populations and in particular their human rights; and debate about the relative merits of "AIDS-focused" versus "integrated" responses. NGOs and CBOs also wanted a larger share of the available resources for HIV/AIDS work, in particular vis-à-vis investments in national AIDS programmes. More recently, a similar consensus has emerged amongst many local NGO and CBO activists, but vis-à-vis international NGOs rather than vis-à-vis national AIDS programmes. Then, as now, it was rare to find individual NGOs or CBOs making a case for different types of response (for example, condom promotion versus youth-abstinence clubs), or between different levels of response (for example, community-level services versus national awareness campaigns), or between different types of actors (for example, national NGOs versus national government agencies). Part of the Alliance's function has been to engender reflection and debate on these issues at a national level, although consensus on such priorities among NGOs and CBOs is probably unlikely to be reached.

In retrospect, one of the most striking elements of the discourse around the Alliance's creation was the focus on the non-governmental sector, differentiated from the government sector, as opposed to, for example, community and district 


\section{Appendix: C Page 12 of 17}

responses differentiated from national or regional responses. Consciously or unconsciously, the Alliance brought together a set of donors who were looking to move beyond WHO/GPA and its support to National AIDS Programmes (governmental, health-focused rather than multisectoral, and largely policyorientated rather than operational), with NGOs and CBOs looking to access more resources for their operations. (The original design of the Alliance did not differentiate between local CBOs or NGOs and international NGOs - this was an added emphasis introduced by the Alliance's Trustees and management in 1994.) Key stakeholders largely missing from the Alliance's original design included people living with HIV themselves, as well as national AIDS programme managers and national governments.

Over the period since the Alliance's establishment, perceptions of "good practice" have been constantly evolving, informed by practice and experience as well as shifting theoretical paradigms. Some generalisations can be made about how "scaling up" is viewed at different levels.

About 1,000 participatory community assessments were conducted with Alliance support from 1994 to 2000. Depending on the priorities of the Alliance partner and the technical and strategic biases of technical support providers, assessment methodologies varied: focused just on needs, or also on resources and hopes; embracing a broad range of community priorities, or focusing on HIV in the context of gender, sexuality and sexual health; working with key populations such as sex workers, or working with neighbourhoods or villages as a whole $e^{55}$. In general, however, individuals and communities tend to see HIV prevention as a medium- or long-term issue: in low prevalence countries, a threat that may emerge in years to come, or in higher-prevalence countries, an important issue for a new generation. A wide range of other issues have a higher short-term profile, from helping young people get jobs to reducing gender violence to maintaining or achieving clean water supplies. The most dominant theme emerging from prevention-focused assessments has therefore been scoping out rather than scaling up - that is, linking HIV to other contextual and development issues, such as gender relations and poverty.

The active involvement of people living with HIV in the process of participatory community assessment and programme design helps to keep results focused on both care needs and the reality of vulnerability to infection. Recently, affected communities have drawn attention to the importance of equity in access to

\footnotetext{
${ }_{55}$ Many of these experiences and methodologies have now been consolidated into a recommended approach by the Alliance, in the toolkit "Getting Started", 2001.
} 
treatment, especially equity with Northern communities' access to anti-retroviral treatment. The stark reality of how few people with HIV have access to any care at all creates a tremendous pressure for scaling up action on AIDS.

From an organisational perspective, community based associations and smaller community-focused NGOs may share an interest in "scoping out" but are often also interested in reaching more people through expanding their own activities, especially to nearby communities, districts or neighbourhoods. Despite this commonality, however, larger NGOs - local, national and international - have quite diverse priorities for increased action on HIV/AIDS, embracing the full range of scale up strategies identified in de Jong's paper. It is rare indeed for an NGO of any size to conclude that it is doing enough, or that it has enough resources.

Not surprisingly, national AIDS programmes (like NGOs) also share the perception that action on HIV/AIDS needs to be scaled up, and the belief that this requires additional resources, but their priorities for scaling up NGO and CBO action vary. Some place a strong priority on an institutional and geographic diversification of support to NGOs while maintaining a belief in "targeted approaches" for particular populations. Others very clearly identify priority districts for increased action as well as functionally supporting particular NGOs to grow in expertise, coverage and resources. Still others appear to argue for increased support to and engagement of community groups, while challenging strong roles for national or international NGOs. These distinctions typically reflect both legitimate differences in priorities in particular places (regarding how and why to scale up action on AIDS), and inevitable differences in politics both within NGO sectors, and between NGOs and governments.

Donor thinking on "scaling up" has also evolved. Rhetoric about "leveraging other resources" or "ensuring sustainability" is still a common feature in much donor discourse - this may be influenced by political concerns. There is also a great deal of recent interest and commitment to having an impact on the epidemic rather than simply "learning" and "piloting" initiatives. Although some donors like DFID place more emphasis on partnerships with governments and others like USAID on partnerships with NGOs, most are more conscious than in the past of how their investments fit in to other activities to achieve a critical mass of coverage. In addition to paying attention to measuring the gross numbers of people reached, there is a strong trend to pay attention to quality, synergies between different approaches, and the potential of partnerships, as well as to impact. This highlights differences of opinion on issues such as the relative merits of rapidly rolling out a limited number of key interventions as opposed to a "programme approach" emphasising a package of responses; the relative priority 


\section{Appendix: C Page 14 of 17}

of working in low versus high prevalence countries; and the relative merits of concentrating limited resources on "core transmitters" versus reaching a new generation of vulnerable young people.

The Alliance's unusual structure of a "two tier umbrella programme" has meant that tensions and synergies between local actors (implementing CBOs and NGOs) and national actors (linking organisations and their donors) are almost always mirrored between national actors (linking organisations) and international actors (the Alliance secretariat and its donors). In almost all cases, the Alliance and its partners have achieved their most notable results in the balance or compromise between competing pressures.

One key tension has been between "community led" and "evidence based" - or "bottom up" and "top down" - approaches. The Alliance began with a strong bias towards community led approaches, but through a combination of donor pressure and internal decisions, began to promote more aggressively what it perceived as good practice (including good practice in being community led!). The strongest and most sustainable initiatives are rooted in processes such as participatory community assessment and national-level decision-making about priorities and strategies, informed by "expert" advice on matters such as key populations for epidemic dynamics, and effective strategies. Balancing these perspectives and processes is slower and more intensive than either a straightforward replication of standard interventions or a laissez-faire approach of funding what the community wants to do.

Another tension has been between "targeted" and "general population" approaches, or "intensive and expensive" approaches versus "broad and cheap". A key lesson from the Alliance's programming experience has been the importance of paying attention to key populations for epidemic dynamics, especially in concentrated epidemics in low prevalence countries. This does not mean ignoring other populations; it is important to recognise that one community impinges on another's choices and options, as well as to respond to multiple and shifting community identities and behaviour patterns. This again points to a view of scaling up that synthesises intensive services and programmes with and for key populations, and working more cheaply with broader communities for awareness, against stigma and to ensure referrals.

Finally there has been a clear tension for the Alliance between intensifying programmes in a smaller number of countries and having some involvement in a larger number of countries and regions. Funding pressures have had more influence than programme strategy on this. It seems reasonable to speculate 
that costs per person reached would be significantly lower had the Alliance worked in fewer countries and languages with the same level of overall funding. The politics and processes of organisational growth and fundraising are central to any strategy to achieve more impact and it is difficult to say whether the Alliance could have achieved more with a more focused strategy, or if its attempts to respond to perceived donor pressures and funding availability were essential to its survival and growth, and to its ability to contribute overall to the scale-up process. 
Table 1: Main community responses supported by the Alliance in the start-up phase, 1994-96

\begin{tabular}{|c|c|c|c|}
\hline Activity & With whom? & Outcomes & Comments \\
\hline $\begin{array}{l}\text { Participatory } \\
\text { community assessment }\end{array}$ & CBOs at community level & $\begin{array}{l}\text { - led to project and programme } \\
\text { design, } \\
\text { - sensitised key } \\
\text { populations/stakefolders, } \\
\text { - begancommunity mobilisation } \\
\text { process }\end{array}$ & $\begin{array}{l}\text { Generally very successful-led to successful } \\
\text { project design and "community ownership" }\end{array}$ \\
\hline $\begin{array}{l}\text { Peer education } \\
\text { programmes for } \\
\text { young people }\end{array}$ & $\begin{array}{l}\text { Young people in and out of } \\
\text { school }\end{array}$ & $\begin{array}{l}\text { - Large numbers of young people } \\
\text { trained in } \mathcal{H} I \mathcal{V} \text { basics, } \\
\text { prevention and referral for } \\
\text { further information and } \\
\text { services } \\
\text { - Condoms demonstrated }\end{array}$ & $\begin{array}{l}\text { Successfully promoted and sustained be haviour } \\
\text { change in peer educators but } \\
\text { little impact beyond awarene } 4 \text { ss raising on wioder } \\
\text { groups on young people }\end{array}$ \\
\hline $\begin{array}{l}\text { Participatory } \\
\text { discussion groups }\end{array}$ & $\begin{array}{l}\text { Members of specific } \\
\text { communities, in age and } \\
\text { gender-specific discussion } \\
\text { groups, culminating in } \\
\text { common discussion group }\end{array}$ & $\begin{array}{l}\text { - } \quad \text { e bates and action planning on } \\
\text { HIV/AIDS } \\
\text { - Change in attitude and } \\
\text { behaviour at community level }\end{array}$ & $\begin{array}{l}\text { Highly effective but expensive and requires } \\
\text { extensive training/skills building }\end{array}$ \\
\hline $\begin{array}{l}\text { Linking these groups } \\
\text { to community } \\
\text { development activities }\end{array}$ & As above & $\begin{array}{l}\text { - Income generation } \\
\text { - } \quad \text { Adult literacy }\end{array}$ & Relevance and impact not clear \\
\hline $\begin{array}{l}\text { Interactive aware ness } \\
\text { raising activities }\end{array}$ & $\begin{array}{l}\text { General population: activities } \\
\text { such as neighbourhood } \\
\text { meetings, World } \mathcal{A} I \mathcal{D S} \text { Day } \\
\text { rallies, red ribbon folding, } \\
\text { pamphlet distribution }\end{array}$ & - Increased awareness of $\mathcal{H I} \mathcal{V}$ & $\begin{array}{l}\text { From } 1997, \text { scepticism about the value, but more } \\
\text { recently, recognition of importance where awareness } \\
\text { is low, to include young people and to create a } \\
\text { favourable environment for more focused activities }\end{array}$ \\
\hline $\begin{array}{l}\text { Creation of self-help } \\
\text { groups for people with } \\
\mathcal{H} I \mathcal{V}\end{array}$ & People with $\mathcal{H I} \mathcal{V}$ & $\begin{array}{l}\text { - } \quad \text { Peer psychosocial support } \\
\text { - } \quad \text { Treatment activism } \\
\text { - Income generation } \\
\text { - Succession planning activities } \\
\quad \text { for children }\end{array}$ & $\begin{array}{l}\text { "With this disease, the people who suffer the } \\
\text { most are the poorest...If we don't get together in } \\
\text { groups and find help and medicines, we don't } \\
\text { stand a chance", person with } \mathcal{H} I \mathcal{V} \text {, member of } \\
\text { EUDES in Ecuador }\end{array}$ \\
\hline
\end{tabular}


Table 2: Pilot Projects 1994-97

\begin{tabular}{|c|c|c|c|}
\hline Activity & With Whom? & Outcomes & Comments \\
\hline $\begin{array}{l}\text { Peer education with } \\
\text { specially vulne rable } \\
\text { populations }\end{array}$ & $\begin{array}{l}\text { Men who have sex with men } \\
\text { Sex workers }\end{array}$ & - $\quad$ Befiaviour change & If run well, particularly cost effective \\
\hline $\begin{array}{l}\mathcal{N G O} \text { based sexual he alt } \\
\text { service de livery and } \mathcal{H} I \mathcal{V} \\
\text { testing and counselling }\end{array}$ & $\begin{array}{l}\text { Sex workers } \\
\text { Attenders at reproductive } \\
\text { he alt } h / \mathcal{M C H} \text { clinics }\end{array}$ & $\begin{array}{l}\text { - } \quad \text { Pre and post-test counselling provided } \\
\text { - } \quad \text { TI counselling, diagnosis and } \\
\text { treatment } \\
\text { - Referrals to care facilities }\end{array}$ & $\begin{array}{l}\text { Particularly effective with specialist government } \\
\text { services eg Philippines services for sex workers } \\
\text { Less effective with } \mathcal{N G O ~ p r o v i d e d ~ R e p r o d u c t i v e ~} \\
\text { health or maternal/child health clinics in lower } \\
\text { prevalence countries }\end{array}$ \\
\hline $\begin{array}{l}\mathcal{N G O} \text { based care and } \\
\text { support services }\end{array}$ & $\begin{array}{l}400 \text { people with } \mathcal{A I D S} \\
\text { and } 5,000 \text { family } \\
\text { members and close } \\
\text { associates }\end{array}$ & $\begin{array}{l}\text { - Home care including } 6 \text { asic medical } \\
\text { care and prevention activities }\end{array}$ & $\begin{array}{l}\text { Cost about } \$ 20 \text { per person with } \mathcal{A} I \mathcal{D S} \text { per month } \\
\text { including start-up costs, with falling costs in later } \\
\text { years }\end{array}$ \\
\hline $\begin{array}{l}\text { Intensive community } \\
\text { development with key } \\
\text { vulne rable populations }\end{array}$ & $\begin{array}{l}\text { Sex workers } \\
\text { Adolescent men who have } \\
\text { sex with men } \\
\text { transvestites }\end{array}$ & $\begin{array}{l}\text { - } \quad \text { community organisation } \\
\text { - } \quad \text { buildingself-esteem }\end{array}$ & $\begin{array}{l}\text { Examples are I WAG-Davao on the Philippines and } \\
\mathcal{F A E S} \text { in Ecuador }\end{array}$ \\
\hline
\end{tabular}

Changes in 1997-2000 are outlined in the text. These included more emphasis care and support through home care, and a greater attention to the integration of care and support, prevention and impact mitigation. Pilot projects began to emphasise work with key vulnerable populations, the introduction of harm reduction concepts community mobilisation linked to children's issues and to voluntary testing and counselling, and initiatives against stigma and discrimination. In Zambia, the Alliance joined a wide range of other partners in the "Zambia Integrated Health Project" a multi-issue health initiative. 


\section{Appendix: D List of Participants and References}

Paurvi Bhatt

Director

Step Forward International

HIV Programs

Abbott Fund

1710 Rhode Island Avenue, NW

Suite 500

Washington DC 20036

USA

Phone: 202-296-8561

Fax: 202-466-8386

paurvi.abbot@abbottfund.org

(At the time of the seminar Paurvi

Bhatt was with USAID)

Ian Campbell
International HQ
Salvation Army
Queen Victoria Street
London EC4
UK
ian.Campbell@salvationarmy.org

\section{Chris Castle}

Horizons

4301 Connecticut Ave NW

Suite 280

Washington DC 20008, USA

Phone: 202-237-9412

Fax: 202-237-8410

ccastle@pcdc.org

\section{Phyllis Craun-Selka}

PACT

Washington DC

USA

Phone: 202-466-5666

pcraunselka@pacthq.org

\section{Jocelyn DeJong}

IDPM

University of Manchester

Crawford House

Oxford Road

Manchester M13 9GH

UK

Phone: 44-161-275-2800

Fax: 44-161-273-8829

jocelyn.dejong@man.ac.uk

\section{Thom Eisele}

Tulane University

1440 Canal St Suite 2200

New Orleans LA 70112

USA

Phone: 504-584-1978

teisele@tulane.edu

thomeisele@hotmail.com

\section{Geoff Foster}

Director

Family AIDS Caring Trust

PO Box 970 Mutare

Zimbabwe

Phone: 263-20-61648

Fax: 263-20-65781

gfoster@healthnet.zw

fact@mango.zw

gfoster@syscom.co.zw

\section{Naomi Gonahasa}

TASO Jinja Centre

PO Box 577

Jinja, Uganda

Phone: 256-43-121-094

Fax: 256-43-121-322

tasojin@swiftuganda.com 


\section{Gail Goodridge}

Deputy Director IMPACT

FHI, 2101 Wilson Blvd

Suite 700

Arlington VA 22201, USA

Phone: 703-516-9779

ggoodridge@fhi.org

\section{Baba Goumbala}

Executive Secretary

ANCS

Villa No 1920-Sicap

Liberte III

BP 10297 Dakar, Liberte, Senegal

Phone: 2218-247-134

Fax: 2218-247-135

ancs@enda.sn

\section{Robert Grose}

DFID

94 Victoria Street

London SW1, UK

r-grose@dfid.gov.uk

\section{Annelise Hirschmann}

Executive Director

ASI (AGPCS)

Guatemala

Phone: 502-220-8506/08/09

Fax: 502-251-6531

asiagpcs@guate.net

annie salazar@yahoo.com

\section{Dixter Kaluba}

Club Development Officer

Family Health Trust

Private Bag E243

Lusaka, Zambia

Phone: 2601-1-223-589

Fax: 260-1-222-834

fht@zamnet.zm

\section{Lilani Kumaranayake}

London School of Hygiene and

Tropical Medicine

Department of Public Health \& Policy

Keppel Street

London WC1E 7HT, UK

l.kumaranayake@Ishtm.ac.uk

\section{Tim Lee}

HIV/AIDS Alliance

Queensberry House

104-106 Queens Road

Brighton BN1 3XF

UK

Phone: 44-1273-718940

Fax: 44-1273-718901

tlee@aidsalliance.org

\section{Hor Bun Leng}

Deputy Director

NCHADS

\#170 Preah Sihanouk Blvd

Sankat Boeng Keng Kong 1

Khan Chamkarmorn

Phnom Penh, Cambodia

Phone: 855-23-216-515

Fax: 855-23-216-515

lhor@bigpond.com.kh

\section{Ruthy Libatique}

Executive Director

PHANSUP

Brickville Condominium

Mezzanine

28 N Domingo Str New Manila

Quezon City

Philippines

Phone \& Fax: 632-415-4381

phansup@info.com.ph 


\author{
Sue Lucas \\ HIV/AIDS Alliance \\ Queensberry House \\ 104-106 Queens Road \\ Brighton BN1 3XF \\ Phone: 44-1273-718945 \\ Fax: 44-1273- \\ 718901slucas@aidsalliance.org \\ Rita Marima-Muyambo \\ Project Manager \\ Project Support Group \\ PO MP 839 Mt Pleasant \\ Harare, Zimbabwe \\ Phone: 263-4-334830 \\ Fax: 263-4-304-921 \\ rmuyambo@esanet.zw \\ psg@esanet.zw \\ Issam Moussaoui \\ Project Coordinator \\ PASA/IST-SIDA \\ C/O AMSED \\ 11 Rue Al Maarif \\ Quartier Aviation \\ Rabat, Morocco \\ Phone: 212-775-9352 \\ Fax: 212-775-0098 \\ amsed@maghrebnet.net.ma \\ Shyamala Nataraj \\ SIAAP \\ 65 Kamareya Avenue \\ $1^{\text {st }}$ Floor I Street \\ Adyar, Chennai \\ 700090 India \\ Phone: 091-044-4416141 (SIAAP) \\ Fax: 091-044-4415821 \\ siaap@satyam.net.in
}

\author{
Jeff O'Malley \\ HIV/AIDS Alliance \\ Queensberry House \\ 104-106 Queens Road \\ Brighton BN1 3XF \\ UK \\ Phone: 44-1273-718909Fax: 44- \\ 1273-718901 \\ jomalley@aidsalliance.org
}

\section{Kevin Orr}

Queensberry House

104-106 Queens Road

Brighton BN1 3XF

UK

Phone: 44-1273-718900Fax: 44-

1273-718901

korr@aidsalliance.org

\section{Pok Panhavichetr}

Executive Director

KHANA

\#13, Street 302

PO Box 2311

Phnom Penh 3

Cambodia

Phone \& Fax: 885-23-214-049

khana@bigpond.com.kh

\section{Helen Parry}

HIV/AIDS Alliance

Queensberry House

104-106 Queens Road

Brighton BN1 3XF

UK

Phone: 44-1273-718953

Fax: 44-1273-718901

hparry@aidsalliance.org 


\author{
Elizabeth Pisani \\ Consultant \\ UNAIDS \\ PO Box 34043 \\ Nairobi \\ Kenya \\ Phone: 254-2-581-470 \\ Fax: 254-2-583-007 \\ pisani@net2000ke.com \\ Margarita Quevedo \\ Program Director \\ KIMIRINA \\ Ramirez Davalos 258 y Paez \\ Quito Ecuador \\ Phone: 5932-568-767 \\ Fax: 5932-556-750/5932-543-246 \\ mquevedo@ecuanex.net.ec \\ kimirina@ecuanex.net.ec \\ Allan Ragi \\ Executive Director \\ KANCO \\ PO Box 69866 \\ Chaka Rd off Argwings \\ Kodhek Rd \\ Nairobi, Kenya \\ Phone: 254-271-76-64 \\ Fax: 254-271-48-37 \\ kenaids@iconnect.co.ke \\ C Ramachandran \\ SIAAP \\ M103/10, 30 $0^{\text {th }}$ Cross Street \\ Beseant Nagar Chennai - \\ Tamilnadu \\ 600090 India \\ Phone: 91-044-442-0302 \\ Fax: 91-044-445-3332 \\ kpp@vsnl.com \\ siaap@satyam.net.in
}

\section{Naomi Rutenberg}

Population Council/Horizons 4301 Connecticut Ave NW

Suite 280

Washington DC 20008

USA

Phone: 202-237-9405

Fax: 202-237-8410

nrutenberg@pcdc.org

\section{Marie-Rose Sawadogo}

Directrice Exécutive

IPC - BP 10220

Quagadougou 06

Burkina Faso

Phone: 226-38-03-60

Fax: 226-38-03-66

ipcbf@cenatrin.bf 


\section{References}

Ainsworth, M. and Teokul, W. (2000) "Breaking the silence: setting realistic priorities for AIDS control in less-developed countries" Lancet, Vol. 356, July $1: 55-60$.

Antivelink, L, Abaliio, A., Byateesa, D., Gonahasa, N., Kabanda, M., Kajura, C., Lukwago, B., Mike, J. Mwiri, M., Shillingi, L., Ssebbanja, P., Watuwa, S. with Mwesigwa, J., Osuga,B., Cooper, R. and Welbourn, A. (1996) "A Participatory Approach to a Mid-Term Review: the AIDS Support Organisation (TASO) Community-Based Care Programme, Uganda." Unpublished mimeo, July 1996 and forthcoming in Cornwall, A., and Welbourn, A., Listening to Learn: Participatory Approaches to Sexual and Reproductive Health, Zed Press.

Asthana, S. and Oostvogels R. (1996) "Community participation in HIV prevention: Problems and prospects for community-based strategies among female sex workers in Madras," Social Science and Medicine, 43(2): 133-148.

Avina, J. (1993) "The evolutionary life cycles of non-governmental development organizations," Public Administration and Development, 13: 453-474.

Billis, D. and MacKeith J. "Growth and change in NGOs: Concepts and comparative experience" in Edwards M., Hulme D., (eds.) 1992, Making a Difference: NGOs and Development in a Changing World, London: Earthscan Publications Limited, pp. 118-127.

Binswanger, Hans P. (2000) "Scaling up HIV/AIDS programs to national coverage," Science, Vol. 288, 23 June, pp. 2173-2176.

Blackburn, J. and Holland J. (1998) Who Changes? Institutionalizing Participation in Development, London: Intermediate Technology Development Publications.

Boyce, W., Johnston C., Thomas M., Enns H., Naidu D.M. and Tjandrakusma H. (1997) "Pathways to scaling-up in community based rehabilitation agencies", International Journal of Rehabilitation Research, 20: 381-392.

BRAC Profile, 2000. Accessed online 15.05.00, http://www.brac.net/profile.htm. 


\section{Appendix: D Page 6 of 11}

Bratton, M. (1989) "The politics of government-NGO relations in Africa," World Development, 17(4): 569-587.

Brown, L., LaFond, A. and Macintyre, K. (2000) Measuring Capacity Building. MEASURE Evaluation project. Unpublished draft.

Burr, R. (1997) "The AIDS Exception: Privacy vs. Public Health", Atlantic Monthly, June 1997

Campbell, C. and Williams B. (1999) "Beyond the biomedical and behavioural: Towards an integrated approach to HIV prevention in the Southern African mining industry," Social Science and Medicine, 48: 1625-1639

Chambers, R. "Spreading and self-improving: A strategy for scaling up," in Edwards M., Hulme D., (eds.) 1992, Making a Difference: NGOs and Development in a Changing World, London: Earthscan Publications Limited, pp. 40-49.

Charlton, R. (1995) "Sustaining an impact? Development NGOs in the 1990s," Third World Quarterly, 16(3): 566-575.

Clark, J. (1991) Democratizing Development: The Role of Voluntary Organizations, Connecticut: Kumarian Press, Inc.

Clark, J. "Policy influence, lobbying and advocacy," in Edwards M., Hulme D., (eds.) 1992, Making a Difference: NGOs and Development in a Changing World, London: Earthscan Publications Limited, pp. 191-203.

Decosas, J. (1994) "The answer to AIDS lies in united commitment" AIDS Analysis Africa 5 (1) 3-4

Decosas, J. (2000) "The local response to HIV in Africa: a question of scale." AIDS Analysis Africa 10(5), 15-16 Feb/Mar.

DeJong, J. (1991) "Nongovernmental organizations and health delivery in subSaharan Africa," World Bank Working Paper, WPS 708, 06.91.

Drabek, A.G. (1987) "Development Alternatives: The challenge for NGOs - An Overview of the Issues," World Development, 15, Supplement, pp. ix-xv. 


\section{Appendix: D Page 7 of 11}

Edwards, M. and Hulme D. (1992) Making a Difference: NGOs and Development in a Changing World, London: Earthscan Publications Limited.

Edwards, M. and Hulme D. "Scaling up the developmental impact of NGOs: Concepts and experiences" in Edwards M., Hulme D., (eds.), 1992, Making a Difference: NGOs and Development in a Changing World. London: Earthscan Publications Limited, pp. 13-28.

Edwards, M. and Hulme D. "Making a difference: Concluding comments" in Edwards M., Hulme D., (eds.) 1992, Making a Difference: NGOs and Development in a Changing World, London: Earthscan Publications Limited, pp. 211-217.

Edwards, M. and Hulme D. (1996) Beyond the Magic Bullet: NGO Performance and Accountability in the Post-Cold War World, Connecticut: Kumarian Press, Inc.

Edwards, M. and Hulme D. (1997) NGOs, States and Donors: Too close for comfort? London: MacMillan Press Ltd.

Evans, C. (1999). "An International Review of the Rationale, Role and Evaluation of Community Development Approaches in Interventions to Reduce HIV Transmission in Sex Work" New Delhi: Horizons.

Foster, G. (2000) "The capacity of the extended family safety net for orphans in Africa" Psychology, Health and Medicine, Vol. 5, No, 1.

Fowler, A. (1991) "The role of NGOs in changing state-society relations: Perspectives from eastern and southern Africa," Development Policy Review, 9: 53-84.

Gilmore, N. and Somerville, M. (1994) "Stigmatization, scapegoating and discrimination in sexually transmitted diseases: overcoming 'them' and 'us'," Social Science Medicine, 39(9): 1339-1358.

Gilson, L., Sen P. D., Mohammed S. and Muljinja P. (1994) "The potential of health sector non-governmental organizations: Policy options", Health Policy and Planning, 9(1): 14-24. 


\section{Appendix: D Page 8 of 11}

Goldin, C.,S. (1994) "Stigmatization and AIDS: Critical issues in public health", Social Science Medicine, 39(9): 1359-1366.

Health Watch (1998) "From contraceptive targets to reproductive health: India's family planning program after Cairo," Unpublished case-study prepared for Health, Empowerment, Rights and Accountability (HERA) meeting in Cocoyoc, Mexico, November 1998.

Herek, G. (1999) "AIDS and stigma," American Behavioral Scientist, 42(7): 11061116.

Hodson, R. "Small, medium or large? The rocky road to NGO growth," in Edwards M., Hulme D., (eds.) 1992, Making a Difference: NGOs and Development in a Changing World, London: Earthscan Publications Limited, pp. 127-137.

HORIZONS (1999) "Horizons Research Strategy: NGO Capacity Building, Roles, Scaling up, and Replication", (Unpublished internal document developed by HORIZONS/Population Council, Washington DC).

HORIZONS (2000a) "Going to Scale in HIV/AIDS Programs: A Review of Current Literature" (Unpublished document developed by HORIZONS in collaboration with Tulane University).

HORIZONS (2000b) Peer Education and HIV/AIDS: Past Experience, Future Directions. New York: Horizons/Population Council.

Howes, M. and Sattar M.G. "Bigger and Better? Scaling up strategies pursued by BRAC 1972-1991" in Edwards M., Hulme D. (eds.) 1992, Making a Difference: NGOs and Development in a Changing World. London: Earthscan Publications Limited, pp. 99-111.

Hughes, H. (1993) "Evaluating HIV/AIDS programmes," Development in Practice, 3(1): 52-54.

Hyden, G. and Lanegran, K. (1991) "Eastern Africa: Mapping the politics of AIDS", AIDS and Society, 2(2): 1, 6, 12-3.

International HIV/AIDS Alliance (2000a) Unpublished Report of Zambia Meeting of Community Lessons, Global Learning Project. 


\section{Appendix: D Page 9 of 11}

International HIV/AIDS Alliance (2000b) Community Lessons, Global Learning Project Unpublished Report of India Meeting.

International HIV/AIDS Alliance (2001) Expanding Community Action on HIV/AIDS: NGO/CBO Strategies for Scaling Up. London.

Jareg, P. and Kaseje, D.C.O. "Growth of civil society in developing countries: implications for health," Lancet, 351, March 14, 1998, p. 819.

Kaleeba, N., Kalibala, S., Kaseje, Ssebbanja, P., Anderson, S., van Praag, E., Tembo, G. and Katabira, E. (1997) "Participatory evaluation of counseling, medical and social services of The Aids Support Organization (TASO) in Uganda" AIDS Vol. 9, No. 1 pp. 13-26.

Klouda, T. (1995) "Responding to AIDS: Are there any appropriate development and health policies?" Journal of International Development: 7(3): 467-487.

Korten, D.C. (1980) "Community organizations and rural development: A learning process approach," Public Administration Review, Sept/Oct, pp. 480-511.

Kumaranayake, L. (2000) "The Economics of Scaling-Up", Paper presented at WHO Commission on Macroeconomics and Health Planning Meeting for Working Group 05.00, London School of Hygiene and Tropical Medicine.

Kumaranayake, L, Watts, C. (2000) "The costs of scaling-up HIV prevention and care interventions in Sub-Saharan Africa" XIII International AIDS Conference, Durban, July 2000. Abstract [TuOrD324]

Kumaranayake, L. and Watts, C. (2000b) "Economist costs of HIV/AIDS prevention activities in sub-Saharan Africa." AIDS 14 (Supp. 3): S239S252.

Kumaranayake, L, Pepperall, J., Goodman, H., Mills, A., Walker, D. (2000) Costing Guidelines for HIV/AIDS Prevention Strategies UNAIDS Best Practice Collection - Key Materials. Geneva: UNAIDS.

Lamptey, P.R., Zeitz, P., Larivee, C. (Eds.) (2001) Strategies for an Expanded and Comprehensive Response (ECR) to a National HIV/AIDS Epidemic. Draft of July 10. 


\section{Appendix: D Page 10 of 11}

Loughran, L. (1995) "Capacity building for HIV/AIDS prevention”, AIDScaptions, II(2): 4-7.

Mayhew, S. (1996) "Integrating MCh/FP and STD/HIV services: Current debates and future directions," Health Policy and Planning, 11(4): 339-353.

Myers, R. "Going to scale," in Cooperson, W. (ed.) 1992, The Twelve Who Survive, London: Routledge, pp. 369-396.

Nnko, S. (1998) "AIDS stigma: A persistent social phenomenon in Mwanza, Tanzania," International Conference on AIDS (Abstract no. 417/34159).

O'Malley, J., Vinh Kim Nguyen and S. Lee (1996) "Nongovernmental Organizations" in Mann, J. and Tarantola, D. (Eds.) AIDS in the World Vol. II, pp. 341-361.

Parker, R.G. and Galvao J. (1998) "HIV/AIDS policy in Brazil," International Conference on AIDS (Abstract no. 355/43560).

Parker, R. (2000) "Administering the Epidemic: HIV/AIDS Policy, Models of Development, and International Health" Ch. 2, pp. 39-56 in Manderson, L. and Whiteford, L.M. Global Health Policy, Local Realities, Boulder, CO: Lynne Rienner

Pearce, J. (1993) "NGOs and social change: Agents or facilitators?" Development in Practice, 3: 222-227.

Phiri, S. N., Nzima, M. and Foster, G. (2000) "Exploring Ways to Scale Up Effective Sustainable Community Mobilization Interventions to Mitigate the Impact of HIV/AIDS on Children and Families" (unpublished mimeo for the Displaced Children and Orphans Fund,)

Rifkin, S \& Walt G (1988) "The Debate on Selective or Comprehensive Primary Health Care", Social Science and Medicine, Vol.26, No.9, p.877-878

Sittitrai, W. (1994) "Non-governmental organization and community responses to HIV/AIDS in Asia and the Pacific," AIDS 8(suppl 2), S199-S206.

Smith, J. and Colvin C. (2000) Getting to Scale in Youth Adult Reproductive Health Programs April 2000, FOCUS Tool Series 3, 69 pages. 


\section{Appendix: D Page 11 of 11}

UK NGO AIDS Consortium (1996) "Effective HIV/AIDS Activities: NGO work in developing countries," Report of the Collaborative Study.

UNAIDS (2000) Report on the Global HIV/AIDS Epidemic. June.

UNAIDS/WHO (2000) AIDS Epidemic Update: December 2000

UNAIDS (2000) Local Response Team, Technical Notes 1, 2 ("The development of Key Notes at all levels of the local response to HIV/AIDS") and 3 ("How do communities measure the progress of local responses to HIV/AIDS?") Available on the UNAIDS web-site.

Uvin, P. (1995) "Scaling up the grass roots and scaling down the summit: The relations between Third World nongovernmental organisations and the United Nations," Third World Quarterly, 16(3): 495-512.

Uvin, P. and Miller D. (1996) "Scaling-up: alternative strategies for local nongovernmental organizations," Human Organizations, 55(3): 344-353.

Van, Odenhoven N. and Wazir R. (1997) "Replicating social programmes: Approaches, strategies and conceptual issues," Management for Social Transformation, Discussion Paper No 18, accessed online 09.04.00, http://www.unesco.org/most/dsp18.htm.

Watts, C. and Kumaranayake L. (1999) "Thinking big, scaling-up HIV-1 interventions in sub-Saharan Africa," Lancet, 354, October, p. 1492.

Wazir, R. and van Odenhoven N. (1998) "Increasing the coverage of social programmes," International Social Science Journal, 55(1): 145-154.

White, S. (1999) "NGOs, Civil Society and the State in Bangladesh: The politics of representing the poor," Development and Change, 30(2).

Wilkinson, D. and colleagues (2000) "An Evaluation of the MoH/NGO Home Care Programme for People with HIV/AIDS in Cambodia." Supported by the International HIV/AIDS Alliance, London.

World Bank (Africa Region) (1999) "Intensifying action against HIV/AIDS in Africa: Responding to a development crisis," accessed 11.01 .00 at http://www.worldbank.org/html/extdr/offrep/afr/aidstrat.pdf. 
World Bank (2000) "The Costs of Scaling HIV Program Activities to a National Level in Sub-Saharan Africa" AIDS Campaign Team for Africa, World Bank, Washington, D.C. 